\title{
An exploration of empowerment and the conditions that empower students in a nursing education context
}

\author{
by \\ Janet Ruth Pearson \\ Thesis
}

Submitted to the Victoria University of

Wellington as

partial fulfilment of the requirements for the degree of

Master of Education ( Research and Policy)

Victoria University of Wellington

1996 


\section{Abstract}

Empowerment is a concept that has recently gained in popular usage and has been applied to many situations including nursing practice. Current nursing practice includes the expectation that registered nurses work with clients / patients and empower them so that they may take an active part in their own health care. Current curricula for the education of nurses in the USA, UK and New Zealand support this emancipatory intent. This study was conducted at Whitireia Community Polytechnic where the curriculum for the bachelor of Nursing Degree Programme is based on the Treaty of Waitangi and intends to empower students of nursing so that they may in turn empower clients.

This research aimed to explore the phenomenon of empowerment from the perspective of the student nurse. Using grounded theory methodology, and emancipatory, feminist and action research philosophies, six year two student participants were interviewed and asked to define the term empowerment and give exemplars (all were from practice based clinical experience settings) of moments when they had been empowered in a teaching learning context. Analysis of data led to the discovery of a theory and development of a theoretical model describing conditions and consequences that led to empowerment. Analysis also uncovered the conditions that led to disempowerment for the participant group. Circumstances which enhanced empowerment included the attainment of year one competencies and knowledge, preparation for practice and sufficient self efficacy to enter the practice setting. The context or milieu influenced the process, and when the milieu provided appropriate responsibility, orientation and positive interactions with a nurse expert (preceptor, tutor or buddy) the student was enabled to engage in praxis. Praxis, followed by self reflection allowed feelings of empowerment which in turn led to raised self efficacy and a desire to engage in further practice experiences. If praxis was not possible a feeling of disempowerment followed student self reflection. Disengagement was a consequence of disempowerment if the intervention of assisted reflection did not occur. Assisted reflection following disempowerment was found to be essential to maintain or strengthen self efficacy to levels sufficient to allow further experiential learning.

The research process was found to be emancipatory for both the participants and the researcher, and the theoretical model which was developed provided a descriptive cycle of empowerment that was considered to be relevant to nursing education and other practice based adult learning programmes. The value of this research was, that actors in the empowering process could identify influential conditions which enhanced the development of a greater sense of control over their learning in a manner that had the potential to result in personal empowerment.

Major recommendations were: that adequate preparation in the Polytechnic setting, prior to clinical placement should be maintained; that preceptorial programmes which include historicsociocultural and political content, are extended to all practice settings in which students gain learning experience; that registered nurses in Polytechnic and practice settings be encouraged to develop increased awareness of how their 'way of being' affects students; that teachers who hold personal philosophical congruence with emancipatory curricula be supported as educators, and; that processes that develop ongoing reflection be promoted in nursing education and practice contexts. Further research to test the theory in other settings was suggested. 


\section{Acknowledgments}

- Student participants for their willingness to engage with me in the research process

- Whitireia Community Polytechnic for financial support

- Kathie Irwin for supervision, guidance and positive interactions that enabled my own empowerment

- My partner Bob for adding the scientific world view and for being a constant, lovingly, 'critical' editor

- Whitireia colleagues for their stimulating conversations, genuine support, and toleration of my absence of body and /or mind.

- Andrew for his assistance with the pilot exercise, supportive love and for being able to once more tolerate an 'absent' parent

- Shane and Maggie for support, dialogue, information and friendship

- Joanna Kidman for editorial advice 


\section{Table of Contents}

1 Introduction $\ldots \ldots \ldots \ldots \ldots \ldots \ldots \ldots \ldots \ldots \ldots \ldots \ldots \ldots \ldots \ldots$

1.1 Purpose and Aims $\ldots \ldots \ldots \ldots \ldots \ldots \ldots \ldots \ldots \ldots \ldots \ldots$

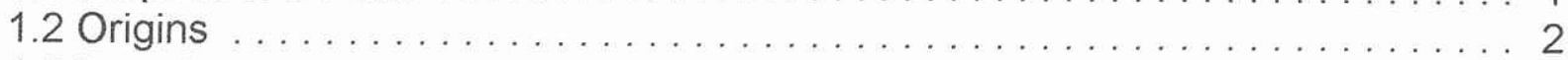

1.3 Learning Environment $\ldots \ldots \ldots \ldots \ldots \ldots \ldots \ldots \ldots \ldots \ldots \ldots$

1.4 My Personal Philosophy . . . . . . . . . . . . . . . . . . . . . . . 6

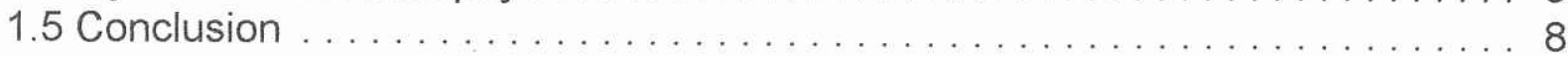

2. Empowerment $\ldots \ldots \ldots \ldots \ldots \ldots \ldots \ldots \ldots \ldots \ldots \ldots \ldots$

2.1 Empowerment and the Social Context .................... 9

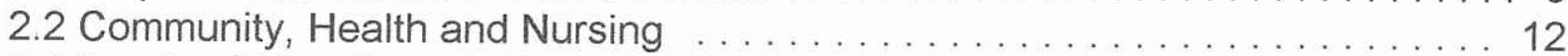

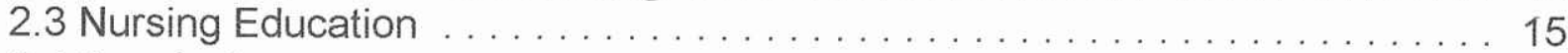

2.4 Conclusion . . . . . . . . . . . . . . . . . . . . 18

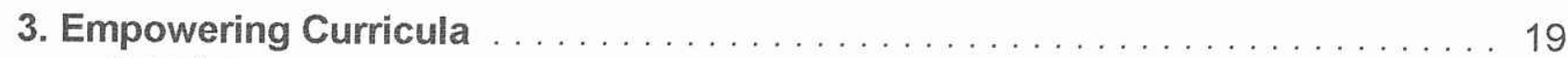

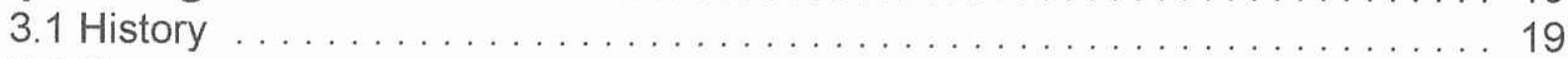

3.2 Changes . . . . . . . . . . . . . . . . . . . . . . . . 21

3.3 Educative Curricula . . . . . . . . . . . . . . . . . . . . . 22

3.4 Dialogue and Meaning Curricula . . . . . . . . . . . . . . . . . . . 23

3.5 Emancipatory Curricula Models . . . . . . . . . . . . . . . . . . . . . . 24

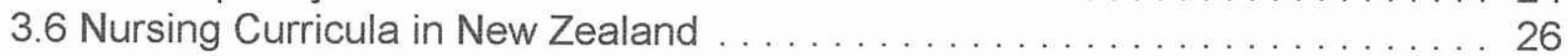

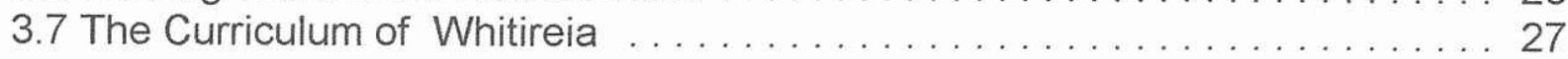

3.8 Conclusion . . . . . . . . . . . . . . . . . . . . . 31

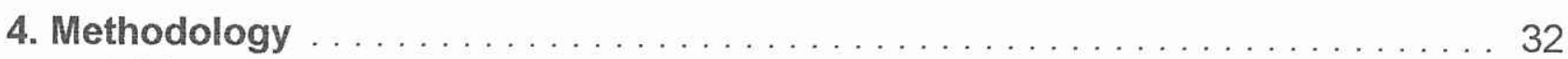

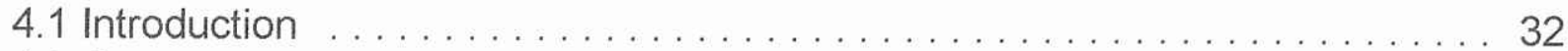

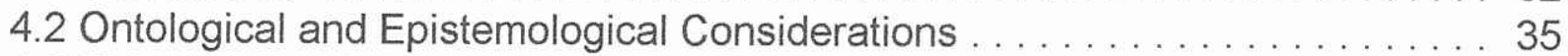

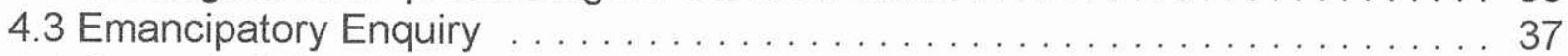

4.4 Grounded Theory . . . . . . . . . . . . . . . . . . . . . . . . . . . 39

4.4 .1 Introduction . . . . . . . . . . . . . . . . . . . . . . 39

4.4.2 Principles and Procedures . . . . . . . . . . . . . . 40

4.4 .3 Coding . . . . . . . . . . . . . . . . . . . . . . . . 42

4.5 Considerations of Validity $\ldots \ldots \ldots \ldots \ldots \ldots \ldots \ldots \ldots \ldots \ldots \ldots \ldots \ldots$

4.5.1 Adequacy and Appropriateness of Data . . . . . . . . . . . . . 43

4.5.2 Data Analysis. . . . . . . . . . . . . . . . . . . . . . . . . 44

4.5 .3 Audit Trail . . . . . . . . . . . . . . . . . . . . . . . . 46

4.5 .4 Generalization . . . . . . . . . . . . . . . . . . . . . 46

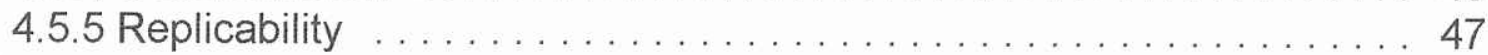

4.6 Enquiry in action . . . . . . . . . . . . . . . . . . . 47

4.6.1 Negotiating Access . . . . . . . . . . . . . . . . . . . . . . . . . . . 47

4.6.2 Participants . . . . . . . . . . . . . . . . . . . . . 50

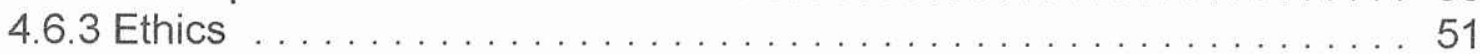

4.6.3.1 Approval . . . . . . . . . . . . . . . . . . . . . 51

4.6.3.2 Participant Considerations . . . . . . . . . . . . . . . 51

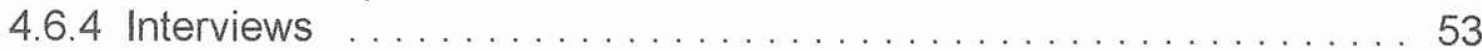

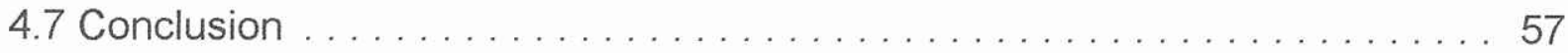

5. The experience of being a student nurse $\ldots \ldots \ldots \ldots \ldots \ldots \ldots$

5.1 Background . . . . . . . . . . . . . . . . . . 58 


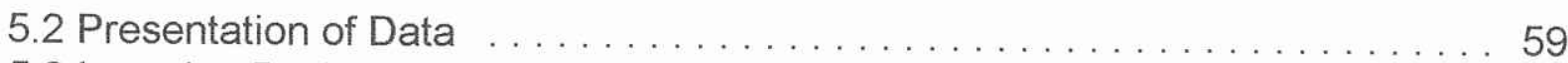

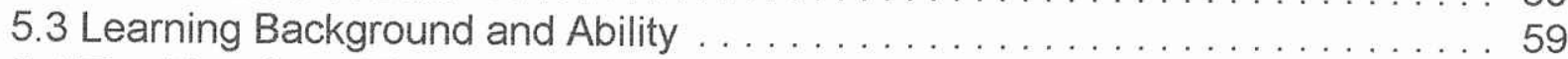

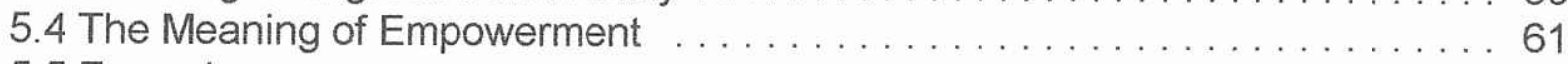

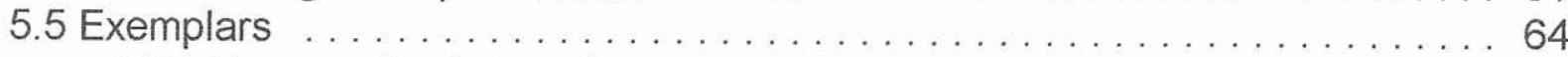

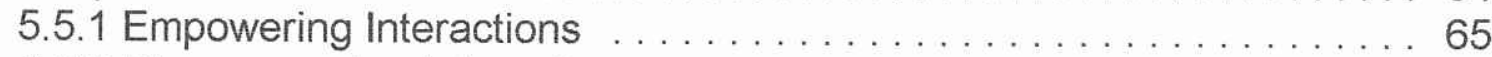

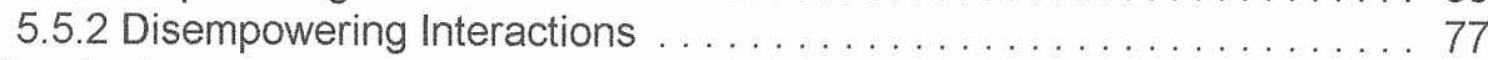

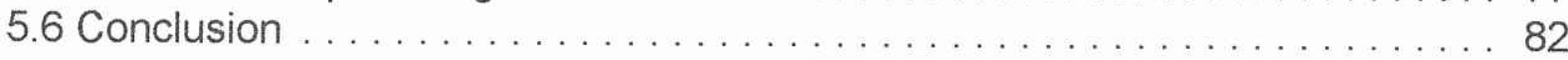

6. Discovering the Theory $\ldots \ldots \ldots \ldots \ldots \ldots \ldots \ldots \ldots \ldots \ldots \ldots \ldots$

6.1 The Process as a Whole $\ldots \ldots \ldots \ldots \ldots \ldots \ldots \ldots \ldots \ldots \ldots$

6.2 Analysis of the Meaning of Empowerment $\ldots \ldots \ldots \ldots \ldots \ldots \ldots$

6.3 Initial Analysis of First Interviews . . . . . . . . . . . . . . . . . . 86

6.4 Concepts and Categories . . . . . . . . . . . . . . . . . . . 88

6.4.1 Analysis of Empowering Interactions . . . . . . . . . . . . . . 88

6.4.2. Constant Comparative Analysis . . . . . . . . . . . . . . . . . . . . 89

6.4 .2 .1 Glenis . . . . . . . . . . . . . . . . . . . . . . . . 89

6.4 .2 .2 Elisapeta . . . . . . . . . . . . . . . . . . 91

6.4 .2 .3 Liam . . . . . . . . . . . . . . . . . . . . . . . . 94

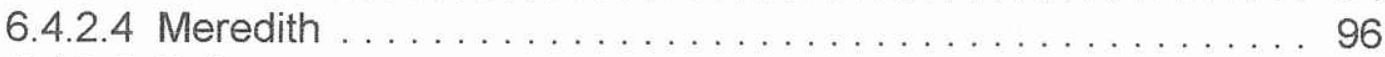

6.4.2.5 Robyn .............................. . . 99

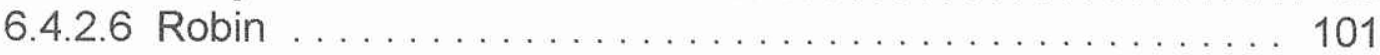

6.5 Concept Comparison $\ldots \ldots \ldots \ldots \ldots \ldots \ldots \ldots \ldots \ldots \ldots \ldots \ldots \ldots$

6.6 Conclusion . . . . . . . . . . . . . . . . . . . . . . . . . . . 105

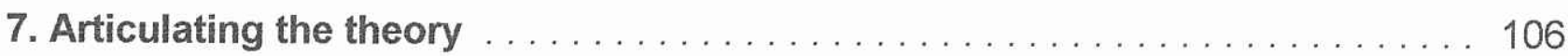

7.1 Theory Development through Reference to Literature . . . . . . . . . . . . . 106

7.1.1 The Place of Self Efficacy . . . . . . . . . . . . . . . . . . . . . . . . 106

7.1 .2 Facilitation of Adult Learning . . . . . . . . . . . . . . . . . . . . . 114

7.1.3 The Role of the Preceptor . . . . . . . . . . . . . . . . . . . . . . . 119

7.1.4 Beliefs, Attitudes and Behaviours . . . . . . . . . . . . . . 121

7.1 .5 Praxis . . . . . . . . . . . . . . . . . . . . . . . . . 124

7.1.6. The Place of Reflection . . . . . . . . . . . . . . . . . . . 126

7.2 The Tertiary Model . . . . . . . . . . . . . . . . . . . . . . . . 128

7.3 Conclusion $\ldots \ldots \ldots \ldots \ldots \ldots \ldots \ldots \ldots \ldots \ldots \ldots \ldots \ldots \ldots$

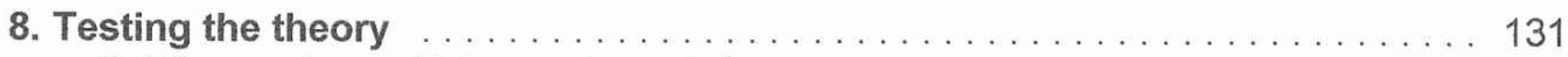

8.1 Comparison with Exemplars of Empowerment . . . . . . . . . . . . . . 131

8.2 Presentation of the Theory to Participants . . . . . . . . . . . . . . . 132

8.3 How the Theory and Model Should be Used . . . . . . . . . . . . . . 135

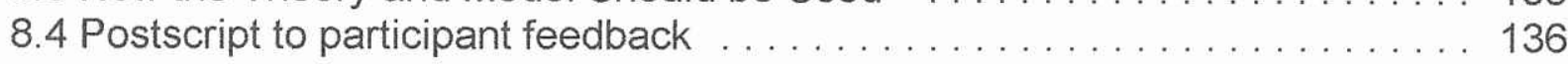

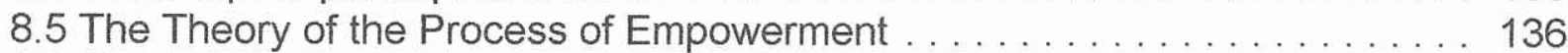

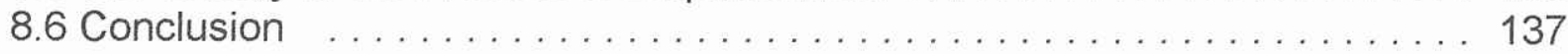

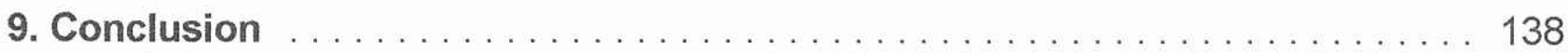

9.1 Research Purpose, Aims and Answers ... . . . . . . . . . . . . 138

9.2 Personal Empowerment through Praxis . . . . . . . . . . . . . . . . . 142

9.3 Implications for Practice . . . . . . . . . . . . . . . . . . . . . . . . . . . . 143

9.4 Recommendations for Practice . . . . . . . . . . . . . . . . . . . . . . . . . 145

9.5 Suggestions for Future Research . . . . . . . . . . . . . . . . . . . . . 146

9.6 Concluding Remarks . . . . . . . . . . . . . . . . . . . . . 147 
Appendices ................................. 156

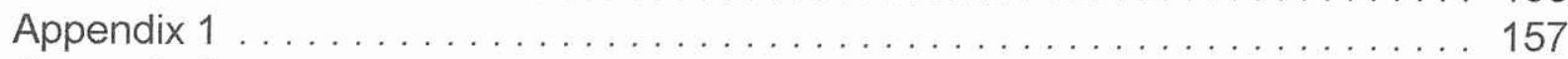

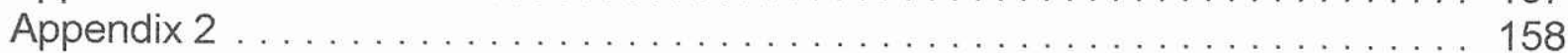

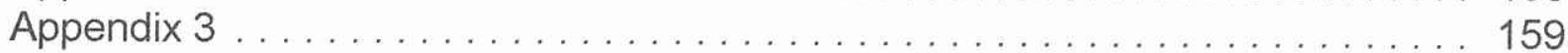

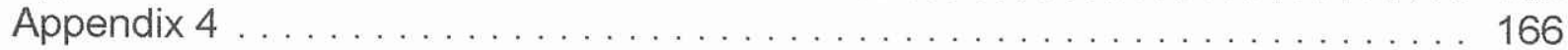

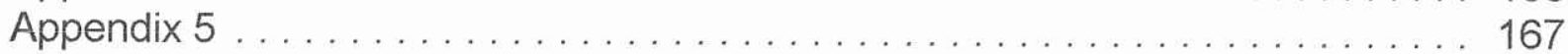

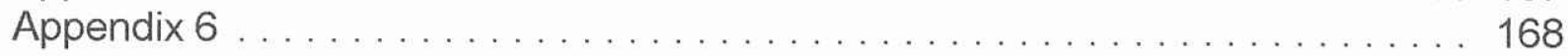

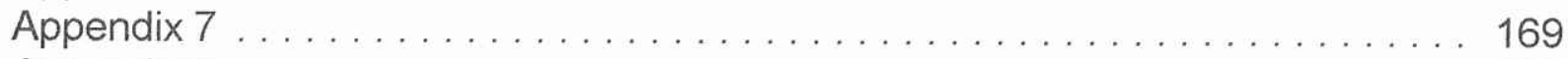

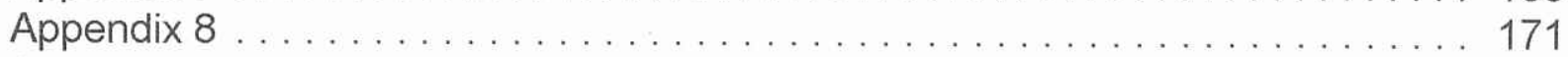

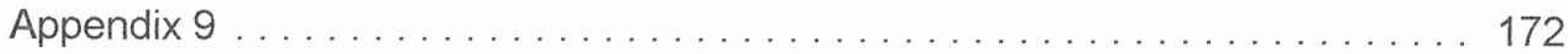

\section{List of Figures}

Figure 4.1 Flow diagram of analysis, theory and theoretical model development. . . . 45

Figure 6.1 Skeletal theoretical model from definitions of empowerment. . . . . . . 86

Figure 6.2 Primary model Including hypothetical categories. . . . . . . . . . . . .88

Figure 6.3 Secondary model developed from analysis of all interview data. . . . . . . 105

Figure 7.1 Diagrammatic representation of actions within the learning milieu. . . . . 118

Figure 7.2 The Tertiary Model . . . . . . . . . . . . . . . . . . . . . . . . . . . 128

Figure 8.1 The Theoretical Model of the process of Empowerment. . . . . . . . . 137 


\section{Introduction}

The origins of this research stem from the need I perceived as researcher to explore, articulate, and make visible a conceptual process that is topical in nursing education and nursing practice in New Zealand. The concept to be explored is that of empowerment. Specifically, empowerment as it relates to the teaching and learning of students of nursing in a degree programme offered by a New Zealand Polytechnic Institute.

\subsection{Purpose and Aims}

The purpose of this research is to explore the meaning of the phenomenon of empowerment, and to uncover the empowering pathway from the perspective of the nursing student. It is proposed that by taking a grounded theory approach, that is focused on praxis, and informed by emancipatory knowledge, it will be possible for this investigation to result in the formulation of a theoretical construct that describes the conditions that facilitate empowerment for a group of nursing students.

Currently it is considered essential for nurses to be able to empower patients /clients in a variety of health care settings. Because empowerment has become an integral part of nursing practice it's inclusion in programmes of nurse education is essential. Therefore I consider that there is a need to gain a common meaning for the conceptual phenomenon of empowerment in order that educators can provide conditions that enhance empowerment for students of nursing. I consider that if students of nursing are to understand the empowering process it is of vital importance that they experience empowerment during their course of study. The aim of this study is to articulate a theory of empowerment. The intention is, that the clarification of the pathway based on my research findings, will assist the continuing facilitation of empowerment for student nurses and ultimately their patients /clients.

\section{The broad questions to be answered are:-}

- What do students enrolled in this Nursing Programme understand by the term empowerment?

- What, in the view of the participants, assists them to become empowered?

- What, in the view of the participants, impedes their empowerment ?

- What, in the view of the participants, could improve / enhance the development of their empowerment?

From the participants responses during interview, and analysis of the data using grounded theory methodology it is intended that these questions will be answered. The purpose being 
to give students and teachers of nursing, insight into the phenomenon of empowerment with the intent that this knowledge can be used to improve teaching and learning conditions and interactions through the application of theory to practice.

\subsection{Origins}

Gibson (1991) asserted that a nurse as a health professional, has actual or potential power that is conferred upon them through their position as expert. Power in this sense can be linked to the concept of control, and as such can be considered as the capacity to exert a degree of influence over other people. Within society, professionals such as nurses assume roles that include holding power.

The level of power conferred on different professions in society is, however, unequal, and is linked in New Zealand society, as are all paid employments, to earning ability and the level of education required to fulfill the role (Elley and Irving 1972). As a predominantly female occupational group, nurses are ranked as one of the lowest professions in the New Zealand Socio-economic Scales (SES) by The Ministry of Education (1993). Whereas other health professionals such as Medical Practitioners, Dentists and Chiropractors are ranked as SES group one (1), General Nurses are ranked as group three (3), with Principal Nurses, Psychiatric nurses and Midwives being placed in SES group two (2) (Ministry of Education 1993).

Sociologists believe that the first interactions involving power are usually those experienced during primary socialisation within the family of origin (Short, Sharman and Speedy 1993). It is in this context that the individual gains an initial sense of ability or lack of ability to influence the world around them (McCurdy 1982). Secondary socialisation generally occurs during middle and late childhood when school, peers and the media also influence the developing person (Short et al 1993). Tertiary socialisation occurs in adulthood and includes occupational socialisation

which requires the individual to reject lay conceptions of an occupational role, and adopt the values, attitudes and beliefs of that specific role to which socialisation is aimed. ( Short et al 1993 p 16)

Traditionally in western influenced cultures female children have failed to gain the same sense of power or competence as male children during their primary or secondary socialisation. Their achievements and accomplishments have not been valued unless they are in the domestic domain, and affirmation has been given to passive qualities such as being 'good', 'pretty' or 'nice'. In this cultural context competition and achievement was 
considered to be aggressive and unfeminine, which encouraged women within these societal structures to believe that being associated with a power figure would advance them more than gaining power through their own success and achievement. Women learned, therefore, to value the approval and gain a sense of self worth from a power figure (McCurdy 1982).

Nursing as a female occupation became accepted as respectable women's work during Victorian times. The roles and behaviours expected of women within the nursing profession therefore are based historically on the socialised norms for women which existed during this period (Jolley 1993). Jolley (1993) has stated that general education for women in Victorian times aimed to develop women's

\section{'natural' submission to authority and encourage their maternal instincts ( $p 7$ )}

and as such assisted in setting the limits of activity for the Victorian woman. Society in Victorian times exerted a powerful control, and although not all women were passive and accepting of their position in society, Jolley (1993) stated that to be different meant to face formidable problems. It was against such a background that the occupation of nursing came to be seen as a 'safe sacrifice' for virtuous and dedicated women (Jolley 1993). The training needs of nurses were subordinated to the service needs of the hospital with the emphasis on 'character development' rather than education. Through such training, and, as an extension of education for women, it was ensured that the deferring nurse never encroached on the territory of the doctor.

If the doctor-nurse relationship reflected, as suggested by Oakley (1984), the family male dominance- female subservience relationship of husband and wife, then the relationship between superintendent and her nurses could also be seen to reflect the mistress-servant relationship of the typical Victorian middle -class household. (Jolley 1993 p 15)

Perry (1993) considered that the 'handmaiden mentality', as illustrated by the existence of assigned nursing tasks was the outcome of a system which supported separations between cure and care, and expected nurses to covertly fill the gap. Perry (1993) also considered that although doctors and nurses have always been closely linked in the care of the sick, doctors have always had power and prestige in the system and nurses have not. Perry (1993) further stated that the hierarchy or pyramid of power supports doctors to have a view of professional plurality, while 
the view of those near the bottom is one of a fairly rigid structure, unsupportive of their needs, with clear boundaries of authority and skill between those that have power to decide and those who do not. This is normality for the majority of nurses in health care.( Perry 1993 p 44)

Short et al (1993) referred to these relationships as being the basis of the 'doctor - nurse game' which they discussed as being the subtle manner in which nurses make decisions, then communicate their recommendations in such a way that the solutions appear to have been made by the doctor. Included in the 'game' is the situation in which the doctor, when seeking guidance does so without being seen or perceived to be actually asking for help. Development of competencies in the nursing role such as 'anticipating doctors needs' (an assessed criteria during my own training) supported this collusion. The negative consequence of this 'game' is that it underplays the decision making roles that nurses actually undertake, and therefore serves to maintain the traditional hierarchy of power because the authority of those with power is never challenged.

To maintain this status quo nurses (like servants) were trained through an apprenticeship system which is considered by Mingay (1993) to be effective in enabling the student to copy skills and attitudes, mainly through the teaching strategy of role modelling. This 'way of being' has been considered as a form of oppression in which women collude to maintain their own subordination. This position is defined as hegemony (Weiler 1988 ), and can be identified in any society where there are a variety of power and class positions. Lack of power is considered by Gallocher-Shearer (1995) to be

the lived experience of all women and to be the focal point of a nursing structure turned on itself. ( $p$ 39)

Brazilian educationalist Paulo Freire discussed how oppressed persons can move from hegemony to achieve freedom through self determination (Freire 1972, Freire and Shor 1987, Freire 1994). Weiler (1988) described Freire, as being committed to a belief in the power of individuals to come to a critical self-consciousness of their own being in the world. Central to this 'being' was the understanding that both teachers and students are agents engaged in the process of constructing and reconstructing meaning. As Freire (1972) contends the great humanistic and historical task of the oppressed is to liberate themselves and their oppressors as well. Freire (1972) believed that the motivation for this drive, stems from the experience of oppression leading to the feeling that one is less human. This in turn leads the oppressed to struggle against those who made them so. Central to this notion is the belief 
that only power that springs from the weakness of the oppressed will be sufficiently strong to free both the oppressed and the oppressor.

I consider that Freire's (1972) ideas are very relevant to nursing and nursing education.

Nurses can be considered as an occupational group that, in the context of the health care system, as well as in general society, have been oppressed by the position which they have historically held as a professional group of mainly female caregivers. The historical context of, nursing education ( within hospitals) as well as the apprenticeship style which characterised delivery of training, has until recently, helped to maintain nurses in this historical position.

Empowerment, as a process, whilst topical in nursing (Wheeler and Chinn 1991, Gibson 1991, Hokanson Hawks 1992, Skelton 1994), education (Freire 1972, Rappaport 1984, Shor and Freire 1987), and health (Kieffer 1984, Labonte 1994), can be applied to many contexts and situations. However, it is essentially only viable or possible when two or more persons are interacting with positive intentions ( Hokanson Hawks 1992). At the heart of the professions of teaching and nursing is the interaction with others that aims for a positive outcome for the client, or at the very least the intention to do no harm. (Doyal and Gough 1991, Southwick 1994).

\subsection{Learning Environment}

As stated the purpose of this research is to explore the meaning of empowerment and to uncover the empowering pathway from the perspective of the nursing student. The student participants in this study were enrolled in the three year Bachelor of Nursing Programme at Whitireia Community Polytechnic. The qualification gained by students upon course completion is, registration as 'New Zealand Registered Comprehensive Nurse' and conferment of a Bachelor of Nursing Degree. Whitireia Community Polytechnic has offered a three year nursing programme leading to registration as Comprehensive Nurse Practitioner since 1986. The programme was originally called a Diploma in Nursing programme with a curriculum Southwick (1994) defined as,

embedded in a behaviourist paradigm. ( $p 5)$

Students of nursing are currently enrolled in a Bachelor of Nursing programme with a curriculum philosophy based on The Treaty of Waitangi, which provides a framework to articulate the concepts of Partnership, Governorship, Advocacy, Empowerment and Protection. The participants in this research were the first cohort in the Bachelor programme. 
The Degree curriculum provides the pathway that presents students with relevant teaching/learning experiences to ensure that they can pass the required internal assessments in order to become candidates for the National Examinations that lead to New Zealand nursing registration.

I consider that the provision of a curriculum that includes an empowering philosophy may not necessarily mean that students of nursing are empowered by the teaching/learning processes in which they engage. In fact I suggest that the sociological, educational and historical background of many nurses involved in the provision of education for students of nursing has the potential to encourage the opposite to what is intended.

This research therefore sets out to explore empowerment from the perspective of a group of student nurses, with the aim of clarifying the meaning of the concept and to describe the conditions and consequences of the phenomenon.

As researcher I am currently employed as a Nurse Lecturer in the first year of the Bachelor in Nursing Programme at Whitireia Community Polytechnic where I have been employed for nine years. I am in my mid forties and identify myself as New Zealand Pakeha.

\subsection{My Personal Philosophy}

Prior to completion of my primary schooling, at the end of Form two, I was told by my teacher that 'I didn't have a hope of getting school cert'. I was never sure if this was stated to inspire me to prove him wrong, or if he believed that I was not capable. I suspect the latter.

However, in spite of this prediction I was placed in the top 'language' form, (3L1)at the local college, following the standard Intelligence Quotient (IQ) test that was given prior to my secondary school placement. No matter how much I applied myself during my four years of secondary schooling I was consistently 33rd out of the 33 students in my class, apart from occasionally ranking 32 equal. Although I achieved well in terms of passing School Certificate and gaining accreditation in University Entrance I left school at the end of the sixth form not feeling at all capable academically.

My memories about career options at the time were that I had a choice of either teaching or nursing. At no stage did I consider university study as an option, although most of my classmates continued on to this level. My father was a professional from a working class background who had attended night classes to gain his qualification, while working full time. My mother, as many women of her time, essentially raised myself, my older sister ( who trained as a primary teacher and now heads a secondary school art department) and my two younger brothers (an art director in the film industry, and an architect) alone. She ran the 
household, took responsibility for encouraging our varied activities and schooling and was highly involved in voluntary organisations in the local community. My father travelled often and usually left for work before we woke, returning after we had gone to bed, for much of my childhood. I remember considering that if I was to engage in the level of caring work that my mother undertook I would prefer to be recompensed in a more tangible manner than she was. I had a strong desire to do what was expected of me at the time and now consider I was very well socialised into the expected female role of the sixties. That was, to engage in an occupation that would be useful preparation prior to raising a family, rather than as a long term career option. I cannot remember talking to my parents about university study as a personal option, and it was only recently that a close friend of my mother's told me that my mother (who died 11 years ago) always considered that I was capable of succeeding at university. I do remember that I had always wanted to be a nurse from the time, when aged nine years, I had been hospitalised.

I was accepted into nursing training in 1966 when the minimum entry criteria was achievement of school certificate. During my training I was always surprised that I was amongst the top students, and it was to my further surprise that I was asked to become a nursing tutor following completion of my three year nursing qualification. I declined the offer in favour of gaining practical 'hands on' experience in nursing practice.

I commenced part time university study in 1980. The motivation, stimulation and enjoyment for learning having come from the completion of Playcentre courses completed whilst my children attended preschool. I completed my undergraduate degree in 1992 having studied part time while working fulltime to support my self and my two children.

I began my nurse teaching role after holding a variety of nursing practice positions. My nursing practice spanned a period of 18 years and included: post registration work in a large city teaching hospital Accident and Emergency Department; and, community health nursing positions as Practice, Plunket and Public Health Nurse. It was in community practice areas while furthering my education that my philosophy of nursing practice really developed. This development took place in tandem with my interaction with clients, in health focussed nursing practice situated mainly in the home environments of clients, and, my university study .

In my practice I attempted to work with clients to assist them to maintain their own health and that of their families. As I studied and reflected on my practice I was able to work autonomously in innovative ways within or on the fringe of the policy guidelines set by my employers whilst increasingly focusing on what was appropriate for the client or client group. While working mainly with women and children for much of this time, I became more conscious of my feminist view of the world, my belief in the importance of education for the 
prevention of illness and maintenance of health and my concern for fairness, justice and the valuing of individual world views.

I now consider that my teaching, nursing and personal beliefs are most closely aligned with feminist and emancipatory theories which I consider can be incorporated into the broad philosophy of Primary Health Care (PHC). The PHC philosophy includes the aim of 'Health for all by the year 2000' (World health Organisation WHO, 1978 1986), and states that populations should have access to affordable and appropriate health care for their individual, family and community needs. The ideology also includes policies and practices, methods and actions that encourage client consultation and active participation in the planning and delivery of health care. As Tones (1991) stated emphasis is on

the need to reduce inequalities, the importance of multi sectoral collaboration, the principle of internationalism, the primacy of 'building public health policy' and the notion of self empowering, participating community. ( $p$ 18)

I consider this philosophy to be relevant to both health and education in New Zealand today, as it has emancipatory potential and congruence with the Treaty of Waitangi.

My nurse teaching role over the last nine years has focused largely on teaching community nursing, health and wellness, and as a lecturer in a programme that includes a diverse student group I believe that the way that I teach, interact with, and support students, with the basic belief that every person has the right to be included and the potential to be a successful learner, is very similar to the way I nursed. In my nursing practice I firmly held to the belief that all people had the potential to manage their own health and health care given the knowledge and resources they perceive to be necessary for them. As a teacher I now firmly hold to the belief that each student is capable of success if the learning / teaching conditions provided meet their needs.

\subsection{Conclusion}

In this introduction I have set out to explain my interest and intentions, the rationale for engaging in this study and the context in which I intend to explore the phenomenon of empowerment. In the following section discussion will focus on a selection of the literature that defines and explores the phenomenon of empowerment. 


\section{Empowerment}

As previously stated in the introductory section empowerment is a concept and phenomenon that has recently gained popularity of usage and has been applied to many situations, individuals and groups. Therefore it is important to review the use and meaning of this word, concept or phenomenon as it has been used, and defined in health and related fields.

I will therefore focus this section on defining the meaning of empowerment in social, community, nursing, and nursing education contexts, with the aim of making overt links with the current study and so setting the background.

Language dictionaries do not actually define the term Empowerment, they do however define Empower. The Oxford Dictionary (Burchfield 1986) states: Empower. Give power or authority to. Whereas the Collins Dictionary (Collins 1987) states: Empower, empowers, empowering, empowered. If someone is empowered to do something, they have the legal authority or power to do it; a formal word. The Collins Thesaurus (McLeod 1984) defines: Empower. Allow, authorize, commission, delegate, enable, entitle, license, permit, qualify, sanction, warrant.

Sociological, Psychological, and Health concept dictionaries and textbook glossaries do not include the term empower or empowerment.

\subsection{Empowerment and the Social Context}

Literature which discusses empowerment in a client / health care professional context is thought to have evolved from the 'social action' ideology of the 1960's and the 'self-help' perspectives of the 1970's. Rappaport (1984) who, in a discussion that focussed on empowerment as a social process, determined that empowerment should be viewed as a process and as such was

the mechanism by which people, organizations, and communities gain mastery over their lives. ( $p 3$ )

He further concluded that

the content of the process is of infinite variety and as the process plays itself out among different people and settings the end products are variable and even inconsistent with one another. (p 3) 
Rappaport (1984) considered however that this potential inconsistency was in the context of outcomes of the process rather than the process itself and that empowerment could be the active ingredient in a wide variety of human interactions. He cautioned, however, that

for some people the mechanism of empowerment may lead to a sense of control; for others actual control, the practical power to effect their own lives. Empowerment can be understood as an internalized attitude, or as an observable behaviour. ( Rappaport 1984 p 3)

Rappaport (1984) also asserted that empowerment was more easily defined in its absence; powerlessness,- real or imagined which he named as learned helplessness (Seligman 1991) ; alienation, or loss of a sense of control over ones own life. He further stated that the concept was more difficult to define in the positive because it takes different forms, in different contexts, with different people. However Rappaport (1984) did suggest that the way in which empowerment was measured was not empowerment itself and that each measurement, intervention, and description in a particular context would add to the understanding of the concept.

Kieffer (1984) studied the process of citizen empowerment and proposed a theory of empowerment in the context of adult learning and development. His theory arose from a study of emerging citizen leaders in the USA. In this context empowerment was described as

the continuing construction of a multi-dimensional participatory competence which encompassed both cognitive and behavioural change.(p 9)

Kieffer (1984) stated that the concept of empowerment is often used as if it were synonymous with concepts such as coping skills, support systems, personal efficacy, competence, self sufficiency, and self esteem. Kieffer's (1984) research analysed the path or passage of a group of people who had arisen from situations of apathy and oppression to socio-political empowerment. The aim of the project was to illuminate patterns and processes of transition from helplessness to powerlessness. Conclusions reached by Kieffer (1984) were that empowerment can be conceptualised as an interactive and highly subjective relationship between individuals and their environments. He described the development of empowerment in four discrete phases.

- Phase 1- the 'era of entry', was likened to infancy, and included the individual demonstrating exploratory participation, determination and a slightly uncertain commitment to self reliance. During this phase Kieffer (1984) suggested that authority figures and power structures were demystified. 
- Phase 2- the 'era of advancement' (childhood) expressed as requiring a mentoring relationship and supportive peers to encourage critical understanding of social and political relations. Attributes said to develop through the individual engaging in problem solving and reflection.

- Phase 3- the 'era of incorporation' (adolescence), regarded as a period of confronting and contending with the permanence and painfulness of barriers to self determination. During this phase organisational, leadership and survival skills were developed.

- Phase 4- the 'era of commitment' (adulthood), occurring when the individual had integrated new personal knowledge and skills into the reality of life. According to Kieffer (1984) this phase was demonstrated when individuals had succeeded in reconstructing their sense of mastery and self, in relation to the political world.

Kieffer (1984) determined that 'Praxis ', defined by Freire (1972) as

Reflection and action upon the world in order to transform it ( $p$ 28)

was an essential part of the empowering process, as he considered that reflection evoked new understanding of experience and was therefore at the core of empowering learning. Kieffer (1984) also considered that

in becoming empowered, individuals were not merely acquiring new practical skills; they are reconstructing and reorientating deeply engrained personal systems of social relations. ( $p$ 27)

Kieffer (1984) also stated that individuals in his study had overcome internalised expectations of helplessness, conflicts during maintenance of collective support, familial disruption, the frustrations of inequity and lack of resources and had endured political intimidation. Kieffer's study illuminated a view of empowerment as an extensively political, as well as psychosocial conception. When further exploration into the meaning of empowerment was undertaken by Kieffer (1984) he determined that there was a distinction between empowerment as a development of skills, and empowerment as an attainment of participatory competence. Kieffer deemed that participatory competence involved an abiding set of commitments and competencies which had three dimensions. These were: the development of a more positive self esteem, or sense of self competence; construction of a more analytical understanding of the sociopolitical environment; and, cultivation of resources for social and political action. Interventions or self initiated efforts which promoted development of any of these competencies were considered to be empowering. Fully established attainment of empowerment was regarded by Kieffer(1984) as having been achieved when all these 
dimensions were developed. Empowered participants said they did not feel they 'had more power', but that they 'felt more powerful'.

The fundamental empowering transformation was considered in this context to be the transition from perception or sense of self as helpless victim, to acceptance of self as an assertive and efficacious citizen (Kieffer, 1984).

\subsection{Community, Health and Nursing}

More recent literature by Tones (1991) has linked empowerment to international initiatives of community health care and health promotion, which are considered to stem from the philosophy of Primary Health Care (PHC) formulated by the World Health Organisation (WHO) at WHO conferences in Alma Atta in 1978 and Ottawa in 1986. In this context Tones (1991) defined empowerment as

the process whereby an individual - or community of individuals - acquires power (p 18)

Self empowerment was considered by Tones (1991) as an individual's capacity to control his or her own life.

The philosophy of PHC, which included development and implementation of initiatives to be incorporated in national policy and health care strategies, was seen as a means of achieving 'Health for all by the year 2000' (W H O, 1986). PHC also includes the philosophy that populations should have access to affordable and appropriate health care for their individual, family and community needs. The aim for each country was to incorporate within their health care policies and practices, methods and actions that encourage client consultation and active participation in the planning and delivery of health care.

Primary Health Care is most often considered to be a strategy that is applied to nursing in a community context (Norrish 1995). However, it can also be successfully used as a framework for nursing in any setting as it has the potential to become an over-riding philosophy and 'way of living' in the world (Shaw 1986).

Wheeler and Chinn in their handbook of feminine process entitled Peace and Power (1991) defined empowerment as

growth of personal strength, power and ability to enact one's own will and love for self in the context of love and respect for others. ( $\mathrm{p}$ 2) 
They further defined the concept in the individual, feminist context, as a form of strength which develops through listening inwardly to our senses as well as listening to others. Empowerment was considered by Wheeler and Chinn (1991) to be possible when there is respect for others and power sharing rather than 'power over' others. Wheeler and Chinn also considered that praxis was essential to peace and power and they referred to Freire's ideology of praxis as being based on reflective action that has the ability to transform the world. Wheeler and Chinn (1991) further defined praxis as

values made visible through deliberate action. $(\mathrm{p} 2)$

I consider that many of the ideas presented here, including the philosophy of thoughtful personal growth and strength that can lead to respect and power sharing, could be regarded as being contrary to the traditional hierarchical health care power structures presented in the introductory section. More recent discussions concerning the nature of nursing practice (Watson 1985, Diekelmann 1990, Bevis 1991) have addressed the place of empowerment in current nursing contexts.

As previously stated, the philosophy and practice of $\mathrm{PHC}$ is relevant to nursing practice. $\mathrm{PHC}$ includes the notion of self help and self determination and is therefore strongly linked to the concept of empowerment. To ensure that nurses are able to care for others using PHC strategies that are likely to be empowering, nurses and nursing students are considered by Zerwekh (1990) to require knowledge, skills and experience of empowerment

Clay (1992) has discussed the need for nurse practitioners in the 1990's to be independent, accountable professionals confident in their contributions to patient care which is based on clinical judgement and skill. Clay (1992) articulated the need to move from traditional nursing training approaches and stated that

education is a fundamental prerequisite for empowering nurses. ( $p .15$ )

Clay (1992) further considered that the need for nurses to be empowered stemmed from the fundamental belief that by doing so they would be able to improve the care of all people, and she elucidated that there was a requirement to empower nurses in order to empower the people they serve. Empowerment within a nursing perspective was deemed by Clay (1992) to stem from the WHO concept of health promotion in practice, and as such was defined as

the process of enabling people to improve and maintain their own health.(p 16) 
The notion of collective social responsibility for health care was considered to be a necessary precondition for developing and ascertaining the health potential of society (Clay.1992).

It follows therefore that nurses must be active on the socioeconomic and political stage in order to influence health and social policy (Clay 1992 p.16)

Gibson (1991) completed an objective concept analysis of empowerment, examining its characteristics and uses. She deduced that in a nursing context empowerment can be conceptualised as a composite of attributes that relate to the individual client, to the individual nurse, and can also belong to both the client and nurse.

In a broad sense empowerment is a process of helping people to assert control over the factors which affect their lives. (Gibson 1991 p 354)

Gibson (1991) concluded, from her study of nurse related literature, that empowerment could be viewed as a process or an outcome, but she stated that empowerment was more than increasing self esteem and self efficacy as it generally focused on solutions rather than on problems, and was dynamic in nature. Gibson (1991) determined that empowerment entailed a process of helping individuals to develop a critical awareness of the root causes of their condition and a readiness to act on this awareness. Empowerment was therefore considered to enable persons to master their environment and achieve self determination (Gibson 1991).

The notion of empowerment arising from self awareness and choice has been discussed by Holly, Millar and Skelly (1994) who considered that in a nursing context

empowerment involves choice: the choice to accept personal accountability for one's decisions; the choice to support the clinical or managerial expertise of one's colleagues; the choice to respect cultural diversity among nurses; the choice to honour patients decisions about their care; and the choice to accept the challenge of transforming the work environment through collaboration among nurses and other health care providers. ( $p 3$ )

During a reflection on professional practice, Labonte (1994) further analysed the concept of empowerment and described it as a dialectical relationship in which power is simultaneously given and taken. Labonte (1994) also believed that the professional role in empowerment was to challenge oppressive and health threatening political and economic structures. In his analysis, key elements in the relationship were that empower was a transitive verb in which 
the subject acts upon the object, and that empower can also be an intransitive verb in which the subject only acts upon itself. In regards to this definition Labonte (1994) stated that

the act of naming one's experiences is essential to an experience of self efficacy or empowerment ( $\mathrm{p}$ 256)

Labonte (1994) discussed the dangers inherent in professionals thinking that they can empower someone other than themselves and concurred with the notion that empowerment of another could only occur when the individual was empowered themselves. Labonte (1994) also reiterated Freire's (1972) idea that the most important power is the power seized by self determined groups or individuals.

The process of occupational education and tertiary socialisation (Short et al 1993) has been discussed previously as the theory of how adults learn and then assume the beliefs, behaviours and roles expected of them as an occupational group. The writing I have considered as relevant to the concept of empowerment in nursing also impacts on how this socialisation occurs and how it is therefore crucial to the education of nurses.

\subsection{Nursing Education}

When completing a concept analysis of empowerment Hokanson Hawks (1992) focused on the conceptual and philosophical application of empowerment in nursing education. From the knowledge gained during this analysis she defined empowerment as

the interpersonal process of providing the proper tools, resources and environment to build, develop and increase the ability and effectiveness of others to set and reach goals for individual and social ends. (p 609)

She (Hokanson Hawks 1992) believed that the existence of a nurturing environment was essential, and that the paramount factor for creating a caring environment was trust between individuals developed from honesty, openness and genuineness. Her analysis also emphasised the importance of valuing others, mutual respect, and courteous behaviour towards others. Hokanson Hawks (1992) considered that the process of empowerment in nursing education should emphasise achieving the purpose rather than following rules, and that empowerment should involve a commitment to mutual decision making and goal setting. She also considered an important factor was that the person being empowered must be willing to assume responsibility. Empowerment was deemed to result from the interaction between two or more people, the person who empowers, (in this case, the teacher who makes possible or enables), and the person who is empowered, (the student who becomes 
capable of setting and reaching goals). Hokanson Hawks (1992) used a matrix, developed from management /organisational theory to measure and provide support for defining the attributes, antecedents and consequences of empowerment, and from this developed a conceptual map. She concluded that 'transformative instruction' as proposed by Freire (1972), Belenky et al (1986), and Schon (1987) could contribute to empowerment in a nurse education setting and that

the line of demarcation between the teacher and student is diminished by the process of empowerment. (p 612)

That.

Empowerment presupposed that the learner is involved in the learning process. For this reason, educational philosophies that see the student as a spectator are incongruent with empowerment. ( $p$ 613) Also that.

Practice or action is critical to empowerment. The student must be active in the learning process. (Hokanson Hawks 1992 p 613)

Manthey (1992) in her discussion of empowerment issues as they relate to teachers and nurses stated that a professional practice learning environment was based on three critical elements, these being leadership, empowerment and team membership. To achieve these goals Manthey (1992) proposed that socialisation should be used to reinforce concepts, principals and ideas so they may become the status quo. Manthey (1992) also considered that empowerment needed to be learned experientially not didactically and that empowerment of nursing students was facilitated by teachers who gave legitimate choices and allowed consequential learning experiences to occur. Manthey stated that this meant giving real authority, allowing clinical decision making ( that will be positive in outcome) and treating students with respect. The three elements embodied in the empowerment process were Responsibility, Authority and Accountability:

- Responsibility was defined as the ability to respond and perform to one's greatest level of competence, which requires task allocation by one person and task acceptance by another.

- Authority was defined as the right to carry out the task or intervention for which the individual has accepted responsibility.

- Accountability was defined as the retrospective view or reflection on the action to determine whether the intervention performed was appropriate (Manthey 1992).

Manthey (1992) considered that graduating students needed to take risks with a degree of comfort that accompanies any judgement based autonomous profession. She also 
considered that role models are necessary to enable students to develop to this level of autonomy (Manthey 1992).

Jarvis (1993) completed a study in New Zealand of 'Student Nurses Learning from Practice' using grounded theory research methodology. Her findings concluded that it was important for students to be given responsibility, to have hands-on practice, to observe, develop confidence, and to have constructive communication with nurse teachers in order that they could become empowered. Empowerment and confidence were considered by Jarvis (1993) to contribute significantly to learning, and she regarded that the two attributes appeared to grow from self confidence and feelings of control. Jarvis stated that

the student is empowered when he or she possesses the skills required to explore and discover for him or herself. ( $p$ 61)

Jarvis (1993) also described empowerment in the context of students taking responsibility for clients, and suggested that clinical experience tutorials should focus on the development of student confidence and the empowerment of students. She considered that self reflection tools were of importance as they encouraged the student to maintain control over their learning and because feeling in control appeared to improve self confidence, which in turn facilitated effective learning. Jarvis (1993) recommended that

a major goal for practical experience should be the development of confidence and the empowerment of students. ( p 69)

When discussing the empowerment of nursing students in a USA context Zerwekh (1990), defined power as

the ability to exert one's influence over others to effect change. ( $p$ 23)

She discussed that in teaching students there was a need to a focus on self esteem which she considered should be fostered by faculty who consciously expressed respect and caring, encouragement and interest in students. The aim Zerwekh (1990) conveyed, was to guide students and so increase their sense of control through planned learning experiences that included: affirming feedback; clear expectations; appropriate responsibility; strong role models; opportunity to make choices and risk failure, and; growth from the experience. Zerwekh (1990) considered that these teaching strategies needed to be developed deliberately throughout the curriculum, and that 
professional power is first discovered by association with powerful caring faculty mentors and expert nurse preceptors, ( $p$ 23)

and that teaching should encourage powerful behaviour by a sequential development process that first provides structure and direction. Zerwekh (1990) suggested that the process needs to gradually increase student responsibility with more and more self direction supported by an atmosphere of mutual respect, which allows students to question, speak their mind, and so test their power. Zerwekh (1990) cautioned that

The degree of student empowerment possible will vary directly with faculty developing their own personal esteem and power. ( $p$ 23)

\subsection{Conclusion}

In this section I have attempted to place the concept, process and phenomenon of empowerment into social, community health, nursing and nursing education contexts through reference to relevant literature. The following section will further address empowerment and how it has been incorporated as an essential element into nurse education curricula. 


\section{Empowering Curricula}

To gain a further understanding of empowerment I consider it important to place the concept within the context of nursing education. To achieve this end the foundation of the education must be examined from its starting point - the curriculum or 'course of study' (Burchfield, 1986). This section will include discussion of the development of curriculum in a nursing education context and how this development has been applied within New Zealand. Dialogue relevant to recent developments in curricula for nursing education specifically the move from a technical to an emancipatory philosophy - will be explored. Finally the curricula of the course relevant to this study, that of the Degree in Nursing at Whitireia Community Polytechnic, will be outlined and discussed in the current cultural, sociopolitical and educational context.

\subsection{History}

Since the mid 1980's there has been a call from nurse educators ( Allen 1990, Bevis and Murray 1991, Diekelmann 1988, Moccia 1988, Watson 1988) in the USA and (French and Cross 1992) the UK to reform curricula for nursing programmes. Curricula have been developed as the basic foundation of the teaching-learning tenet. From the curriculum, programmes are taught and evaluated and students are assessed against the objectives defined within it. The debates that have been recently articulated in the nursing forum are concerned with the fact that current curricula have evolved from the basic principles for curriculum and instruction developed by Tyler in the 1950's (Bevis 1988). During the intervening years since the development and adoption of the Tyler model of behavioural objective curricula, nursing education has physically shifted from 'health' institutions (hospitals) to educational institutions (universities and polytechnics) which has changed the focus and purpose of nursing education. The move from 'training' with an institutional 'medical Illness' focus to an education of independent adults focus has taken place over the last 25 years in the USA (Diekelmann 1988) and the last 15 years in New Zealand. In New Zealand this trend commenced in 1973 and ended with the last hospital training schools closing in 1988. The increase in educational courses for nurses provided outside of hospitals is still growing in the UK (Reed and Procter 1993).

Students of nursing in the hospital context were employed by the institution and trained in an apprenticeship model ( Mercer 1994) where, following an initial induction course, practical learning was based on 'on the job' requirements, enhanced with regular classroom instruction and assessment in both settings. The philosophical assumption with this teaching was that 
once students were given information in the classroom they were able to go and apply it in the practical setting. Therefore, in order for students to learn everything required to become a nurse it was considered essential that all students should acquire some 'essential knowledge and skills' as identified by practitioners and teachers and that all students should have experience in every general and speciality area of nursing ( Diekelmann 1988).

The Tyler curriculum model was well suited to this type of learning mode

The Tyler model places high value on effectiveness, efficiency, certainty, and predictability, and emphasizes individualism and competition. It assumes knowledge consists of facts, generalizations, principles, laws, and theories, and things that can virtually always be explained by giving causal, functional, hypothetical or deductive reasons. It assumes knowledge can be directly and easily translated into specific behaviors, and it emphasizes future outcomes while de-emphasizing the 'here and now'. (Diekelmann 1988 p 139)

Bevis (1988) considered, however, that the use of behavioural objectives as learning tools left as irrelevant the large mass of learned aptitudes and that it discounted insights, analysis and patterns. It is also said to have discounted what Watson (1985) termed the 'soul' or the inner spirit, which she described as a greater self-awareness, a higher degree of consciousness, an inner strength and a power that can expand human capacities and allow a person to transcend themselves.

Nursing training using behavioural objectives served the functional requirements of nursing in the time and context of its existence, that is it served the needs of employers of nurses in the hospital setting. As Reed and Procter(1993) contend, nursing education was primarily concerned with ensuring a steady supply of conforming, obedient, non-critical, young (mainly female) employees. Bevis (1988) and Jolley and Brykcynska (1993) stated that one result of this type of training, and the curricula that supported it, was that there was in fact more than one curriculum operating. Three curricula have been identified by Bevis (1988) : the legitimate, written curriculum that has measurable objectives to be taught and assessed; the illegitimate curricula, or what is taught, but not assessed, for example insights, patterns, creativity, strategies and understanding; and the hidden curricula described by Jolley and Brykcynska (1993) as the set of influences that includes the pervasive values that one is expected to acquire by a process of 'institutional seepage'. For example one is expected to acquire punctuality, good behaviour, tolerance, and loyalty - the how to think and feel like a nurse,- which Bevis (1988) described as the subtle socialisations. In the hospital context students of nursing were trained in content and prescribed practice through application of the 
legitimate curriculum. They were also socialised within the hierarchical profession of nursing in relation to its status with the medical profession, and its place within the essentially illness focused institution by means of the hidden curriculum ( Jolley and Brykcynska 1993).

\subsection{Changes}

With the move to tertiary institutions of learning nursing students now encompass the new possibilities of the role of student and the current nursing role that places emphasis on maintenance of wellness and nursing within communities as well as hospitals. In this context curricula that were appropriate to hospital training have been found lacking and no longer relevant to the current educational setting, and the focus of nursing care.

The difficulty was, that curricula for nursing education programmes tended to reflect and encourage the focus on technical / practical knowledge that forms the basis of skill training rather than the educative, enquiry focus perceived to be more relevant to adult education, professional programmes and current nursing practice (Bevis 1988). The Tyler model of curriculum has, however, as Bevis (1988) stated, served an important purpose and function as it has

focused the training and instructional aspects of nursing in such a way as to help lift it to a highly organized, evaluation-orientated, and regulated group that provides services of reliable quality. (Bevis 1988 p 32)

A dilemma that forms part of this discussion is the problem that these curricula have been encompassed by governing bodies in both the USA by the National League for Nursing (Bevis 1988) and in New Zealand by the Nursing Council of New Zealand and the New Zealand Qualifications Authority (NZQA) (Mercer 1994). Curricula are used by these bodies to evaluate the quality of programmes and to allow graduates from programmes with approved curricula to be put forward as candidates for examinations leading to nursing registration ( Bevis 1988).

For some years the profession of nursing has been recognized as requiring more than a practical skills based training for practice preparation. Nurses require the ability to act as client, and self advocates, to work autonomously and to actively participate in current health care settings, which are continually changing (Reed and Procter 1993). Indeed French and Cross (1992) asserted that

the role of the professional nurse practitioner of the future must be a self reliant, critical and reflective practitioner. (French and Cross $p$ 83) 
For this to be possible a level of education that moves beyond that provided by the behavioral objective (Tyler) model of curriculum is required (Maclean 1992).

A clamor for change to nursing curricula has taken place during the past decade. In the USA debate concerning curriculum change has been termed a 'revolution' by the National League for Nursing. This 'revolution' being a call to move beyond the Tyler model of curriculum to include what has been 'hidden' and 'illegitimate' and to make all tenets of nursing overt and valued. Curricula have been changed in tandem with the move to tertiary educational institutions however such changes have only reworded, reworked and reapplied what is essentially the same content and teaching processes traditionally used to train nurses to work in hospitals(Bevis 1988). The call for 'revolution' has been a call to move past the focus on content and what is 'essential' or 'not essential' to teach a student nurse, and to a focus on teaching and learning for nurses through a congruent curriculum. (Bevis 1988). Congruent meaning that the content should be suited to the teaching methods used. For example it would not be considered congruent to teach nursing students how to become empowered and to participate in their own learning within a lecture theatre context using a didactic teaching approach.

\subsection{Educative Curricula}

In the USA Bevis (1988) has proposed a Professional or Educative model for curricula that includes congruent nursing philosophy, research and education and distinguishes between learning in order to train and learning that is education. In the Bevis model there have been six types of learning identified.

- The first is Item learning of separate pieces of information, individual factors and simple relationships such as lists and procedures - for example, how to take a temperature.

- The second is Directive and is concerned with rules, injunctions and exceptions to the rules - for example when, and when not, to take a temperature.

- The third is Rational learning which uses theory to inform practice, with a rationale for using an intervention decided on the basis of logic and theory.

These first three types of learning strategies are considered to be the focus of training and technical nursing programmes.

- The fourth type is Syntactical learning, defined as focusing meaningful wholes, relationships and patterns so that individualised client care may be given. This type of learning is said to enable students to make intuitive leaps and to trust their intuition and is also regarded as assisting to clarify the links between theory and practice.

- The fifth type is Contextual learning, or the sociocultural context of the discipline, the mores, folkways, rites and rituals that are the accepted ways of 'being a nurse'. It includes political expertise and its use, power and its use, role relationships, ethics and 
philosophy and therefore can influence nursing interactions so that transactions are caring, compassionate and positive.

- The sixth type of learning is defined by Bevis (1988) as Inquiry learning, and includes creativity, investigation, theorising, strategising, identifying, clarifying, and categorising problems, and approaches to solving them. Bevis states that Inquiry learning is about moving beyond words to understand their implications and applications, questioning validity, generating ideas and enjoying the quest for knowledge as much as the success in finding the answer.

This typology has been used by Bevis (1988) in researching different types of nursing programmes and examining curricula to determine the degree of 'training' or 'education' addressed by each type of nursing programme. She stated that by using new curriculum development paradigms, nursing undergraduate degree programmes should become more focused on the syntactical, relying on student teacher interaction as a major teaching method.

Diekelmann (1993), also from the USA, considered that in nursing we should perhaps never agree on what is 'required' or 'essential' content as it is dependent on the context of nursing care. She contended that students need to have the information to care for the patients that they work with, and therefore schools should teach different content depending on the population they serve. Diekelmann (1993) also saw a danger in the focus on curriculum content as it presents the possibility of taking education back to the behaviourist pedagogy, by keeping the emphasis on the application of content to a specific situation without taking different contexts into account. By doing this, Diekelmann (1993) contended that thinking is devalued, and it is the enhancement of this thinking, and thinking in a critical manner, that is emphasised by those wanting to change from the status quo of nursing curricula.

\subsection{Dialogue and Meaning Curricula}

Diekelmann (1988) proposed a Curriculum as Dialogue and Meaning model for nurse education which has a phenomenological basis. The model proposes an alternative way of conceptualising Nursing Education and is based on a restructuring of the relationship between knowledge and skill acquisition. In this model the curriculum is developed through dialogue among teachers, practitioners and students, concerning what will constitute knowledge in the nursing curriculum, and the role experience will play in it. The curriculum is based on what it means to be a faculty-teacher-researcher, a practitioner-teacher and a student nurse. The Curriculum is both constituted and constructed by these people. Dialogue is stated as more than 'being-in -the-world' with others through language and experience. In 'dialogue' it is assumed that decisions are only meaningful in the context in which faculty, students and practitioners experience them. Dialogue is joint reflection on a phenomenon and 
'problems' of curricula are solved through meaningful dialogue. In this curriculum model there are two kinds of knowledge:

- The first instrumental and theoretical -in other words 'knowing that' and the second

- The practical, is dependant on experience- in other words 'knowing how'.

In this curriculum model attention is paid to the issues of socialisation as well as to the learning of the necessary clinical judgement skills. The model focuses on the development of new relationships between teachers and practitioners that include empowerment through self-knowledge and inquiry, collaboration between students and teachers, and situated study which is defined as a pedagogy in which the study of one exercise merges into another and students become engaged through interest rather than following a syllabus. Diekelmann (1988) considered that

critical models also emphasize dialogue; where they differ from phenomenological models is in their emphasis on a commitment to emancipation. Teachers who use these models seek to make visible to themselves and their students the power imbalances that occur in both our schools and our practice. They place high value on their critical processes of dialogue and debate, and they bring feminist and emancipatory approaches to the examination of issues confronting nursing students, both within the school and in the practice environment. Dialogue as a critical process is the foundation for this model. ( $p$ 144)

\subsection{Emancipatory Curricula Models}

The development of curricula models that include critical social theory have been made visible in the UK by French and Cross (1992), and in New Zealand by Clare (1991), MacLean (1992), and Southwick (1994) who have used the theory of knowledge proposed by Habermas (1971) as an organizing framework.

The three areas, or learning domains described by Habermas (1971) are named as the Technical, the Practical and the Emancipatory. Each domain is both distinct and interrelated and represents specific constructs.

- The Technical refers to the way people control and manipulate their environments. Empirical-analytical sciences are employed using hypothetical-deductive theories to make generalizations through controlled experimentation and observation, thus increasing an understanding of this knowledge domain.

- The Practical domain is another way of seeking to control and manipulate our environment. It involves interaction and communication and aims to understand and interpret the meaning of social activity or phenomena. 
- The Emancipatory domain involves the development of self knowledge through self reflection. As such it involves gaining power over the forces that control or shape our lives through insight, said to be possible through critical self awareness. Emancipation is considered to be possible when the reasons for limitations and problems are understood through critical reflection. The theory includes the notion that social and personal change is possible if we become aware of how ideologies contribute to our dependancy on reiefied powers (Clare 1991, MacLean 1992).

As Clare (1991) states it is

grounded in the human capacity to act rationally and to reason self critically. ( $p 6)$

By using the knowledge domains of Habermas it is possible to gain an understanding of the philosophical underpinnings of different curriculum models and then to define their use and congruence within the current situation of nursing education.

Bevis (1988) stated that Tylers' model with its use of behavioral objectives is congruent with a philosophy of empiricism which is out of step with humanistic-existential goals and nursing as a human science. Humanistic nursing models, arise from practical domains (Habermas 1971) that attach socially constructed meanings to nursing phenomena which are congruent with the traditional concerns that nursing has for the person in their environment. They focus on the interpersonal processes and are influenced by the nursing theorist Martha Rogers who is credited with the legitimisation of emotion, values and beliefs defined through the use of interpretative research processes in nursing (Clare 1991). However as Clare (1991), Maclean (1992) and French and Cross (1992) contend, the interpretive model does not assist the nurse to understand structural conflict within society, or material conditions of people.

It neglects the crucial problems of inequity, injustice, social conflict and social change. (Clare 1991, p 7)

To overcome these restrictions the emancipatory interest or critical social approach is said to be required to

secure freedom from the patterns of domination and subordination inherent in all social relationships. (Clare 1991 p 7)

However as French and Cross (1993) state all three areas of cognitive interest are of importance in nursing education. A nurse who can think critically and reflect upon the social situation of her clients is not an educated nurse unless she also has knowledge of 
communicative and interpretive knowledge and this knowledge domain in the profession of nursing also requires knowledge from the sciences and the technical knowledge interests, to form a basis for safe skillful nursing care.

Nurse Educators in the USA involved in the curriculum debate consider that the inclusion of interactive communications are the key components of nursing (Diekelmann 1990, Moccia 1988, Bevis 1988, Bevis and Murray 1990, Watson 1988). However nurse educators in the UK (French and Cross 1992) and in New Zealand (Clare 1991, MacLean 1992, and Southwick 1994) place a stronger emphasis on the the inclusion of the critical paradigm as essential to nursing and nursing education. That is, the knowledge that includes the ability to critically reflect on current practice and to operate in a political, social and professional manner in order to assist the health status of the client group. This form of practice requires active interaction and involved awareness on the part of the nurse, a stance that is supported by other voices in educational reform circles, namely Apple (1990), Freire (1972), Freire and Shor (1987), Rogers (1983) and Carr and Kemmis (1986). Apple (1990) stated that the development of a critical perspective within the educational community can contribute to the creation of alternative programs of research and development that challenge the common sense assumptions that underpin the field. He also asserted that advocacy models of research and practice are needed because hegemony makes many people feel that social, educational and economic institutions are basically self directing and therefore do not require their input. He therefore concludes that curricula must take an advocacy position.

New Zealand nurse educators such as Clare (1991), MacLean(1992), Jackson ( 1994) and Southwick (1994) have all been involved in the debate on nurse education curricula and the need for change. They, along with other nurse leaders, have been in a position to influence changes to curricula that encompass the ideology or philosophy of the times.

\subsection{Nursing Curricula in New Zealand}

In 1971 an investigation was commissioned by the New Zealand Department of Health, which was undertaken by Dr Carpenter (Director of the School of Nursing, University of Toronto). The resulting Carpenter Report recommended that nursing education be positioned in tertiary institutions of learning (polytechnic institutions) rather than hospitals and that psychiatric and psychopaedic programmes should be phased out and a national comprehensive education programme be developed. The first trial programmes for comprehensive nurse education commenced in 1973, and by 1990 there were 15 comprehensive nursing programmes provided by polytechnics throughout New Zealand (Whitireia Community Polytechnic, 1993). In 1990 an amendment to The Education Act made it possible for polytechnic institutions to teach degree level programmes. By 1995 all schools of nursing in New Zealand were either teaching, or had applied to be accredited (to 
$\mathrm{NZQA}$ ) to teach, the pre-registration comprehensive nursing course as an undergraduate degree programme.

As part of this process, curricula have been rewritten to include a greater level of research and enquiry and coincident with this opportunity it has been possible to take up the challenge to write nursing curricula to include ideology relevant and current to nursing and health issues in the New Zealand context.

\subsection{The Curriculum of Whitireia}

Whitireia Community Polytechnic completed the rewriting of their degree curriculum and submitted it to NZQA in 1993. Motivation to rewrite the curriculum

arose out of a shared perception that, in fundamental ways, the curriculum originally developed in 1985 was an inadequate tool for expressing the unique teaching/learning experience that was Whitireia...

It had become increasingly difficult for both tutors and students to accept the reductionism of a behaviourist-driven curriculum in an environment that valued difference and uniqueness. (Southwick 1994 p 7)

It was considered that a curriculum reflecting and interlinking three core values was required. The core values were.

- the need to acknowledge the context of Whitireia as being situated within a bicultural and multi cultural community;

- the desire to emphasize collaboration and inclusion through a supportive and encouraging teaching / learning environment; and,

- equity, inclusion and nurturing as essential to the ethic of caring, and caring as fundamental to the profession of nursing. (Southwick 1994 p 7)

These values and beliefs were

seen to contain the tension and contradiction that is experienced in all aspects of social life. (Southwick 1994 p 7 )

The aim of the curriculum was to move beyond a view which was perceived to be limiting and to pursue the metaphor of partnership. The concept of 'partnership' came from Te Tiriti O Waitangi (appendix 1) and the curriculum incorporated the intention of the Three Articles of the Treaty. Also incorporated was the work of Habermas, in an attempt to interweave the three types of knowledge (technical, practical and emancipatory) with the intention of the Treaty. (Southwick 1994). 
an understanding, signed and marked on and after 6 February, 1840, between a representative of the British Crown and certain Maori chiefs. (Orsman and Orsman 1994)

To the British The Treaty of Waitangi was the means through which they gained sovereignty over New Zealand, but to Maori people Te Tiriti O Waitangi had a very different significance (Orange 1987). The Treaty of Waitangi specified certain unambiguous social and economic rights which have been undermined by the historical process of colonialism, increasing marginalisation of Maori and the evolution of neo-racism (Ramsden and Spoonley 1993).

The Whitireia nursing degree curriculum aimed to address these issues. The impetus to move in this direction came from internal dissatisfaction with the 1985 curriculum, the desire to become more openly congruent with the institutional goals (Appendix 2 ) as well as the policy statements originating from Health and Nursing Education legislative bodies (Southwick 1994).

In 1985, the Standing Committee on Maori Health recommended that the Treaty of Waitangi be regarded as the foundation for good health, and as such, all legislation relating to health should include recognition of the Treaty (Durie 1994). Also in 1986 a workshop held as the culmination of the first phase of the Review of the Preparation and Initial Employment of Nurses recommended that nursing education and nursing service be committed to biculturalism ( Boyd 1991). The philosophy of biculturalism was in this context defined as having its roots in Te Tiriti O Waitangi and having the potential to be the driving force behind the aspirations of national solidarity. The philosophy of biculturalism also requires systems of relationships which promote power sharing, understanding, mutual respect for language, lifestyles and beliefs which could lead to beneficial interaction between the two major and inter-dependant cultures ( Cooper 1991). Biculturalism was defined at Whitireia Community Polytechnic (at that time named Parumoana Community Polytechnic) in 1987 as referring to the heightening awareness of aspects of Maori culture, including acceptance and sensitivity towards biculturalism itself. Biculturalism is also defined in the context of The Treaty of Waitangi as the recognition of the two cultures of Maori and Pakeha and the equal rights of the two. (Mulgan 1989) Partnership was defined in accordance with the Treaty of Waitangi, as referring to the sharing of power and resources (Parumoana Community Polytechnic 1987). 
In 1990 a report on cultural safety was commissioned by the Heads of the schools of nursing in New Zealand.

The report described ways in which cultural safety might be incorporated into nursing education and was the product of wide ranging discussions with Maori, including Maori nurses. (Ramsden and Spoonley 1993 p 162)

'Cultural safety' was the term Maori preferred to describe the outcome of health service delivery to Maori as they found the term 'culturally appropriate' to be, inadequate in both sense and meaning (Ramsden, 1993). The decision was made by the New Zealand Nursing Council (statutory body for nursing registration) to require nursing schools to include the obligations of the Treaty of Waitangi into mission statements and nursing philosophies. In 1991 the national registration examination included cultural safety as a required competency for candidates and in 1992 the Nursing Council commissioned a set of guidelines with the aim of determining the content of cultural safety in curricula throughout the country (Ramsden and Spoonley 1993). The intention behind the inclusion of cultural safety in curricula was to address the inequities that had developed between the Treaty partners and which had led to a health service that had not protected the rights of Tangata Whenua, or allowed their participation in health matters (Durie 1994). The need for nursing education to address these issues was perceived as being, that in New Zealand the nursing service had been 'overwhelmingly' monocultural and as such had not met Maori requirements. As Ramsden and Spoonley (1993) contend

an understanding of cultural influences needs to be combined with an understanding of the economic dimensions of health... Nurses as front line workers in primary health care, require a critical understanding of the effects of poverty on health, and the attempts of indigenous people to re-establish the economic and emotional stability of their own cultural systems as a means of combating such poverty. ( $p$ 164)

Therefore it was deemed to be an appropriate time for the Treaty of Waitangi to be situated within the curriculum of the Whitireia nursing degree, within a critical social framework of knowledge.

The three articles of the Treaty of Waitangi are incorporated into the Whitireia Nursing degree curriculum philosophy ( Appendix 3) thus: 
Article the First - Kawanatanga/Governorship. The first article of the Treaty of Waitangi is the basis for the claim that the Treaty is the cornerstone of New Zealand's nationhood. Social existence is dependent on the organization of mutual relations of human beings and classes of human being in community. By signing the treaty, Maori mandated to the Crown the authority to secure an ordered social system within which Maori and those represented by the Crown could live together in community. ( $p$ 10)

This article is discussed as including the basic or cornerstone knowledge from the empirical I scientific or technical domain as previously described.(section 3.5) This knowledge is required to ensure that beginning nurse practitioners can make sound value judgements. The knowledge from this domain includes subjects such Anatomy and Physiology and incorporates the teaching of nursing skills such as temperature, blood pressure and pulse taking. The Whitireia nursing programme curriculum addresses the need for students to have empirical knowledge within an 'ordered system' and for the teacher to have authoritative responsibility and obligation to the student by way of including knowledge that the student needs to become a safe nurse practitioner.

Article the Second - Tino Rangitiratanga/Autonomy. At the very least The Treaty articulates the right of Maori to their separate identity as Maori. The Crown guaranteed to protect those institutions, customs and artefacts by which Maori express and know themselves as Maori. We have interpreted Tino Rangatiratanga to mean the right to be self-governing and self-determining, and the term 'Autonomy' to represent this meaning. ( Southwick $1994 \mathrm{p} 12$ )

This includes the notion of autonomy not only as individual self but also as the self in community. With autonomy comes the responsibility for decision making.

Autonomy expressed as Tino Rangitiratanga is the possibility Maori people have to critically reflect on what it is to be Maori within the context of the dialectic tension between kawanatanga and tino rangatiratanga. (Southwick 1994 p 12)

In this context The Treaty of Waitangi provides the opportunity between Maori and Tau iwi for a potentially transformative relationship. Shared meanings of 'reflections on experience' can occur through dialogue and allow each person to understand the situation of the other. In this way the practical knowledge interest is placed within the second article of The Treaty of Waitangi. (Southwick 1994) 
Article the Third - Kia Rite Tahi/Empowerment. The third article brings the concept of Kawanatanga into relationship with Tino Rangatiratanga. It articulates two obligations of Crown to Maori and by inference suggests the responsibility of Maori to Crown. The first obligation is for Crown to protect Maori. (Southwick 1994 p 14)

This first obligation has been interpreted by Southwick (1994)as the obligation to do no harm. The second obligation as the right of citizenship, has been interpreted as the right of inclusion.

The significance of defining protection and inclusion is that it places some boundaries on the nature of the relationship formed by the two parties to the Treaty. (Southwick 1994 p 14)

The notions of protection and inclusion oblige both parties to participate and take responsibility. As Southwick (1994) states, the three articles of the Treaty of Waitangi create the possibility of a partnership between the founding peoples of New Zealand, which acknowledges past relationships of power and subordination as well as the effects that this history has had on Tangata Whenua. These effects include injustice and oppression stemming from the relationship of hegemonic privilege. As Southwick (1994) further stated.

When we begin to understand, through critical reflection, that The Treaty enables both partners to define themselves in relation to the other, then the whole concept of partnership becomes one of emancipatory potential. This potential occurs when people are able to engage in what Habermas defines as the undistorted communication of discourse. When discourse occurs, all the dialectic possibilities are attendant in a relational in which authentic self engages with authentic other to act. Empowerment is achieved when this emancipatory potential is realized. (p 15)

\subsection{Conclusion}

In this section I have explored nursing education curricula and the development of curricula that include emancipatory philosophies. I have concluded by focussing on the curriculum at Whitireia Community Polytechnic. It is against this background that I intend to explore the concept of empowerment as it relates to students of nursing from this programme. The following section will outline the methodology, participants and process I used to complete this study. 


\section{Methodology}

In this section methodology will be outlined, considerations of validity discussed, and the enquiry in action described.

\subsection{Introduction}

Lather (1992) defined methodology as

the theory of knowledge and the interpretive framework that guides a particular research project. ( $p 87$ )

This particular research project has been guided and informed by multiple theories of knowledge and interpretive frameworks, which will be discussed in this section. Relevant to this is the notion that the methodology of choice is said to reflect the values, beliefs and perspectives of the researcher (Anderson 1990), or to be consistent with their socialised world view (Baer-Doyle 1988, Glesne and Peshkin 1992, Lather 1992). Given my socialised world view and values, beliefs and perspectives it should, therefore, not be surprising that a synthesis of philosophies has been attempted.

This study is at its most basic level Educational Research defined by Anderson (1990) as

A disciplined attempt to address a question and solve problems through the collection and analysis of primary data for the purpose of description, explanation, generalisation and prediction. ( $\mathrm{p} 4)$

However because of the topic and context of this research it could also be defined as essentially Praxis-orientated in form and function and Emancipatory in intent ( Lather 1986) According to Lather

Emancipatory knowledge increases awareness of the contradictions hidden or distorted by everyday understandings and in doing so it directs attention to the possibilities for social transformation inherent in the present configuration of social processes. ( Lather 1986 p 259) 
I also consider that because of the educational context and emancipatory potential of this study it could also be defined as Emancipatory Action Research (Kemmis 1985, Carr and Kemmis 1986, Tripp 1990) which has been defined by Kemmis (1985) as

a form of self-reflective inquiry undertaken by participants in educational situations in order to improve the rationality, justice and satisfactoriness of (a) their own social and educational practices, (b) their understanding of these practices, and (c) the institutions and situations in which these practices are carried out.(p 156)

Kemmis (1985) further states that

Emancipatory Action Research involves participants in planning action (on the basis of reflection); in implementing these plans in their own action (praxis); in observing or monitoring the processes, conditions and consequences, of their action; and in evaluating their actions in the light of the evidence they collect about them (returning to reflection) as a basis for replanning further action. ( $p$ 156)

Lather (1986) states that praxis refers to activities that combat dominance and encourage social change through self-organization and that for praxis to be possible theory must 'illuminate the lived experience' of progressive social groups and be informed by their history and struggle. Lather (1986) also asserts that emancipatory theory building differs from grounded theory building in that praxis orientated research has as central to it a priori theory, whereas in grounded theory the theory arises from, and is grounded in the data (Glaser and Strauss 1967). However Hutchinson (1990) considers that grounded theory research is a form of social criticism as it makes judgements about identified patterns of social interaction. As Hutchinson stated

the mere documentation of social phenomenon evokes an awareness that social reality is communally contracted and is thus subject to change. ( $p$ 136)

I consider that these philosophies are not mutually exclusive. That whilst my overall intent is that this research illuminates the lived experience of the participant group - with the aim of giving power to them through the insights gained - it is my belief that the perspectives and lived experiences that are to be uncovered can only be truly illuminated by the use of a grounded theory approach.

The purpose of this research is to give students and teachers of nursing knowledge of the phenomenon of empowerment with the intent that this knowledge can be used to improve 
teaching and learning interactions through the application of theory to practice, for the benefit of all involved.

Therefore this research has used the grounded theory approach whilst being informed by emancipatory knowledge. Hutchinson (1990) contends that educators need to use grounded theory methodology to explain the everyday world of teachers and students. This need is based on the notion that by using grounded theory social psychological consequences can be explored in educational contexts. Hutchinson (1990) considers that these social psychological factors are perhaps the most relevant factors in human behaviour and that grounded theory offers a systematic method by which to study human experience and generate relevant, plausible theory which can be used to understand the contextual reality of social behaviour. The aim being to assess what is happening and plan interventions to improve the quality of education (Hutchinson 1990). Stevens Schade Chalk and Slevin (1993) ascribe to the potential value of grounded theory for nursing because nursing is relatively new to the field of research and the development of concepts and theories which can be applied to it's practice.

The nature of this enquiry led to the use of this qualitative paradigm because it is qualitative research methods and analysis that aim to capture what people and their lives are about. Glesne and Peshkin (1992) consider that by immersing themselves in the setting and working to understand the participants perspective, the qualitative researcher aims to show the complexity, contradictions and sensibility of social interactions .

In this study I considered it important to explore the phenomena from a fresh perspective. The intention of the research being to develop a theory based on the analysis of the real life events of participants. Therefore the grounded theory approach was considered to be the most appropriate broad methodological framework. Stern (1980) considered that the strongest case for the use of grounded theory was to gain a fresh perspective in a familiar situation. Glaser and Strauss (1967) and Corbin and Strauss (1990) have stated that to be valid, theories should be qualitatively grounded.

The following subsections will discuss ontological and epistemological issues relevant to this research, the philosophies and methodologies of critical social enquiry and grounded theory, describe the participants, discuss issues of ethics and validity, and outline the methods used to gather and analyse data. 


\subsection{Ontological and Epistemological Considerations}

Enquiry and discussion into the paradigms or basic beliefs that underpin research is important because it serves the function of clarifying what is, and what is not, within legitimate enquiry limits (Guba and Lincoln, 1994). As previously discussed the beliefs of the researcher are influenced by their world view and in turn their world view will influence perceptions and ultimately conclusions reached within an enquiry. The aim of exploring these enquiry paradigms is therefore to describe and so make explicit these basic beliefs .

Guba and Lincoln (1994) believe that by exploring the ontological, epistemological and methodological paradigms clarification of beliefs that must be accepted as givens will be possible. Ontology is defined as

A branch of metaphysics dealing with the nature of being. (Burchfield 1986)

and Epistemology is defined as

A theory of method or grounds of knowledge (Burchfield 1986)

Baer-Doyle (1988) contends that ones epistemology is an account of what one really believes about knowledge and knowing as well as what one considers is worth knowing.

As outlined in the introduction the methodology underpinning this study was defined by the need to collëct qualitative data that would uncover the emic or insider view of participants. The ontological limitations can be clarified by asking the question,

What is the form and nature of reality and therefore what is there that can be known about? (Guba and Lincoln 1994 p 108)

The aim of this question is to explore the trustworthiness of a research approach.

The assumptions made in this study were that 'a truth' could be discovered through the process of collecting information in a manner that ensures that what is discovered is the 'reality or truth' for the participants. Grounded theories are guided by the assumption that people have patterns of experience and that they order and make sense of their environment. The order or pattern is derived from their shared social and symbolic interactions which lead to the conclusion that reality is a social construct ( Hutchinson 1990). Analysis of data is carried out in such a way that another researcher following the process of analysis could clearly see how the theory has been developed from that data. The aim being to ensure the 
trustworthiness of the method used and therefore to discover the reality or truth of the phenomenon and process of empowerment in context for this participant group.

Guba and Lincoln (1994) propose the epistemological question :

What is the nature of the relationship between the knower or would be knower and what is known or knowable? (p 108)

According to Guba and Lincoln (1994) the answer to this question is constrained by the answer to the previous ontological question.

Having made the previous statement that one reality is assumed when it is possible to discover a theory from participant information is to place this particular research project within a post positivist paradigm (White 1996). This position would assume that the researcher can take a position of objective detachment in order to discover how things really are (Guba and Lincoln 1994). However as the researcher in this study I have not entirely assumed this stance, because I consider that the relationship of the knower to the knowable in this study is more closely aligned to a position of intersubjectivity. Essentially this is because I am aware that the study has been driven by my personal interest in the research topic and the desire to engage with it in a practical manner. However, the desire to engage with this topic and with student participants who are engaged in the process of empowerment I also considered is fundamentally a critical social action research process that has the potential to be emancipatory or transformative in nature.

Lather (1996) describes the position of researcher in emancipatory research as moving from the status of stranger to friend in order to gather personal knowledge from participants. In conducting a grounded theory study however Bowers (1988) considers that optimally the researcher should be able to maintain one foot in the world of the subjects and one foot outside that world, viewing actions from the perspective of the subjects while standing back and asking questions about what the subjects take for granted. This position is also referred to as 'marginality'. Bowers also considers that taking on the perspective of the subjects and adopting it as truth or reality, can have the effect that the researcher may lose the heightened sensitivity that comes with a marginal position. Consequently the researcher can become unable, or less able, to see objects in the world under investigation. Bowers (1988) regards that to overcome this difficulty, the grounded theory researcher must work to maintain marginality by continually comparing the accounts of the research subjects with each other, their own reflections, and the literature. 


\subsection{Emancipatory Enquiry}

Because of the topic and focus of this enquiry I consider it appropriate to discuss other philosophical underpinnings that have informed the nature and the process used in this research.

Broadly speaking this research is a critical social enquiry in that it is informed by feminism and explores the notion of empowerment for nursing students, the majority of whom are women. Feminist research has from it's beginnings been preoccupied with the politics of knowing and being known. Ideologically most feminist research assumes that 'ways of knowing' are inherently culture bound and that researcher values permeate enquiry (Scott 1985, Lather 1992, Middleton 1993). Therefore research informed by feminist philosophy can be considered emancipatory because it has as a focus the aim of consciously helping participants to understand and change their situations through a process of critical enquiry. 'Transformative' and 'Emancipatory' are also terms given to describe research that involves critical social enquiries. (Lather 1986 1990, Deshler and Selner 1991)

Transformative research is defined as research that is ethical, emancipatory, empowering and holistic in both its implementation and the use of its results (Deshler and Selner 1991). Transformative research has also been discussed as being an act of adult learning and knowledge generation because it includes the notion of learning through enquiry. This form of practice for educators and the philosophy of how research is conducted has been stated by Deshler and Selner (1991) to be a political statement about who and what is important to the researcher. Emancipatory research has been discussed by Lather (1986) as research that includes empowering approaches whereby both the researcher and the researched become the changer and the changed. Lather (1986) asserts that for researchers with emancipatory aspirations research offers a powerful opportunity for praxis to the extent that the research process enables people to change by encouraging self reflection and a deeper understanding of their particular situations. Praxis is the term given and defined by Freire (1972) as

The action and reflection of people upon their own world in order to transform it.

Middleton (1993) asserts that research is an intervention in the lives of those being researched and as such can bring about a change in the way people perceive their lives. The perception of which may stimulate them to make changes. This position Lather (1986) defines as catalytic validity and Freire (1972) as conscientization. The aim of emancipatory research is the collaborative or participatory (Glesne and Peshkin 1992) approach to critical enquiry with the focus on empowering the researched. Lather (1986) considers that there are several 
procedures important to the validity of emancipatory research that need to be incorporated within a research design. These include Triangulation by using multiple data sources, methods, theoretical schemes and designs that allow counter patterns as well as convergence. Construct validity, face validity and catalytic validity are also of importance (Lather 1986).

- Construct validity encourages self-critical attitudes to preconceived ideas through the researcher using the process of reflexivity.

Marcus (1994) defines reflexivity as the self critical nature of the researcher in feminist and other forms of emancipatory research.

Reflexivity has been more recently discussed and theorised as the practice of positioning which is most committed to the situatedness and partial claims to knowledge... and assumes all work is incomplete and requires response ( and thus engagement) from others positioned differently ( p 571-572)

- Face validity includes reciprocity or mutual negotiating of meaning and power within the research process.

Reciprocity in research design is considered by Lather (1986) to be a matter of both intent and degree. Intent in that the aim of the research is to assist change and awareness for the participants and the degree that participants are included in negotiating and working with the researcher as part of the overall research design. An essential element in the process is open communication and negotiating access with participants throughout the research process. Lather (1986) considers that one of the most important procedures is the giving back to participants the picture of how the data are viewed, with the aim of returning something to the participants as well as to check descriptive and interpretive / analytic validity of the research. In this context reciprocity is more that a simple member check as defined by Denzin and Lincoln (1994). Lather (1986) proposed that

the goal of emancipatory research is to encourage self reflection and deeper understanding on the part of the persons being researched at least as much as it is to generate empirically grounded theoretical knowledge. ( $\mathrm{p} 266)$

Procedures deemed necessary to attain reciprocity are: interviews conducted in an interactive dialogic manner that require self disclosure on the part of the researcher: sequential interviews; negotiated meaning which at minimum entails recycling description, emerging analysis and conclusion; and, discussions of false consciousness that go beyond simply discussing resistance to Marxist interpretations. 
there is a dialectic between peoples self understandings and researcher efforts to create a context which enables a questioning of both taken for granted beliefs and the authority that culture has over us. (p 266)

- Catalytic validity specifically refers to the aim of consciously using research to help participants understand and change their situations (Lather 1986).

The basic premise of critical enquiry being that it is fundamentally about dialogue and is a mutually educative process (Lather 1986 1992, Middleton 1993).

\subsection{Grounded Theory}

\subsubsection{Introduction}

The Grounded Theory approach was developed by Glaser and Strauss in 1967 and derived its theoretical underpinnings from pragmatism and symbolic interactionalism (Corbin and Strauss 1990). Corbin and Strauss (1990) consider that two important principles drawn from these philosophical and sociological orientations are built into the method. The first is the notion of change and the acknowledgment that phenomena change in response to evolving conditions. An important component of the method is to build change, through process into the method. The second principle is the notion of determinism. Determinism meaning that

actors are seen as having, though not always utilizing, the means of controlling their destinies by their responses to conditions. (Corbin and Strauss $1990 \mathrm{p} \mathrm{5)}$

Grounded theory seeks to uncover relevant conditions of how actors respond to changing conditions and the consequences of their actions. Techniques and procedures of analysis set down by Glaser and Strauss (1967) Glaser (1978) and Corbin and Strauss (1990), enable the researcher to develop a substantive theory that meets the criteria for 'good science' or sound research in that it is of significance, generates a theory, ensures comparability, generalizability, reproducibility, precision, rigour and verification (Stevens et al. 1993). The usefulness of the method is that the researcher can start afresh and not be influenced by present knowledge about certain phenomena (Stern 1980). Grounded theory has not changed in function since it was first introduced in 1967 but the specificity of its procedures have been elaborated in more detail since it originated (Corbin and Strauss 1990). Grounded Theory is basically defined as a qualitative research method that uses a systematic set of procedures to develop an inductively derived grounded theory about a phenomenon (Stevens et al. 1993). 
In grounded theory the researcher invites subjects to explain or describe the object or phenomena and it is considered crucial for the researcher not to provide subjects with a definition (Bowers 1988). The procedures are designed to develop a well integrated set of concepts that provide a thorough theoretical explanation of the social phenomena under study (Corbin and Strauss 1990).

\subsubsection{Principles and Procedures}

Corbin and Strauss (1990) state that the most notable variations from other research methods are: that when following the grounded theory method a hypothesis does not precede the enquiry but rather is generated towards the end of the study, as the theory is developed and tested against the data collected; and, that literature is used to guide aspects of the study but not to fully inform the researcher about the nature of the phenomena prior to the study. The phases of literature review, questioning / hypothesis generation, data collection and analysis occur simultaneously rather than as a sequence of distinct phases (Bowers 1988). In grounded theory data is gathered as soon as the researcher has identified a researchable question and setting. Initial observations enable descriptions of the social structure, patterns of behaviour and the environment. The interpersonal interaction that is required by the method demands that the researcher becomes aware of their own preconceptions, values and beliefs. These preconceptions must be transcended during the research if the phenomenon under study is to be seen in a new perspective, a process which is termed bracketing by Hutchinson (1990).

The procedure recommended to help the researcher become aware of, and be able to bracket, their own values is keeping a journal in which personal feelings and reflections are recorded on a regular basis throughout the research process (Hutchinson 1990).

In grounded theory data collection and analysis are interrelated processes. Analysis begins as soon as the first data is collected because it is used to direct the next episode of data collection and to guide the questions asked.

The carrying out of procedures of data collection and analysis systematically and sequentially enables the research process to capture all potentially relevant aspects of the topic as soon as they are perceived. (Corbin and Strauss 1990 p6)

Data gathering in educational grounded theory research may include observations, interviews student records, school policy documents, researcher journals and any information that expands and clarifies the phenomenon (Hutchinson 1990). Glaser and Strauss (1967) 
considered that diverse data ensures density and different perspectives for understanding social phenomena.

In the grounded theory approach the research process is said to guide the researcher toward understanding and every concept discovered in the process is at first considered provisional. Concepts earn their way into the theory by repeatedly being present in interviews, and documents (Corbin and Strauss 1990).

Concepts are the basic units of analysis in that conceptualizations of the data, not the actual data, are used to develop the theory. Incidents, and events are analysed as potential indicators of the phenomena by defining the concepts present in the examples given. (Corbin and Strauss 1990). Concepts become more numerous and abstracted as the analysis continues and categories are developed from these concepts. Concepts that relate to the same phenomena are grouped to form categories, however not all concepts become categories. Categories are more abstract than the concepts in that they are representations of concepts. Categories are generated through the same analytical process of making comparisons to highlight similarities and differences as is used in the generation of concepts. Categories are defined and given explanatory power and eventually become related to one another to form a theory. (Corbin and Strauss 1990)

Sampling in grounded theory proceeds on theoretical grounds in that rather than sampling many persons who may have experienced the phenomena being studied, many events and examples that are related to the phenomena are studied. The action / interactions by which the phenomena is expressed, and the consequences that result, are the focus of the data collection. The aim is to ultimately build a theoretical explanation by specifying phenomena in terms of conditions that give rise to them, how they are expressed through action I interaction, the consequences that result from them, and variations to them. The aim is not to generalize findings to a broader population per se (Corbin and Strauss 1990).

Analysis makes use of constant comparisons in that as an incident is noted it is compared against other incidents for similarities and differences. Making comparisons is said to assist the researcher to guard against bias and achieve greater precision. Patterns and variations must be accounted for as finding patterns or regularities helps to give order to the data and assist with integration. ( Corbin 1986 Corbin and Strauss 1990)

Writing theoretical memos is an integral part of grounded theory as it constitutes a system for keeping track of how the formulation and revision of the theory occurred. It is advised by Glaser and Strauss (1967) Glaser (1978) and Strauss and Corbin (1990) that memos are 
written continuously from the time coding commences and continue to the end of the research. Hypotheses about relationships among categories are developed and verified as much as possible during the research process and memos record this development. Corbin and Strauss (1990) state that a key feature of grounded theory is not that hypotheses remain unverified, but that hypotheses are constantly revised during the research until they hold true for all evidence concerning the phenomena under study.

\subsubsection{Coding}

Coding is the fundamental analytic process used by the researcher. There are three types of coding. Open, axial and selective ( Corbin and Strauss 1990)

Open coding is the interpretive process by which data are broken down analytically. Its purpose is to give the analyst new insights by breaking through standard ways of thinking about or interpreting phenomena reflected in the data. In open coding, events/actions/interactions are compared with others for similarities and differences. They are also given conceptual labels. In this way, conceptually similar events/actions/interactions are grouped together to form categories and subcategories.(p 12)

Following the identification of categories and their properties categories become the basis for sampling on theoretical grounds and therefore are used to guide further questions and for constant comparison. It is through the use of open coding that grounded theory is said to break through subjectivity and bias.

Axial coding involves noticing and including within categories the conditions, context and consequences of an action/interaction.

In axial coding categories are related to their sub categories, and the relationships tested against data. Also further development of categories takes place and one continues to look for indications of them. Through the 'coding paradigm' of conditions, context, strategies (action/interaction), and consequences, subcategories are related to a category. (Corbin and Strauss 1990 p 13)

During axial coding hypothetical relationships may be proposed through the process of deduction which must be considered provisional until repeatedly verified from the data. This means that a single incident is not sufficient basis to verify or discard a hypothesis. The purpose of axial coding being to systematically seek the full range of variation in the 
phenomenon being researched, through the inclusion of the conditions, context and consequences.

Selective coding is the process by which all categories are unified around a 'core' category.

Categories that need further explication are filled-in with descriptive detail. This type of coding is likely to occur in later phases of a study. (Corbin and Strauss 1990 p 14)

The core category represents the central phenomena of the study and may be represented in diagrammatic form. The grounded theory method proposes that sufficient coding will eventually lead to a clear perception of which category or concept integrates the whole analysis (Corbin and Strauss 1990).

\subsection{Considerations of Validity}

Morse (1994) stated that the methods used to ensure rigour in qualitative research are intricately linked with reliability and validity checks. Lather (1986), Guba and Lincoln (1990), Corbin and Strauss (1990) and Denzin and Lincoln (1994) also discuss the principles and processes of validity in qualitative research. The main methods used to ensure validity are criteria checks for adequacy and appropriateness of data, an audit trail and verification of the study with informants (Morse 1994). The intention was to plan the project to be rigorous in all stages of the process, and therefore consideration was given to the following issues.

\subsubsection{Adequacy and Appropriateness of Data}

In this study adequacy of the data included the amount of data, the type of data and the complexity or richness of data.

The amount of data collected was not defined by recruiting large numbers of participants but by eliciting many examples of the phenomenon or 'exemplars' (to be discussed in section 4.6.4) from each of the participants. As Sandelowski (1995) stated, numbers of participants are unimportant in ensuring adequacy of data sampling. Determining adequate sample size is a matter of judgement in evaluating the quality of the data, research method and intended research product (Sandelowski 1995). As this study progressed saturation of information was considered to be reached when repetition of the information provided confirmation of data previously collected (Corbin and Strauss 1990, Morse 1994). That is when enough exemplars of empowering interaction were describing and explaining the same sequence of events or type of interactions. At this stage the amount of data was considered sufficient. 
Theoretical sampling also addressed the adequacy of the data and included the use of negative cases - or examples when participants felt they were disempowered in the teaching I learning process. The use of this information helped to explain variations as well as serving to enrich the model which emerged.

Appropriateness of data was ensured by the use of sequential interviews that focused on the phenomena. Interview processes and procedures that encouraged truthful responses to general open-ended questions and the use of interview techniques that drew out responses and checked meaning also served to provide appropriate data collection (Morse 1994). Presenting questions to participants prior to the interviews and maintaining focused interviews that aimed at eliciting exemplars from which theory was developed were all strategies used to assist the gathering of appropriate data or addressing construct validity (Lather 1986).

A difficulty described by Lather (1986)as

the tension between letting data speak for itself and using abstract categories

was addressed by presenting full transcripts of exemplars in the following section (section 5) as well as describing how the concepts and categories were developed (section 6). The aim being to

explain the lives of others without violating them. (Lather 1986 p 271)

\subsubsection{Data Analysis}

Methodical data analysis in this project followed the grounded theory approach described by Corbin and Strauss (1990). This method was used to ensured rigour of analysis and to allow other researchers to follow the development of the theory. The method was augmented by the reciprocity maintained between the researcher and participants that sought to share ideas and finally the draft theory following it's development. Lather (1986) describes this procedure as ensuring face validity but warns that the trustworthiness of the method may include problems of false consciousness. Lather (1986) stated that

for reasons illuminated by Gramsci's (1971) theories of hegemony most people to some extent identify with and /or accept ideologies which do not serve their best interests. (P 271) 
As researcher I reflected on these words and considered that the educative process in which the student participants were engaged made false consciousness less likely. However during the data analysis I was further informed by literature relevant to the data so that I would maintain congruence with the context and intent of the study. Through this process I also aimed to enlighten the participants and therefore assist them to develop awareness or conscientization (Freire 1972) in order to enhance the empowering potential in their own learning.

A final meeting during which I presented the theoretical model included asking the participants how they felt this information should best be used and disseminated for the greatest benefit of themselves and the student group they represented.

The process of analysis and development of the theory and theoretical model is represented in the following flow diagram (Fig 4.1). The skeletal model (Fig. 6.1) was developed from analysis of the participant meanings of empowerment. The primary model (Fig. 6.2) was developed from analysis, using open coding, of my initial impressions from first participant interviews. The secondary model (Fig. 6.3) arose following analysis of exemplars using axial coding from which concepts and categories evolved. The tertiary model (Fig.7.2) was developed following reference to literature, and the final theory and theoretical model (Fig. 8.1) was crafted following participant confirmation of the tertiary model.

Figure 4.1 Flow diagram of analysis, theory and theoretical model development

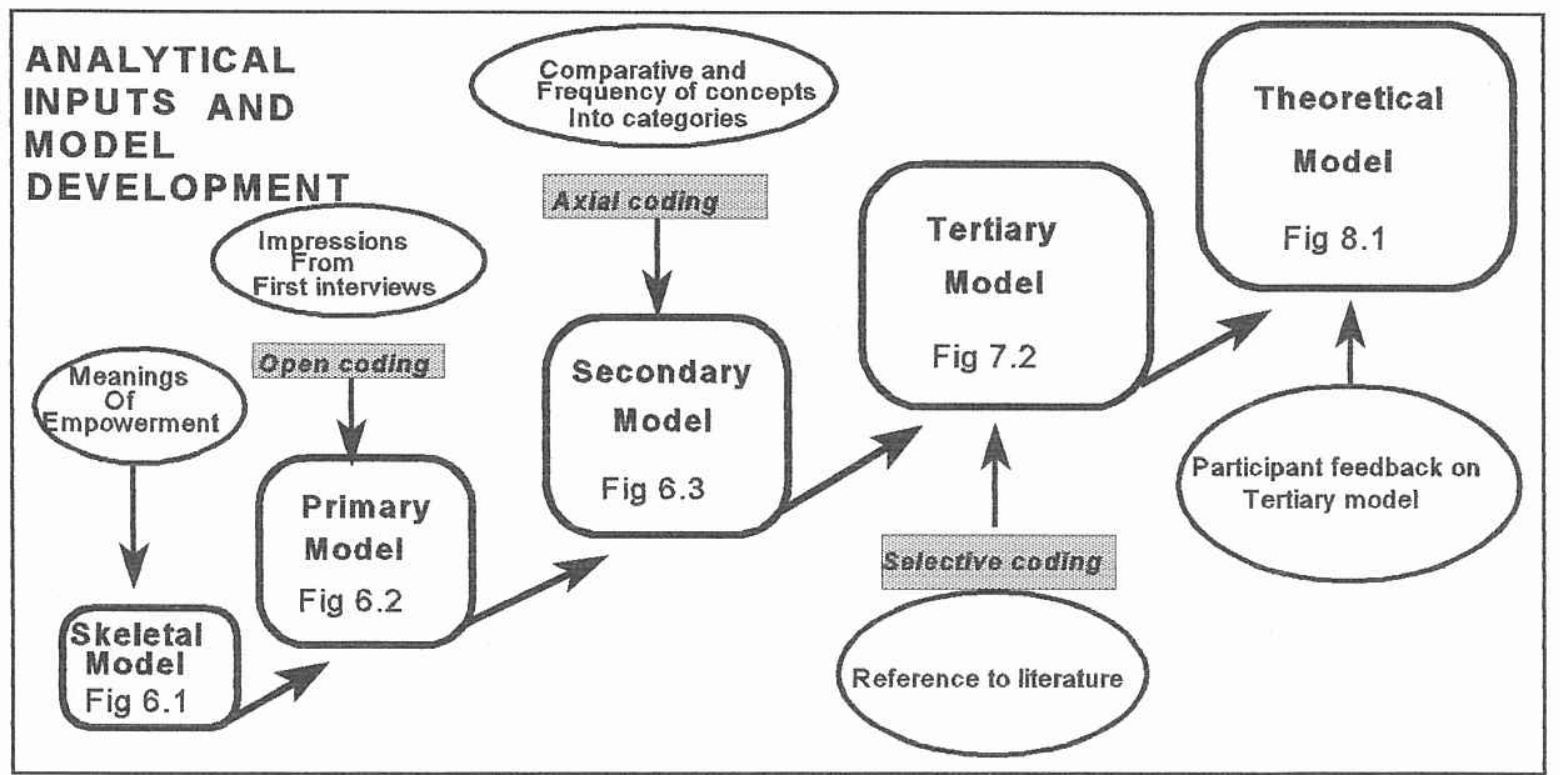




\subsubsection{Audit Trail}

The audit trail (Corbin and Strauss 1990, Lather 1986) in this study included careful documentation of the planning, ethical and procedural stages as well as conceptual development of the study. The aim was to leave an adequate amount of evidence to ensure that the process of theory discovery could be clearly followed.

Documentation included : transcripts of all taped interviews; categories developed from the transcripts; concepts developed from the categories; memos and journalled reflection on the process and development of the theory; diagrams and visual representations of the model during development; and, drafts of work in progress.

\subsubsection{Generalization}

Generalization is considered by Hutchinson (1990) not to be possible in this type of research as the social and interactive nature of the phenomenon under study means that no other study could exactly mirror or replicate this research. Therefore findings cannot be generalised to other settings and populations per se. Generalization in grounded theory however is considered by Corbin and Strauss (1990) to be partly achieved through the process of abstraction that takes place throughout the course of the research. The more abstract the concepts the wider the application of the theory. However grounded theory also specifies the conditions and context of the discovered theory. Therefore the extent to which the theory applies to a broad range of situations depends on the study context and the degree of abstraction of the theory.

A grounded theory is generalizable insofar as it specifies conditions that are linked through action/interaction with definite consequences. The more systematic and widespread the theoretical sampling, the more completely the conditions and variations will be discovered, permitting greater generalizability, precision, and predictive capacity. (Corbin and Strauss 1990 p 14)

As Corbin and Strauss (1990) also stated.

Given the theoretical perspective of the original researcher and following the same general rules for data collection and analysis, plus similar conditions, another investigator should be able to arrive at the same general scheme. The discrepancies that arise should be resolvable through re-examining the data and identifying special conditions operating in each case.( $p$ 15) 
A grounded theory is reproducible in the limited sense that it is verifiable. However because the theory that is developed deals with social psychological phenomena no conditions could exactly match those of a specific study.

Rigour in grounded theory is assured by following the prescribed methods of data collection and analysis. Guba and Lincoln (1994) state that validity in new paradigm research is assured by the use of techniques such as triangulation, reflexivity and member checks. Lather (1986) asserts that triangulation is critical in establishing data trustworthiness and should include multiple data sources, methods and theoretical schemes. Triangulation may include multiple sources of different types of data or multiple data sets of data that describe the phenomena, in this case multiple exemplars. The researcher

must consciously utilize designs that allow counter patterns as well as convergence if data are to be credible ( Lather 1986 p 270)

Lather (1986) also discussed construct validity as involving a self critical attitude towards preconceived ideas and considered that systematized reflexivity is essential on the part of the researcher to reveal how theory has been developed. However because people share common circumstances, and therefore patterns of meaning and behaviour, relevance to other settings may be perceived by those who identify with the patterns and model identified in a particular study. (Hutchinson 1990)

\subsubsection{Replicability}

Replicability is not relevant to this study as the point of theory generation is to offer a new perspective on a given situation that can then be tested by other research methods (Hutchinson 1990).

\subsection{Enquiry in action}

\subsubsection{Negotiating Access}

This research was carried out in the institution in which I, as researcher, was employed. The participants were former students of mine. The phenomenon under study involved explorations of teaching and learning interactions which had the potential to, and did in fact, reveal information about specific lecturers and students not participating in the study.

Prior to the collection of data the planning process involved planning procedural and ethical consideration for other persons affected by the research as well as constantly negotiating access to the participant group. As Bell (1987) stated this planning and careful negotiating is essential for an inside researcher and needs to take place a considerable time before the study is commenced. Bell (1987) warned that care must be taken not to assume rights of 
entry and that because a researcher is an insider and will continue to work with those affected by the study careful thought and consideration needs to be taken to consult, establish guidelines and not to make promises that cannot be fulfilled.

The institution where the study took place had guidelines / procedures to be followed prior to research commencing which included submission and approval of the research proposal by the Nursing Centre of Learning (COL) Manager and the Whitireia Community Polytechnic (WCP) Research Committee. Documentation was submitted to the research committee following COL manager approval in December 1994 and research committee approval was granted in February 1995.

Faculty of Education Ethics committee approval was requested by thesis supervisors at Victoria University of Wellington (VUW) and was granted in May 1995.

Following (WCP) approval discussion took place between myself (April 12 1995) and the Nursing COL Manager to determine which cohort of students to approach as potential participants. Initially I had considered that third year students would have had more experience of teaching/ learning situations that were empowering and may have engaged in more critical reflection about empowerment and it's place in nursing. However difficulties were that the third year group were completing the final Diploma in Nursing programme and their teaching programme was very pressured in terms of available time for students to take part in research. With final examinations taking place in November and the warning from Bell (1987) that

research generally takes longer than you think it will (p 46)

the decision was made to approach second year students who were in 1995 the first cohort in the Bachelor of Nursing programme at WCP.

Following this decision I discussed with all academic staff at a COL meeting in mid April 1995 the intent, processes and procedures that were planned. I considered that it was very important that Lecturers knew the aims and intentions of the research and so did not feel that information about their teaching was being gathered for any other purposes. The assurance of confidentiality was also made to this group and that results and conclusions would be presented to the group following completion of the research project.

Following this meeting I met with the programme manager for the second level (year) of the programme ( June 2 1995) to discuss the teaching schedule for students, discover when 
students were on campus as opposed to in clinical / practical placements (in hospitals and communities) and check which time of the week was most suitable for initial contact between myself and the student group. As students were close to end of semester examinations it was considered timely to delay the contact until a few weeks into the second semester of 1995. Once the week and potential time had been negotiated between myself and the programme manager I approached the lecturer teaching during the selected time period to negotiate a short timeslot (ten minutes) at the beginning or end of the lecture. On July 201995 initial contact was made with students when I attended the last ten minutes of a Nursing Research lecture to present the aims and intentions of my research study to the students and ask for voluntary participation.

Twenty information / consent forms (Appendix 4) were handed out to the group of forty to fifty students at this meeting. Questions about the project were answered and intending participants were requested to return the completed form to the researcher as evidence of their informed consent to participate in the study.

By July 251995 five students had approached me and returned completed consent forms. A sixth student returned a consent form on August 17 1995. The group comprised four female and two male students, one of the group identified as Maori and five identified as Pakeha in ethnic origin.

Extensive consideration was given at this stage as to whether I should approach other students to gain a broader ethnic sample but this idea was dismissed after due consideration of the overall intent and focus of the research. The thinking behind this decision was that the intention of the study was to explore similarities of teaching / learning experiences for a group of nursing students and develop theoretical understandings from that data set. The initial intention of the research did not include exploring experiential differences between ages, gender or ethnic groups. Sandelowski (1994) discussed purposeful sampling in qualitative research as meeting the needs of the research intent. Although it was recognised that contrasting examples would be needed to check the robustness of the theory (Corbin and Strauss 1990) it was considered that these contrasts would come from examples of disempowerment that would be elicited at the interviews with the number of students who volunteered to be participants. Therefore no other students were approached to participate. It was also considered totally appropriate to the planned study that only those who had expressed interest without any coercion from the researcher, take part and, that all of those who had expressed interest were included in the project. 
At this stage numbers were assigned to the students to be used on tapes and any other documentation with the aim of maintaining maximum confidentiality. Students were then contacted and appointments made for an initial individual interview.

\subsubsection{Participants}

The participants in this study were six, second year nursing students who were enrolled in the three year Nursing Degree programme at Whitireia Community Polytechnic. Four females and two males formed the group, who volunteered to take part in the research process. There were two participants aged 20 to 25 years, two aged 25 to 30 years, one aged 30 to 35 years and one over 35 years of age.

As stated one of the group identified as Maori and the other five identified their ethnicity as Pakeha or New Zealanders of European descent.

The highest school qualification held by one member of the group was a pass in three seventh form subjects. Two participants had attained sixth form certificate level in some subjects, one had achieved a pass in two school certificate subjects and the other two participants had left school during the fifth form year prior to sitting the school certificate examination.

Four of the group had been in full time paid employment, and one in part-time employment for a number of years prior to course entry. Employment positions for members of the participant group included, nurse aide, bank clerk / teller, cook, builder and painter. Some of these positions included either on the job training or seminar / workshop day long staff development occasions. Other tertiary courses in secretarial skills ( two participants), computer skills, child care, food hygiene and social science university papers (one participant) had been undertaken by members of the group. One participant had been involved in full time child care since leaving school. Three of the participants had completed a four week Introduction to Learning course (taught by myself) and one, a full year 'bridging' course at Whitireia, as a prerequisite to entry into the Nursing Programme.

At the end of the data gathering process participants were asked why they had agreed to participate in the research. Their responses were

- Because I thought you were a really good tutor and that you were looking to further yourself and I thought I might be able to contribute to that. 
- Because you were a really helpful tutor in year one so I thought I could help you in return.

- Because I think that, you're talking about empowerment in education and that's how I got around to hearing about it and, I still remember my secondary school days and the very patronising way that the teachers tried to teach you. It was very much a conformative way that they thought they could educate the whole student body and it didn't work that way. It was only when individual teachers approached individual students that you got the results and that's why, I kept thinking of things like that. I also thought I've had so many bad experiences with teachers I might as well tell you all about them.

- Because I value what you're doing and I think if I ever want to do something like this I would like you to help me - and secondly two peers gave me a hard time to make me participate

- Because I found you have been a really supportive and encouraging tutor in the first course I had at this Polytechnic and I know a lot of other students who really respect you as a tutor and I'm really only too happy to help. But I also wanted to give some of what we've received from the Polytech, and the tutors back. I think its important- to identify needs and trends and you wont get anywhere if you don't .

- Because I think you are a really great tutor.... You had a need so we filled it

\subsubsection{Ethics}

\subsubsection{Approval}

As previously stated ethical approval was gained from the Whitireia Community Polytechnic Research Committee on 15 February 1995, and from Victoria University of Wellington Human Ethics Committee in April 1995.

\subsubsection{Participant Considerations}

Considerations made and taken into account by myself as researcher throughout the study were that :

- The respect and rights of the participants were paramount in the study. Care was taken not to co-erce students to participate and recognition was given to the potential power relationship of myself over the students. 
- I was aware that students of different ethnic and cultural origins to myself were participants in this study. An environment of cultural safety was considered essential to ensure validity. Therefore every attempt was made to set up interview environments that were appropriate and safe for each person, to treat information elicited in a manner that valued the person, and to check meaning of data that may have been open to misinterpretation by my personal world view. Every attempt was also made to follow up situations revealed by students that may have had ongoing effects on their sense of wellbeing (for example, racism).

- I retained a high level of awareness of the workloads of second year nursing students and endeavoured to plan and make allowances for their study commitments, when requiring time with the participants. Interview times were negotiated between myself and individuals and dates made when students were on campus rather than during 'clinical weeks' when students were based in different nursing environments between Waikanae and the Hutt Valley.

- A comprehensive explanation of the aims, objectives, data collection methods and intended use of outcomes was given in verbal and written form at an initial meeting of potential participants and this was reiterated at the final group interview in March 1996. Participants were asked to sign a consent form at the initial meeting and were informed that withdrawal from the study was acceptable at any time. Further consent was also requested specifically for publication of transcript data following explanations of potential consequences ( ie. possible identification) at the final group meeting.

- Confidentiality was maintained by the coding of all audio tapes and transcripts. Identification records were kept separately and all data and information were be kept in a locked filing cabinet in a locked room.

- I also undertook to retain confidential information given at interviews to myself and not divulge / discuss or identify participants with any other lecturers. I also undertook at the outset to endeavour to ensure that no person would be identifiable from quotes or results published in any form. However given the small participant group and likelihood of identification from circumstances described by the participants further informed consent was sought prior to publication. The use of pseudonyms, chosen by participants, also served to maintain anonymity, and include participants in the process. 
- Participants were given transcripts of their interviews to check for content and meaning, and will have access to a copy of the final written document.

- Participants were kept informed of the research progress by ongoing individual memos from the researcher and the calling of a group meeting following data analysis. The aim of which were to inform participants, ensure validity of findings and allow the opportunity for participants to act as an advisory group to guide and assist the research process.

\subsubsection{Interviews}

Initial Interviews took place between August 16 and October 12 1995. Audiotapes were used to record the interviews and tapes were transcribed by a typist outside the institution, following participant agreement. It had been planned that the researcher would transcribe the tapes but lack of time for this task meant that this was not possible.

Planning and discussion with colleagues preceded the initial interviews. As cited previously Bowers (1988) considered it crucial in grounded theory studies that a researcher not provide participants with a definition but rather needed to invite them to explain or describe the phenomena. With this in mind it was planned to ask for a definition of empowerment from participants prior to asking them for descriptions of moments when they had felt empowered in teaching learning situations. Because of the nature of the enquiry, and the potential for a power imbalance being set up if I as researcher / lecturer asked questions that may imply there was a correct answer expected careful consideration was given as to how interviews were to be conducted. The concern was that participants should not feel 'put on the spot' as it was considered that this may cause anxiety which could lead to an interview that was more like an interrogation rather than open and truthful sharing of information.

The solution to the dilemma was formulated following a pilot exercise (Hitchcock and Hughes 1989) and studying the methodology used by Benner (1984). The pilot exercise involved the posing of open ended questions (Appendix 5) to a student from a different discipline and a follow up discussion of how this felt and how the questioning could have been made more comfortable and likely to elicit a maximum amount of information. It was determined that the interview schedule would be given to the participants prior to the initial interview. The intent was that students could then reflect on their experiences and think about a definition of empowerment prior to being asked the questions. Consideration was also given to the context and setting up of the interviews.

Interviews have been defined by Anderson (1990) as 
a specialised form of communication between people for a specific purpose associated with some agreed subject matter. ( $p$ 222)

Anderson (1990) further described an elite interview as being one that is directed to a participant who has particular experience or knowledge about the subject being discussed. Interviews are considered to be appropriate for building understanding and can teach the interviewer about events and personal perspectives (Anderson 1990).

The type of interview chosen in this study could be defined as a semi-structured interview (Hitchcock and Hughes 1989), in that it was planned to provide the opportunity to probe and expand on the responses given by the participants. The aim was, to gather rich data for analysis by eliciting as many examples of empowering interactions as possible.

The individual interview process was used in this research as a means of encouraging students to reflect and think about their learning experiences and the meaning of the concept I term empowerment for them in an educational (teaching/learning) context. I therefore asked students to provide exemplars or specific descriptions of interactions or events which had affected them and their learning in a significant manner (Benner 1984). The use of exemplars by Benner in her cardinal work From Novice to Expert (Benner 1984) was considered as being appropriate for the current study because, as previously stated, it was a means of providing rich descriptions of nursing practice and maintained the context of the practice therefore providing a holistic, rather than elemental description. In Benner's (1984) study, nurses were interviewed and asked to describe patient care episodes in narrative form with as much detail as possible, including their intentions and interpretations of the events, and the chronology of the action and outcomes. Benner (1984) provided a written outline of the kinds of clinical description of interest to prior to the interview.

The use of exemplars in this research project is methodologically at a variance to Benner's study as Benner's (1994) work did not intend to come up with a theory but rather set out to identify meanings and content of nursing interactions with clients, using 'Heideggarian Phenomenology' as methodology.

In the current study I considered that the use of this familiar ( to students of nursing) data collection process would provide rich sources of data for analysis and encourage rich description of the milieu (Boud and Walker 1990 ) or thick description (Denzin 1978). Exemplars are based on reflection of events involving interactions. Participants had previously been encouraged to use this process to journal, discuss and learn from clinical experiences ( Street 1990, Reed and Procter 1993). 
The initial Interviews were conducted in a quiet, small, empty classroom with researcher and participant seating pre-arranged face to face, a comfortable distance apart that did not invade personal space. The audiotape was situated on a desk to the side, between the researcher and participant. The aim of the detail to seating and microphone placement was to allow myself as interviewer / researcher to see and respond to verbal responses and body language unimpeded while ensuring that the tape recorder was not intrusive but was visible so I could ensure that it continued to record. Anderson (1990) considered that in educational research previous contact and common background can lead to trust on the part of the participant and therefore to effective communication. It was hoped that this would be the case in this situation. During interviews clarity checks were made constantly to ensure questions were understood. The active listening strategies that I employed involved relaxed posture, eye contact, respectful verbal response and affirmation that the information given was what was wanted for the research purpose. Openness and empathy were expressed by paraphrasing what was said to acknowledge the participant intention with the aim of increasing validity ( Banister et al 1994).

No notes were taken at the time of interview, as I considered that writing while interviewing would have been intrusive and detrimental to the flow and exchange of ideas and concentration of the participant and myself.

Each interview was followed by a period of reflection on the content and process and my thoughts were briefly recorded (journalled or memoed) following each interview. These notes were needed on one occasion when a tape malfunction affected the conclusion of one recording and notes were used to remind me of some issues discussed by the participant, prior to checking back with the person concerned. Reflections were also used to record ideas about future interviews and the ongoing development of concepts and categories and theoretical models.

Transcription of the tapes, initial analysis and review of literature were concurrent at this stage of the research process and were followed closely by the second interviews. Initially it was intended that a group meeting be held to discuss the finding from the first interviews but due to lack of time on the part of myself and the end of the academic year fast approaching for student participants a group meeting was not held at this stage. Transcripts of the initial interviews were returned to the students and a second interview was held to get feedback on the transcripts and to ask further questions ( Appendix 6) that were prompted by the initial analysis of the first interview data. 
Questions for the second interview were not presented prior to the interview as it was considered that participants were now familiar enough with the topic and expectations of the interview situation not to require this assistance. The focus of the second interview was on eliciting further exemplars of empowering interactions and investigating, thoughts and ideas that may have arisen from the transcripts. The aim of the second interview was also to get contrasting material, if it had not surfaced during the first interview. The first interview was directed at the positive notion of empowerment. At this interview some of the participant group described times of disempowerment and described empowerment as an opposite phenomena. Some participants stated that they were better able to describe empowerment because of the disempowerment they had encountered. Therefore those that had not given exemplars of disempowering experiences were specifically asked about this phenomenon at the second interview. Other questions included enquiry as to why students had volunteered to participate and what they thought about the notion that the drive to be empowered comes from self determination that arises because a person has previously been disempowered. (Freire 1972)

Four of the second interviews were held in the same environment as the first interviews with the other two being held in an office situation where interruptions (telephone and knocking on the door) meant that there was some discontinuity of discussion, flow and follow up of information.

Second interview audiotapes were transcribed by the same typist as the first and transcripts were returned to the students for comment at the beginning of the 1996 academic year. Ongoing memos to students and informal contact was maintained by the researcher during periods when there were no meetings and in February 1996 formal contact was made to arrange a group meeting to present the developed theory. This meeting was held at the end of March 1996, when the theory and theoretical model were presented, explained and questions answered. Following this discussion initial responses to the presentation were elicited and further written responses requested after participants had time to reflect upon the information in the context of their personal experience. Participants were also asked to provide pseudonyms as the use of assigned numbers was considered to be too objectifying for this study and the choosing of pseudonyms too personal to be decided by other than individual participants.

Further consent to publish raw research data (interview transcripts) was requested and discussions to alert participants about the possibility of identification were initiated to ensure any consent given was based on awareness of the consequences of the action. 


\subsection{Conclusion}

In this section I have outlined the methodology, used, including philosophical, ethical and validity considerations, methods of data collection and analysis, and the planned process of enquiry. The following section will present exemplars and relevant interview data elicited during first and second individual interviews with participants. 


\section{The experience of being a student nurse}

In this section information elicited from participants during interviews will be presented. The information will be presented as raw data, that is, the narrative of the participants will be presented.

The interviews were semi-structured, therefore answers to the questions posed in the interview schedules (Appendix 5 and 6) were given in various ways. Some participants engaged in free narrative and others were prompted by further researcher questions. Consideration was given to presenting these narratives in bibliographic form. However the researcher was concerned that this would allow for identification of the participants by others. Therefore, in order to maximize confidentiality the decision was made to present the information in grouped sections that form responses to the general questions posed.

Pseudonyms, chosen by individual participants, are used throughout.

\subsection{Background}

As discussed previously, participants in this study were in the second year of the three year Bachelor of Nursing programme. When interviewed participants had completed a first semester nursing practice paper - either paper 211 - Nursing Practice - Child Bearing Families and Children, or paper 212- Nursing Practice - Adolescents and Young Adults. The aims and rationale for these papers are:

Using a holistic perspective these papers aim to increase the students knowledge and understanding of health status and developmental transitions related to (the specific group) and common disruptions to whaiora during this time. These papers aim to assist the student to integrate nursing theory and practice by providing relevant care in a variety of nursing contexts. The papers also aim to promote an approach to learning that is self directed, and to inspire the student with a desire for lifelong learning. (Whitireia Community Polytechnic 1993)

The teaching/learning programme in each of these papers included a two or three week block of time at Polytechnic, during which theory of care, specific related knowledge and procedural skills were taught. These weeks were followed by two or three week blocks of 'clinical' practice in relevant settings. For example, hospital or community health care facilities, or with a child bearing family. Other knowledge relevant to the preparation of the student experience were the papers taught as pre-requisites in level one of the programme and level two co- 
requisite papers. These papers were papers 101, 102, 103,104, 105, 107, 111, 112, 113, $115,117.201,202,204,207,213,215$. (see Appendix 7 for a brief description of individual papers)

\subsection{Presentation of Data}

As discussed in the previous methodological section, each participant was given a copy of the relevant interview schedule prior to the first and second individual interviews. (Appendix 5 and 6). Participants were asked about their previous experience as a learner, how they perceived their learning ability on course entry and how they perceived their learning ability at the time of interview. Participants were then asked to give a definition of empowerment and to give an exemplar or exemplars of empowering teaching/learning interactions that had occurred for them.

On interview all participants arrived prepared and ready to share information with the researcher.

In the following sections participants narrative will be presented in italic font and linking lexplanatory words and questions will be presented in lower case font.

\subsection{Learning Background and Ability}

Robin had left school after a second fifth form year, having gained school certificate in two subjects. He had completed a computer course prior to entry into the nursing programme and had enrolled in the four week Introduction to Learning course immediately before entry to the bachelor programme. Robin's working history had included cooking, spray painting, metal construction, house painting, and tree planting. The realisation that a qualification was needed to gain entry into the skilled workforce had prompted his nursing enrollment. Robin's description of self as learner on course entry was as being 'apprehensive about learning ability but confident in self'. Robin stated that his abilities now included 'learning and retaining information and knowledge, thinking and analysing situations ' and being able to use 'global thinking and communicating skills'.

Elisapeta had left school following the completion of three seventh form subjects and had completed a six month secretarial course prior to becoming a parent involved in full time child care. On course entry feelings about learning ability were 'low' and Elisapeta did not think she had the ability to succeed for the first few months. Anxiety about learning ability was stated as a factor that adversely affected that same ability 'especially in maths and science' 
learning. Elisapeta had felt 'confident about English and writing skills' on programme entry and now felt 'quite good' about her ability. Stating that her thinking was now 'quicker', and that she was 'more relaxed, able to understand the work and able to focus'. Elisapeta also stated that feelings and perceptions of her ability had been 'reinforced by getting good marks'.

Robyn had left school after spending two years in the fifth form to gain school certificate and one year in the sixth form to gain passes in four subjects. Following school a food hygiene and a CPR certificate had been gained, and a one year nanny (child care) course and a defensive driving course had been completed. Robyn had then commenced two Massey University, extramural papers in English and Human Development, but had not completed, deciding that enrollment in the Bachelor of Nursing programme was more desirable. On course entry, having been a successful tertiary student Robyn felt 'good' about learning ability as 'prior courses had raised it (learning ability) from school leaving stage'. Robyn currently stated she still felt 'good' and was really enjoying clinical placements and described her learning ability as being able to be 'self directed, questioning, understanding and able to make links'. Comment was made that the 'overt curriculum and the teaching methods (encountered at Whitireia) had helped '.

Meredith had left school without qualifications in the fifth form year. She had disliked school and worried that success was not possible so 'didn't try'. Since leaving school Meredith had worked in various unskilled, part time employments, mainly, active, outdoor work, whilst also being engaged with the care of children. Meredith had come to the programme via a full year bridging course at Whitireia Polytechnic which included fifth and sixth form level study. On course entry Meredith was 'not confident' and still felt a degree of 'fear of failure' and was also unsure if Nursing was the right direction for her to take. On interview Meredith stated she was 'less confident, not understanding the jargon, and still feeling a degree of fear of failure similar to the fifth form experience'.

Post Script :- Meredith completed the academic year and level two papers then withdrew from the Bachelor of Nursing programme, but continued to participate in the research study.

Liam had gained school certificate and University Entrance before commencing a mainly 'clerical job in banking for eight years'. This employment had provided staff development courses that were enjoyed by the participant because they were light hearted, good learning 
experiences'. Other courses completed prior to entry to the Bachelor programme were First Aid; Outdoors Education and the four week Introduction to learning course at Whititreia. On course entry Liam felt 'confident of being an average student'. Following 'some failures in year one' Liam stated that 'now I've improved, I'm able to retain more, have learnt exam technique and assignment writing format etc'. Liam was 'enjoying the application of information learnt in the classroom and being self directed".

Glenis 'Didn't sit school certificate and didn't pay much attention at school'. Following school Glenis became a 'bank teller', and engaged in staff development workshops run by the employer. Other occupation had involved child care and nurse aiding, and a six month secretarial course that had been completed prior to enrollment in the Introduction to Learning course at Whitireia. On enquiry about her ability on course entry Glenis stated '/ had very little self esteem I suppose when I first started. I didn't think I could achieve... I was even amazed that they accepted me. I didn't even think I could do any of it." Currently Glenis stated that her feelings were that.. 'I can do anything. It just blows my mind to think that I've actually got this far and that I'm getting the marks that I'm getting. I love it (the learning) actually'. Glenis further stated that her abilities and skills included 'remembering, learning, making links, reading, understanding, as well as being able to write and sit exams'. Mention was also made by Glenis about the enjoyment of the 'style of teaching' at Whitireia.

\subsection{The Meaning of Empowerment}

The following definitions of Empowerment were offered by participants

Glenis stated' To me it means knowing that you can do it or being shown the ways to do it so that you know how to do it. And by watching people around you, watching how the tutors (do things) and thinking, I'd really like to be like that. But knowing that you're not going to be like them, but that you can, in yourself, do it. I think just... being able to stand up and say that you can do it. You can do it, and knowing that even if you're having trouble you can go to someone and say... Well I don't understand would you be able to help me through it and do it with you. To me it's more like just standing up and saying I know I can do that, and I think we've been shown that in the last two years. You're not made to feel stupid for asking any questions several times over or going and saying well I don't understand something because nobody makes you feel stupid, like nothing's too small or too big to ask. And all of it has to do with your own attitude. Because I sort of think, well ... the tutors have really been there for you.. really there to help you. But if you've got that attitude of, well they don't really care anyway, then I don't think that you're going to be able to do anything. In my opinion... well for me personally, I think that you tutors actually gave me that belief in myself 
more than me going home and getting it, it was sort of like ... yeah, I was sort of made to feel that I could do it and then, achieving things actually showed me that I could do it. I'd been doubting myself. Like I mean, like last year I can't really think of anything in particular but it was like you tutors were saying you can do it but I was thinking, no I can't do it you know, and, then, doing it and passing it and thinking well... they were right ! I think a lot of it comes from what you give, what you tutors give to the students really.

Liam stated : It means the giving over of power from someone who holds it to someone that doesn't hold it or perhaps isn't aware that they have power. Its giving someone else the ability to make their own choices and decisions. And that can be two ways. You can either be the recipient of it or you can be the one who's facilitating. That is the other possibility and in nursing it's obviously a big issue because the patients do have rights. I know when I've been a patient I've been aware of what my rights are. You know, I could say 'no' to this or 'no' to that but, you know the doctors know what they're doing so you just trust them and I guess that's the common belief. I mean doctor's do know what they're doing. I've got no doubt of that in my mind but you've still got the right to say l'd like to try something else or do something different or get more information. Making sure the patient's aware of that and they can utilise that to the fullest is really important for their own health and for the nursing professional. To make sure they're accountable in some way. People need to know they can say how they'd like this or that done or I'd prefer not to have that done. Just makes life a lot easier on you, the process is a smoother ride and each party's aware of what can be done. You know being there for the sake of the patient rather than for the sake of the medical goals and desires. It's more patient focused and centered. You know it's got to be, it's surely what the whole process is meant to be about. That's one way to make sure that its the way it does work rather than an ideal that's not adhered to. But working towards that's obviously going to take a while to achieve. To make a huge shift like that too quickly will be disastrous. But slowly training up people like nurses and other staff as well, to just get that and be aware of, and to utilise the concept of empowering in practice.

Meredith stated. To me the ability to seek knowledge and facts and come to a constructive decision on an issue. To be able to speak up. To be able to speak out confidently on an issue or to speak up for somebody to know the facts

In the context of teaching and learning it means 
To feel comfortable in saying what you feel and think. Points of view put across and whatever is right at that time for that situation.

Robyn stated Empowerment... I think its giving somebody the confidence to be themselves and whether that is, in what ever role that takes, whether it's a patient a student or a teacher. You know, because students can disempower a tutor.

Well I think if you all went into a class and you were totally rude and disrespectful to that tutor, that tutor would think... 'What am I doing here and I should just leave'. 'They don't respect me. They don't care'. Whereas if you went into a class and you were there and you were quiet you're empowering that tutor to think you've got something to offer and they're (students) here to listen to me. The same way as if you go into a client and you say to them... Right you've got to do this, this and this, you know what you've got to do, yes, don't you and you're very quick and you hasten them to think... 'I obviously don't know what I'm doing here I'll just let them go'. Whereas if you sat down and you talked to them and you said... 'Right you've signed a consent form, or you haven't signed a consent form. Do you want me to go through anything? Are there any questions that may pertain to the operation, that you'd like to ask me?' You're going to empower them to think. 'I'm here for me, I've made the decision to be here', and its kind of empowering them into making them be themselves. So they still make decisions and they kind of feel respected and feel confident.

In the context of teaching and learning it means

Like with a tutor you'd ask them questions that were relevant to them. You wouldn't ask them about their personal life because, you know, empowering them as a tutor, that's the role you play with them and the same with a client. If you have a client that is a nurse you wouldn't treat them as though they were a really silly person. You'd use technical jargon, you might even bring in their report from theatre if that was appropriate.

You know, I would say if you're honest with a person they're going to be honest with you so you feel more obliged to empower them. You're not going to belittle them and I think it's also sharing in respect of your roles. So I think to empower is not that you'd see yourself as an equal but you'd see your role as respecting of each other.

Elisapeta stated that empowerment meant to. Keep control. Keep control, over myself and what I want to do. Self determination I suppose.

In the context of teaching and learning it means 
It's up to me to control what I want to learn, how I'm going to go about learning it. Like if I don't want to listen that's my empowerment, my own self. I don't want to listen. I look at the clock, then I'm not going to learn. So I control things around me so as to better myself in the learning experiences. My conscience plays a part in that... keeps me on track.

Robin stated that. Knowledge is power if you use it right. Not that I'm after power rather than knowledge. Just which will bring me to empowerment. I really do feel that the more you know about a subject the better you're able to communicate the information that you've got to give to your client.

I'll use a nursing situation... and thus give them an informed decision and empower them to make their own decision through the information given. The better you know your subject the better you're going to be able to do that. That's basically what empowering is to me. It's, educating people, giving people the information and sifting through it so that they're getting what they need, and then allowing them to make the choice that they need to make.

In the context of teaching and learning

I see that it works that tutors here have very good knowledge of their subjects and in handing it down to the students or handing it on to the students it empowers the students themselves. Makes them feel a little bit more safe and confident in their knowledge which has been empowered to them from the tutors.

\subsection{Exemplars}

Exemplars recounted by the participants mainly described experiences from clinical situations. They involved interaction with a nurse or client which the student nurse perceived as having contributed to a feeling of empowerment. In many cases the exemplar was given by the participant and was followed up by the researcher who enquired as to what else had happened and why the participant thought the event had impacted on them in the manner described. These researcher enquires will also be presented following on from exemplars as appropriate, in order that the full context and thoughts of the participant are presented congruently.

The exemplars given have been grouped into two main types. These are empowering interactions, and disempowering interactions. 
In the first interview the researcher focus was on positive examples of the concept of empowerment to gain positive examples from the participants. For the most part exemplars given were those that gave an empowering outcome. Some participants also gave examples of disempowering experiences and determined that they knew about empowerment only because they had prior disempowering experiences. If the concept of disempowerment did not arise at the first interview enquiry was made about this concept at the second interview.

The exemplars that follow describe interactions with Tutors (Lecturers who teach in both formal class and clinical situations), Preceptors ( Registered nurses employed by the clinical agency who work in the area to which the student nurse has been assigned. Preceptors are educated / prepared to take on the role of working with and teaching student nurses), and Buddy Nurses ( Registered nurses who are employed by the clinical agency and work in the area to which the student nurse has been assigned. The buddy nurse has not received special training/preparation for the teaching role.)

\subsubsection{Empowering Interactions}

Glenis recounted ... When I read the question, the only thing that popped up into my mind that's really stuck with me during this whole thing is when I was bathing this man in the shower last year and.......(tutor) was standing next to me and she was going stop the shower. And I was thinking... Why does she want me to stop the shower and I just sort of carried on showering. And it was because he ( the patient) had done this big turd (bowel motion) on the drain and it was actually blocking it up and ....... ( tutor) just sort of walked in, picked it all up, and put it down the toilet, and just carried on. And I sort of thought... Oh wow. And I was sitting here and that's really stuck in my mind and, and, it just blew me away really. The whole thing was like... the way she did it, and because she didn't put you down for not seeing it, and the fact that she just sort of got in there and just did it without making you feel stupid for not seeing it. I think that to me sort of made me feel .... I sort of stood there and I thought, gee I'd really like to be like that one day. I was being assessed at the time for giving this man a shower anyway, so I was really anxious I think I had the nozzle all over the place anyway. I mean this poor man had dripping hair and everything. The rest of his body was sort of like dry and l'd start on his feet and forget about the middle part and it was like......(tutor) just sort of stood there calmly and watched and she'd suggest but she wouldn't suggest in a way that made you think.. I should have done that, I should have known that. It was like, you could do it that way. You know, I like the way that you did this but she sort of gave you a "I like" statement before an "I think you could do something better or do it differently". She never said "better" ... its just her whole way of being I think and she didn't sort of make you feel stupid for missing the fact that this poor man had had a laxative that morning. I can still remember, and it was dreadful. 
Glenis was asked if there was any further interaction and discussion between the tutor and student after the event.

The response was: Well not really because afterwards I'd sort of turned around and took my gumboots off and put my shoes on and had left this man standing and he started to fall and so that sort of took away the moment really.

A further enquiry was then made as to whether Glenis had thought about the incident afterwards.

Well, yes, it was after we'd come back to tech and they (the other students) said "Oh how was your placement" and I said well .........(tutor) is really different on placement than she is in tech, you know, she just sort of gave me a whole new view of herself. I mean to me its just stuck in my mind as one thing in clinical placement where I felt really supported by her and I didn't feel put down. And I didn't go home feeling dreadful about the experience. I went home, and looked at it and instead of putting myself down for what I didn't do I sort of had a chuckle over the fact that I hadn't seen the faeces anyway.

I think we tend, as students, to see tutors as constantly marking. Like you're constantly being marked for three years. You know that everything you do is going to be marked ...how you are in the classroom is going to be marked, and you tend to see tutors as people up there, taking notes of what you do and don't do in class and out there in clinical. Its like you're actually seeing the tutor as a nurse and a peer rather than just as a tutor who is marking. Not equal but a sort of .... well to me its like .........(tutor) is there as a charge nurse. A person who, well she took control of the situation but she did it in such a way that it didn't make me feel like I was losing my power, and she didn't make me. It was just like... you know I think just saw her in a whole new light somehow. Knowing that you can depend on them (tutors). I think its important. I think it just gave me a different look of how a tutor was out on clinical. Because I think in a class you are a tutor but when you are out on clinical I think you actually become quite different. I think, you become more nursing than you do teaching. You're doing both at the same time but it seems so smooth that you sort of don't really notice and you don't feel as though they're (tutors) constantly marking you like you do in a classroom situation. You're working In partnership. Yes. I think that's really empowerment to me.

Glenis then went on to discuss the concept of empowerment and how it occurred.

I just think the whole way of Whitireia... how its set out, especially in year one. I think year one gives you more the way of knowing how to deal with things than when you get to year two where everything is so rushed its like you don't have time to worry about whether you're 
participating or not because its got to be done and that's all there is (to it). I think year one really showed me that I could do it and that I didn't feel that I was being put down.

Glenis gave a further example of an empowering episode when, as explained, a tutor was supported by Glenis's action.

Its not really a teaching, learning experience but it was quite huge for me. It was when we were in a meeting in the council room having NZQA years ago (a visit that was part of the authorisation process for to the department to teach the Bachelor of nursing programme. The NZQA panel met and talked to students about the programme and teaching of the Diploma in Nursing programme). I can remember sitting over in the council chambers and being in a rescuing situation I suppose. Because they (other students) were all sort of picking on.......and ......(tutors) and I really think that ......(tutor) puts herself out for people and I sort of got...., I sort of stood up in front of all these people and defended her, and I thought... Well that was really empowering. For me.... its not like me to be in front of groups of people that I don't even know and say things. But it was the fact that I stood up and did it and I thought... Oh, well ,yes, I did feel empowerment to do that. And it was the rescuing in me coming out, but I walked out and thought... On I felt quite good about doing that .

Glenis was then asked if it was possible to identify what had made this episode empowering or what had moved Glenis to act in that way. The response was:

Well, I think I felt really angry that people (other students) were just picking on tutors. I mean, the whole idea, well to me (the one sided view that I have) is that if you want something you've got to go out and work for it and you can't just expect the tutors to just give it to you on a plate and although...... (name of paper) is a hard paper I really do think that you can't expect them to just give it to you. You've got to really work for it. I really think......(tutor) puts herself out for a lot of people and so I suppose, I just got really angry I think. More than anything I just got really fed up with the negativity of it. I thought, get on with it. You know.

When Glenis was asked to think about factors that have helped her empowerment the response was .....

Being here, just the fact that the tutors don't make you feel stupid. I mean you can come up with a comment and people don't put you down for it. The tutors in particular, and the fact that the group of people that I'm close to here, I suppose, don't make you feel stupid for what you say. They accept you for who you are and what you've done. And the fact you can go home at night time and acknowledge the mistakes you've made without feeling really bad about 
them and if you've got something that ...If you've, just done something, you can go home at night time and think... Ok, well, I did stuff up but that's ok because nobody will put me down for it, and you don't go home and beat yourself up over it. If you had just been put down you'd sort of think to yourself... well.. people! I think it's, you just learn it, I don't know, you just, at the end of the day you go home and think... Well that's ok you know. I can screw up and still look myself in the mirror.

Liam described the following empowering experience on interview

The situation I've been in was in Ward.... in ......(hospital name) and I was quite keen to learn from one of the preceptors I was with. And she admitted a young child with gastroenteritis. She said "Well you'd be able to look after this patient" She took the protocol book and said "Read this and get the information you need". I wrote a list of things I needed to do. So I knew what I had to do. She went in and introduced me to the patient and his Mum, said, "This is Liam who will be looking after the child. I thought that in that situation I was given a responsibility to pass on to the mother and child. Mostly the mother, as the child would be about two years old and wasn't going to understand a lot of the things that were happening. And say (to the mother) this is what's happening, this is what you can do and just let her know what she was able to do. That was quite exciting to be given that level of responsibility. It built up my confidence. It also made me see that I didn't go in there as being a know it all. I did have knowledge but I didn't know it all and I shared what I did know with the mother. Answered a few questions and if I didn't know, I sought the answer. I then got to her and gave the answer that she did need. And that was quite exciting. I was given the opportunity to be in a position of trust from both the mother who trusted me with her child and the nurse regarding the patient. But it also involved me, you know, trying to give the Mum help.

The nurse had said if I had any problems come and see me and it was really quite some relief to know that. Well I would have gone back anyway even if she hadn't said that because that's my point of contact. But she was really, really keen to help me take a position that was rightfully hers. You know, so that was giving over the power there. To care for the child in some ways it was really quite a challenge getting through to the end and the nurse she was always only too keen to pass on knowledge and leave it to me to do it. It was the first experience of this sort that I had had. I was there just three days.

That ( the first day) was the beginning of a routine for me and it was a very short routine each day. It still gave me the opportunity of not to take it as being in a position of power but being in a position of an assistant. I was there to assist the young child to an improvement of health 
by following the protocol and just doing basic obs (Measuring and recording of Temperature, Pulse, Respiration and Fluid balance). So I was just trying to reassure the mother, taking her concerns as real, validating her feelings. So in some way that's what empowering is. But its, its really good to be involved in more than just objective things. It was quite a range of things. Everybody said its going into more than just physical to nurse. Its about holistic care. So it was taking in a few more areas of the nursing caring situation and realising other skills. So in many ways it involved quite a few different experiences all in one which was really valuable.

When enquiry was made about the interaction and relationship Liam had with the nurse. The response was:...

I just thought of her as being a professional and myself as being the student. Which is accurate. That's where it is. But she treated me with a lot of respect and saw me as being capable and confident and she expected a certain level of competence and, and after the first day with her she obviously thought I had enough competence to take over a case or a patient. She just quietly encouraged me to do things. Gave me what I needed (for example) protocol accounts, (said) "Here's what to do, read it and understand what to do and then just follow a sort of routine". So she gave me everything I needed and it wasn't a buddy friendship relationship. It was still like we were working together but she was still the one I was accountable to. You know... she was so busy doing her own work so I'd see her in the morning. We'd talk about things and I'd say what I was going to do and share what I had planned for the day. And she would say... "Yep that's fine". If I had any queries I'd go and ask her. So it was more a professional working relationship rather than strict student Ipreceptor. I found it was more relaxed but it wasn't too relaxed. It was quite comfortable. There was still room for me to, just step back. And that was the idea. She's the registered nurse and she'd done more training and had more experience and I relied on that. But she was only too willing to pass it on. And that helped me grow in my knowledge and grow in my skills and confidence. So that brings me up a little notch. Which is good. She had a bit more experience. She could work with me and encourage me and give me more of her knowledge and skill to bring me up to a level that she had and I could also encourage her to move on to other areas and be able to put it all together in every field. Quite a symbiotic relationship. Like, I'd go up to her and say.... This is the situation, can I do this.. or this. She'd evaluate what was going on and say.. "Well you can't do this one, but this one"........she'd suggest one. I'd go up and say.. This is the situation, and she'd come along and do something and say "that's it", if it was. She'd listen, evaluate it and then give me the benefit of her experience and knowledge. Which is above mine, and suggest what was the more appropriate way. And she would remark that that was ok and l'd go ahead and do what needed doing. Yes, it was very interactive, very. I really enjoyed that placement. 
Meredith also described an empowering experience during interview.

In some hospital placements and.........(name) Medical Centre where I was, I had some really good placements because it was the staff there, the nurses there. If I felt that I wasn't getting enough experience or anything I could approach them and tell them that I was always open to do anything and everything whenever they saw fit ..from filing right through to giving needles and drugs and whatever. I thought that was really good and if anything did go wrong I would speak to the nurse first and get their thoughts and ideas on whatever it was and then see the tutor. If I thought something wasn't right or wrong. If I wasn't getting enough of what ever. But I would never go, l'd never go to the tutor first. I found that sometimes, I know they see heaps and heaps of students but sometimes by the end of the day they get tired just like us all but sometimes tunnel vision and they direct that "This is what's got to be done", and I think there are more ways to skin a cat.

Meredith went on to discuss what it was about her individual learning style that enabled learning .

It's just because of me. It's just, its because of what I am and I'll keep skinning the cats any ways I can do it. I'm better being self directed, doing things like that. So when I want answers it's grab your books and find them .

Robyn came to interview prepared to give the following exemplar about an empowering experience.

I've got one example in clinical.. This woman who was my day case, (I'd been given her as my day case) and she came back (from theatre) and her blood pressure was really low. So I tilted the bed down just a little down, towards her head end and everything like that as we'd been told to, and it ( the woman's blood pressure) was going down a little more and I checked the record and she hadn't had morphine or anything and so I told this nurse. So she (the nurse) went and took her ( the patient's) blood pressure with the machine that l'd taken her blood pressure with and it was low. Then she took that blood pressure machine away and she had it in her hand and then... I actually realised later when I took it, I thought it was the same machine, I took it (the sphygmomanometer) from the trolley and went and took her (the patient's) blood pressure again and it was quite high. Well it was back to normal. It was like 100 over 75 (normal) for her and then the nurse came back and she still had the blood pressure machine in her hand and I said "Maybe its the machine then because its normal now". And I said "This is what I got from this machine". Because it looked as though I'd taken 
the wrong blood pressure reading. Like it was too high, it couldn't have been her.. type of thing. And so she (the nurse) took it with the machine l'd used and it was correct. She said "No that's fine", I said "So I took the right one". She goes, "Yep you did, so its obviously the machine" and so she took it (the machine) back.

But it was really good that I had to make decisions for myself and she worked with me. She never patronised me at any time for being a stupid nurse. She assisted me in trying to figure out what the problem was and... and she kind of affirmed me when I got the blood pressure reading right. She even took it again and said "Well they're exactly the same". And that was really good. I found that I had confidence and even when that woman (the patient).... when she woke up, I was able to explain everything to her and the nurse just stood there and she never butted in or anything. I was able to explain to her, what had happened and that her blood pressure was still a bit low but she had slept it all off, and it was really good. So, that made me ... it showed me, it was also a bit empowering for me and it showed me a good way of leading a person. She (the nurse) she never pulled me up because I was never actually wrong. We were just kind of learning together. Because she didn't know what was wrong either. But she was still my teacher. So that was really good. And I remember that. I kept telling all the other student nurses that I got the blood pressure right. Because everyone kept thinking it was my patient and I was losing her. So that was really good. It was like if you aren't understanding to put your hand up and if, if you think the reading on the blood pressure machine is wrong or if you think its too low at least you're not putting yourself in jeopardy and if you're also being affirmed that's quite good. Like the buddy nurse you know when she came on she said... "We'll deal with it." And then she took me along, and we dealt with it.

Enquiry was made about the nurse and whether there was anything in particular, about that nurse that had made it easier for the student to go and ask. The response was.

She was really friendly and I could ask her anything and nothing was a stupid question. She's just a patient person. Its just a really good attribute really. That's why I like some tutors, because they're just quite patient people. You can ask them a question, it may sound silly, but because they're quite patient they just listen to you say it and then they say the answer or they just say "We'll deal with that later if it happens again". You know... they don't go off the deep end and they never patronise you for anything you've said, anything in the past you've ever said and they never bring up. Like sometimes if I say the wrong answer... they'll ask me something and I'll say the wrong answer... and she'd go.. "No that's not right ". But she'd never use that against me in other situations if that came up again. And I think that's really important. Like people start clean every class or every day. It can be the same with some buddy nurses if they never compare me to other students they've worked with. 
Robyn went on to explain ..

I think also in clinicals if you turn up prepared as a student you're going to get treated like a student and they're going to teach you, instead of guide you... Its kind of different. Whereas in the first clinical week you need to be taught. You know. Like protocols and things like that. And if you turn up with the objectives and kind of act like a student - "I'd like to do this, I'd like to learn that" they're going to teach you and show you and explain things. Whereas if they're going to guide you they come and just guide you and its like when they guide you through something rather than doing it and showing you. Like you're standing there away from them and they're showing you how they do it which is like teaching you the correct way and I think that's its very important when you start off to build up that relationship where they are still your teacher.

Robyn also explored how empowerment could occur even when a clinical situation did not go as well as expected. The outcome of the experience in this instance was empowering for Robyn because the person chosen to talk to /gain support from was chosen by Robyn.

Tutors can find it very easy to slip into adult child role. And it can really just put you off. Like you just don't want to be around them. Because it, it brings you down. I was also thinking of tutors that I know would do that if they are the tutors that come and visit me on clinicals. If something has gone wrong I would prefer to actually go to my own buddy nurse than go to them (certain tutors) and let my buddy nurse deal with it with me because I know my buddy nurse is very much a buddy. She's just there as a peer to help you and assist you. She's not there to teach you and that's how it comes across especially the younger ones. They say "Oh follow me around for a day and then I'll give you a couple of your own patients and you can come to me if you've got problems" and that's the way they deal with it.

An example then given by Robyn was..

This man came back from theatre and I was asked to give him his post op wash because my buddy nurse had taken off to do a fire seminar workshop. So they (the nurses) asked if I could go do it and I said "that's fine". I delivered a bowl, some soap and flannels and some towels and I said "I'm just going to give you a wash to make sure that after I wash you there's no extra wound ooze and things like that" and I was trying to explain to him what was going on and then he was fine with that. But he did... because he'd had a hernia operation.. he felt very uncomfortable about me giving him the wash. So I said "Well that's fine, its up to you" and he said that he'd like to do it. So I put it (the bowl) beside his bed and he just gave himself a bit of a wash and then I got called away. I told the person that called me away 
"There's a man giving himself a post op wash in that cubicle" and I told her and she said she wanted me to hand over the notes of my buddy nurse. That's why I was called away. It got all convoluted. So anyway, I took off to hand over these notes and she was aware that if he (the patient) used the buzzer it was him, and to go... running basically. Then what happened was .. about five minutes afterwards, she came in with me to deliver some notes and so I realised... The lights went off in my head that there's this guy giving himself a post op wash and nobody's aware that if his buzzer goes off its a kind of run situation. So I went back and I found out he'd tried to move the thing himself and his Luer (Intravenous line) had come out, and so his blood was everywhere.

I found this out because the charge nurse came and got me and told me. So I apologised for that, and I explained the situation and I kept very much in the subservient role there and I left it like that. When my buddy nurse came back I explained the situation to her. I knew that the tutor that was coming that afternoon. There was no way that she would be... she would put it in a learning experience framework. She would put it into .. "You shouldn't have done that then"... you know. Whereas my buddy nurse would say "Oh, ok". She told me she went in and saw the patient and she said it looked quite funny because he just had like a little cotton ball like thing (over the area) and everything was fine and he thought it was quite funny because he'd never seen blood sort of shoot out of this Luer before. And we were quite glad he was taking it quite calmly but my buddy nurse then took me aside and we had a bit of a chat about it and she said "Yeah that happens, but you've got to know what to do. You should have just told on ....... (the name of the nurse you told) and I said "Yeah but I wouldn't do that, I'm not a person to implicate someone else in my crime". And she just went "Oh, ok". She said "That's the only way you're going to defend yourself" and I said "Ok". And I learnt from that, but I knew that the tutor that was coming on that day isn't like that. And I knew that to keep myself safe.. like emotionally and mentally safe I had to not tell her. But yet my buddy nurse was aware of it. The charge nurse was aware of it, and she also helped to do my summative assessment. So I had no problems that if she was worried about it she would have said something. So / left it.

Enquiry was made by the interviewer "And so what you're saying is, you actually select people you know will empower you rather than disempower you in their manner of interaction?"

Yes.. its, its more like... its as though l'm being empowered as in, what's going to benefit me from this experience. If I don't want to be bought down, and pulled down a couple of rungs, and if I don't want to participate in that, then I just don't do it. Because I know that at the end 
of the day, that experience with that tutor's going to have repercussions. And so I prefer to leave it. And also I still know now to never leave somebody alone post op.

Elisapeta recounted the following experience.

I was at the children's ward and I felt really disempowered for about a week and a half and it was my last night and my buddy nurse was sick and another nurse came in and she said to me "What have you been doing?" and I said, "Not much, I'm not very good at it" - as I had got that impression from the other nurses. And she said. "You are, and you will, and you'll do what I tell you do to, because you can do it." And then I thought.. Oh dear. But she was absolutely wonderful and I walked out that night thinking. I am a nurse, I'm going to be a nurse. Because, that week I had been thinking, Oh no I haven't got it, I can't do it, I'm never going to be a nurse, I'm not a nurse. But she gave me the power to get out there and do it and without being sarcastic or degrading me. She was really good.

Enquiry was made as to what exactly the buddy nurse had done. The response was..

Oh well... She introduced me to this family and said "Here's a student nurse, and a wonderful nurse to be" she sort of picked onto my insecurity, I suppose, and then it was her smile. I just thought... I am going to show the family that I am a student nurse, I am going to do it. I ended up doing this task, that was, draining the haemovac, and I thought .....Well here's me behind the curtain and feeling quite scared and remembering the other buddy nurse saying, 'Oh no no you can't do this", and I turned around and said "He's (the patient) due for an injection isn't he?" and she (the nurse) said "Yes, and you're going to do it, aren't you?" and I said "Yes" and I wasn't nervous or frightened or anything. I could do it. And that night I did more things than in the whole two weeks I had been there.

Further enquiry was made as to whether the nurse had talked things through with the student and how the nurse had determined her ability and confidence level. The response was :-

I told her l'd never done it before. But she said, "If you need me l'm right behind you." So she didn't talk things through because I did it without her having to, but I knew that if I got stuck she was there. I think she knew that I really wanted to learn, that I wanted to do it. I think she also knew about the environment that I had been in. That they (the other nurses) wanted to keep me down. That they weren't going to help me, she knew what was going on. l'd been there two weeks and it was the last night that there was the good buddy. The one I really 
liked. You know.. if it wasn't for her, I might not have been here now. I feel really emotional about it. l'd really started to doubt myself because of what had happened.

Later Elisapeta was asked if there were any further examples she wanted to discuss. The response was .

I was in a Psychiatric ward and most of the staff were quite helpful. They said you can have two clients instead of one, they said I was capable, I felt quite proud.

The participant affirmed the interviewers analysis that it was about nurses noticing what you were able to do, and actually pushing your learning a bit further, adding something, so you learnt a bit more. Enquiry was then made as to what part communication played in this. The response from Elisapeta was

Yes, I think that's the key factor really. Because when I don't feel empowered I sort of feel like I'm down, that people are talking down to me. Like a clinical environment when you don't know anything.

Further affirmation was given to the statement made by the interviewer "So it's about being treated as an equal, a person, part of the team "

Elisapeta: Yeah, yeah

On interview Robin stated that..

There were a couple of instances, and they were involving pain relief. One instance was when a guy had just had an operation and he was in pain. But he refused needles. Panadol didn't work. Voltarin he had to eat with dinner, so he was just confused about it all. He was fourteen and he was dead set against needles but he's in a lot of pain, you know, So with my knowledge of how IM (intra muscular) injections work and the benefits of ( injections for pain relief), I approached the guy and said to him, explained it to him, you know, on a level that he would understand. And then, then his face lit up and he said "Oh, oh ok, I'll have an injection then. Nobody said that to me". Which made me feel good about saying that. And the empowerment was, that I was able to educate this person into making a decision for himself without being authoritarian. Without saying you must take this injection because it will do you good. I explained why. So I guess that's an example. He took the injection and 
allowed me to give it and he was happy. Fifteen minutes later he was without pain. Yeah, so that's good.

Another lady who was against needles as well and wanted a suppository. So she had the suppository and then didn't want another one, you know, for the pain relief. And then I was able also to explain to her the benefits of having an IM injection and purely, that it's a safe procedure. And I allayed her anxieties around that and she also agreed to have IM injections. And that to me was, I felt empowered because I had the knowledge and I don't know if that was empowerment or manipulation. I think it was empowerment, you know, being able to give that knowledge to them and because they were scared of needles and they'd obviously heard something bad or had a bad experience with needles and I just allayed their fears and assured them that it would be alright and there'd be no complications so they... then they had (an injection) Then the ball was in their court really.

When enquiry was made about the student as learner the following exemplar was given by Robin ..

Well there was a case where l'd been to surgery and followed this person through surgery to ICU (intensive Care Unit). I'd watched the whole operation. It started out to be gynae and then turned out it was general. So another team came in and a different operation was performed. This poor lady didn't know anything about a second operation until she got out and then we were in ICU and the family turned up and the ICU nurse just made a bee line for the coffee room. She just didn't want to know about it. So I was left standing there taking obs (measurements of Blood pressure, pulse etc.) and recording them and the family starts asking me questions and I really didn't want to divulge the information that I had, after seeing the operation. Then I thought, well just be honest. So I told them about the procedures and that sort of carry on and it turned out to be the wrong thing to do because it wasn't my job to do that. It was the surgeon's job to do that. The surgeon wasn't there so you know I was on the spot. And on getting back to the ward I explained the situation to the CNS (Clinical Nurse Specialist) and she talked me through it and then made me realise that although I'd done it right it wasn't the correct thing to do. So she talked me through it and said "This is what you should have done". I should have waited until the surgeon herself came up and conferred with her (the patient) or I should have liaised with the ICU nurse and seen what she would have done in that case. I'd already seen what she would have done in that case, the beeline. So I was helped through that situation where I felt, I don't know whether it was powerless... It was! It was really uncomfortable and there was no back up anywhere. 
Enquiry was then made as to how the participant had felt after being talked through the correct procedure.

I felt a lot better because I had definite boundaries to work to, and guidelines, I felt a lot better you know and I now know that in a future similar circumstance, I will be able to react accordingly.

When asked "Was there something about the way that this nurse talked to you that didn't make you feel as if you made a big mistake or anything but actually made it feel like a positive learning experience ?" The response was.

Yes. Well ... I explained the situation and said what I had said and she says, "Oh that's very good, that's excellent, you're acting as a patient advocate you know and you were honest" So she started out by giving me compliments and saying that it was a good thing to do, but not necessarily the right thing to do. Then she went on to say what the right thing would have been to do but there's to be no shine lost, you know.

Enquiry was then made as to the role of this nurse The response was....

She was actually the CNS- clinical nurse specialist (Not the central nervous system)and she was just there. I was actually looking to tell somebody about it because I didn't know whether I'd done right or wrong. So I told the clinical nurse specialist who seemed to me quite accommodating. She was most helpful and she didn't let off alarms about it, you know, and I heard her later on as she was walking off saying to another nurse, "That student's good". And I thought... well good, even though I did wrong, I didn't do bad, you know. Which really helps.

\subsubsection{Disempowering Interactions}

As previously discussed, in some instances participants gave exemplars of disempowering interactions at the first interview. If this did not occur, these exemplars were sought during the second interview.

Liam responded to the enquiry with...

That's seeing another angle isn't it. Disempowering... There was a bad day when I had an assessment done at one of the wards and the comments that came back from that, I thought most of them were accurate but some perhaps went a bit overboard. I had spoken to the 
tutor and talked about one (comment). I felt a bit disempowered from that, I thought.... well the rug had been pulled out from under my feet sort of thing. And, it took away a lot of the confidence I'd built up to that point. I got on and had another placement since that one and had other assessments since then and they've come out a lot more positively and I've had my confidence built back up in the wards. I went to a psych ward and had a bit of responsibility there from one of the staff nurses and that was quite exciting and he (the nurse) took a lot of time to talk to me and encourage me to do things. You know, "So here's a book on the mental health act, read this and get familiar with it". And he had a really relaxed attitude about it, everything was quite... quite laid back in the way he came across. But he's had many many years of experience in the field so he can be quite laid back in his approach because he knew what he was doing. And he was quite encouraging. He would just sit back and quietly, calmly just talk through things and nothing was a big deal or a problem, you know, that's fine, just move on, learn from it if something went wrong. The whole attitude of being relaxed and encouraging and, was pretty ... It was pretty supportive but he was, the guy was all incorporated in the one, you know He just came across really nicely and I remember that he built me up quite well and gave me the chance of getting to have the patient and having to follow it through and just be trusted in that way it was quite a good builder for me again.

When further enquiry was made about the negative feedback the response was..

I thought some parts of it ( the feedback experience ) were hammered, you know, they took one example... one example was taken and produced to colour the whole process. And l've noticed, I've resolved that, and you go on from there. So while at that time it was pretty much disempowering and I had a hard, a really hard time of that for a couple of weeks. I guess two or three weeks... it was really difficult. I've managed to move on from that and get something positive out of it so it wasn't ...I don't think .. a major hiccup. I guess it was a learning curve. A learning opportunity. I didn't see it initially as being that but now it kind of does help give it perspective. Especially when you bounce ideas off other people and talk to other people about it and you get other views that are different from your own and you follow the path again. You get tunnel vision on... on things and that (the experience) helps to widen your perspective. It helped me to widen my perspective. Well the tutor assisted in that as well. The tutor said "Try to look on it as being a positive thing" where I initially thought that it wasn't. As time went on it did become. So it's learning from chewing over my mistakes and my own reflection. So, yeah, there's a lot of things incorporated into making that a learning experience. 
The prompt for the next exemplar was an invitation to the participant to tell the interviewer about a disempowering experience. Meredith stated..

If I go back to last year there were a few times I've been (disempowered). That's because there were a lot of things going on. When you're in the clinicals, being a student you daren't speak out about anything although you know things are wrong. When I was on maternity work a couple of weeks ago there was nothing there to do. It was just a waste, a waste of time. So I spoke to .... (the tutor) about it. She said "that's the way it is". She said "That's just part of it. "And I still felt dissatisfied. So when I spoke to the nurses there (in the maternity unit ) some of the independent midwives said they were happy to take us out if the Polytech would let them know in advance. And when I spoke to the tutor about that she said "Well the midwives don't want you out there and all this and everything else". And when I bought it up to her that no one had ever suggested it to the ones I had spoken to she then approached the midwives. Now the students are going out for their maternity experience. But that took . it took like... two or three days of my clinical experience was taken up with that issue. It was a missed opportunity really, on the maternity ward. So probably because of my speaking out and saying what I said and the tutor actually listened the other students have got a better opportunity now for going out and experiencing bookings and ante natal classes and meeting the mothers. And have now got more opportunity for seeing the birth of the baby....... I suppose the tutor listened so I suppose its part of empowerment. I felt able to speak out.

It didn't work for me. By the time I got it sorted out it was the end of my placement. But it was good to see other students going out with the midwives and it's good to see that I was heard I suppose and something's done about it. But you see I just felt .... I felt it unjust. Being on a clinical where there's nothing constructive ...no learning. So I don't see it as empowerment, you know what I mean. It was just something that needed to be done at the time.

Meredith also discussed another example of when she had experienced disempowerment

Meredith: I was at a local school (in a special learning unit) and, and there was no nursing needs there. These kids were either disabled or very able and went to the bathroom like any kids to wash their hands take prepared lunch and some of them had motor problems in their walking and co-ordination and they were a lot slower than the average child to do things. But they showed enthusiasm and entered the task when you showed them how to do it and encouraged them. And l asked the tutor what the nursing aspect of this was, and every time she tried to tell me I would challenge her and in the end she got really annoyed and said to me that (type of placement) is nursing council requirement and that was it. And I just 
thought... The hell if it's come to that and I can't have a proper answer because l'd gone to a special school for children who were disabled... for a morning with these kids. And to me that was more nursing orientated than being in a local school (with children in a special learning unit) and when I even broached that subject to her (the tutor) and got the reply "That there's not enough clinicals around and you've got to take what you can get." And that's scraping the bottom of the barrel and that's to me.. that's not good enough. Because personally I'm interested in disabled kids that need nursing care and I would fit into any situation where I'm at. Helping someone to bathe and to feed them and give them some sort of quality. So I got pissed off and when I had my assessment done she bought it up and said that I get frustrated when my needs aren't being met. And I thought ... Oh, I just figured it was just a personality clash now because from how I reacted to her. I just felt put down. Because I wasn't being answered... then she said "Oh I get frustrated when my needs aren't being met". She didn't even attempt to give me the answer... ..because it was a nursing council requirement. Because I found that even training teachers don't even go to these places so why the hell should I. When I could be somewhere...

The incident was then explored with the participant, who further stated

I needed a full explanation as to why I was there and when I wasn't given it, and I didn't accept what she said....She just turned upon it, she turned upon me and then I felt that l'd got no power l'd got nowhere else to go.

On interview Robyn volunteered..

I've got a couple of examples I was thinking about when I was reading the transcript. Well one of them was a tutorial when I was in clinical and there was a tutor that was going around and asking everyone to speak about their day. And I was like the second person on. She asked me what had happened on my day and I started telling her about how I went down to theatre and that I had watched a carpal tunnel release and I showed her the palm of the hand where this was operated on. And she shook her head and said "that's not where its done so it mustn't have been a carpal tunnel release," And I sort of thought.... hold on here, I'm telling the story, and I kind of felt at that moment that I really did want to turn around and say to her. Don't invite me to speak and then interrupt me. Because I would not expect that of anyone. And, and I didn't. I just left it. And she did that to everybody else as well so I didn't feel so bad because I obviously was in the same position and that was obviously like a personality thing on her behalf. She was a bubbly person and it doesn't go down too well because its not very empowering because it... it shows a very patronising way of doing 
things. All l'd said to her was... I'm sorry but the surgeon said (that's what it was) and the informed consent was for a carpal tunnel release. That's where he'd performed the surgery on and then I just went round and I just kept on with what I was saying. But I felt very.... at that point, l'd never... I'd only met her one time before that and I was quite glad really. And when l'd been talking to other students about that experience, they'd said the same thing. That talking to her, even though she comes across as very nice and very genuine, there are some things where she's not up to the play as far as tutors and students. We're not sort of sitting down here absorbing their wisdom, we're interacting with what they're discussing about. And its a very different way of doing things. And so there was that experience which really made me think about how she... just her interrupting, puts a stop on everything in that room. And it also isn't very good because it centred your attention onto the person who was talking. Like what I was saying was wrong rather than her waiting, listening to the whole thing and then saying. "I've never heard of it done that way before." I've normally heard of carpal tunnel releases done closer to the wrist area than the palm of the hand. But it was after l'd discussed that with other students that we'd come... sort of come to the conclusion that the tutor in general does that and that's when you go back to that whole teacher child thing.

Elisapeta Who had previously described empowerment in comparison to a period of disempowerment was asked about the experience. The question that was asked was..

What did they do to make you feel that you were not going to be a nurse?

Elisapeta : They made me push a pram up and down the ward all one day and I thought .. Why can't I do something more constructive. And then they were doing the drug calculations and she said, "Can you figure that out?" and I said. "I'll try to" And she said "Oh no, no you're too slow" Things like that, day in, day out. And I thought... Oh no. They didn't actually go out to help me.

Interviewer: What happened if you approached them?

Elisapeta: Oh their body language.. you know.

Interviewer: It just stopped you?

Elisapeta: Yeah, so I couldn't do it. It's sad, they could have wrecked my career 
Interviewer: So you'd been in the situation of just being told what to do and you'd really felt that you had not been able to ask and...

Elisapeta: I couldn't ask any questions. Like (taking) blood pressure and things like that. They said.. "Well you can go and do it, but you have to do it correctly"... Things were different... They didn't know if I could do it but they...

Interviewer: They were undermining your confidence.

Elisapeta Yeah, they were undermining my confidence, I think they were trying to break me down.

As Elisapeta described, her awareness of empowerment was heightened by previous experiences of disempowerment.

At the second interview participants were asked whether they considered that it was necessary to be aware of their own disempowerment before they could understand the concepts and seek to become empowered. All, except one participant considered that following experiences of disempowerment, reflection and learning from the situation had increased their determination to have greater control over their own learning and so become empowered through increased knowledge.

\subsection{Conclusion}

In this section I have presented exemplars of empowering learning experiences volunteered by participants on interview, which form the data base of this enquiry. In the following section I will describe the process of analysing the data and the path taken to discover the theory. 


\section{Discovering the Theory}

\subsection{The Process as a Whole}

The process of discovering the theory involved constant and comparative analysis of the data which began with the collection of first data at the initial interview. Prior to the first interview each participant was given the interview schedule which focused on the individual learner's background, definition of empowerment and exploration of exemplars of empowering interactions that had occurred during their nursing education. The direction of each interview differed depending on what definition, information and exemplars were offered by each participant. Consequently further questioning and exploration of conditions and consequences was driven by the content, context, circumstance and interaction which the individual participant shared at interview. Because of the nature of the approach peripheral questions were also asked of participants as appropriate, and hypotheses were formulated by myself during the ongoing analytic process.

The aim was to build a theoretical explanation of how empowerment may occur in a teaching I learning interaction. Therefore description of categories within the empowering process, the conditions that give rise to these categories, and the consequences that resulted from variations to them, was part of the overall goal during data analysis. The primary analytical phase involved the synthesis and interpretation of data given by each participant when defining the meaning of empowerment. These definitions, and the analysis of them served as a skeletal theoretical model (Fig.6.1). This model was then further developed to provide a fuller picture of the interaction between teacher and student (Fig.6.2), as first interview data was compared and analysed using 'open coding' (Corbin and Strauss 1990).

The Primary theoretical model conceptualised at this point was initially perceived as being tentative. Full concept then category analysis of each consecutive interview data set was used to add to and explain further complexities of the phenomenon of empowerment. The primary model therefore served as an outline of the initial hypothetical theory with categories also being viewed as separate hypotheses. These hypotheses were then confirmed or rejected during a second phase of 'axial coding' (Corbin and Strauss 1990) that involved the process of line by line comparative concept analysis. Further revision was made to this model until it was considered that each concept held true for each category. Validity was assured by completion of a data frequency comparison following which a secondary theoretical model was proposed (Fig. 6.3). 
Further literature was read and referred to during this analytical process which served to expand knowledge about categories and develop ideas that surfaced during the process. Literature also assisted in explaining and grounding each of the categories during the process of selective coding ( Corbin and Strauss 1990).

During the early stages of analysis it was thought that the phenomena of disempowerment may be the opposing force or opposite phenomenon to that of empowerment. However this hypothesis was disproved as the complexity of the interaction was uncovered during a second phase of analysis of the concepts and categories. Disempowerment became a category within the whole phenomenon of empowerment, an outcome or consequence of what may have been a potential empowering interaction had the conditions been different. When analysis of all interview data was complete, literature referred to, conditions and consequences explained within categories, and hypotheses proven or disproved, the tertiary theoretical model was deemed to be complete (Fig 7.2). Validation at this stage was achieved by checking that exemplars and researcher experience could be explained within the theoretical framework. Final confirmation of the theoretical model came with the presentation and explanation of the model to the participant group. Participant feedback during and following the presentation confirmed the 'fit ' of the theory and model in explaining what had happened during empowering and disempowering interactions. Further modifications to improve the visual representation of the theory resulted in The theoretical model of Empowerment (Fig. 8.1)

In the following sub-sections the analytical process will be presented in chronological order. The process however was not a simple linear progression, but rather a complex picture that developed over time as the interview data was collected then analysed, and as time for reading, thinking and linking the parts into a whole became available to me within a busy life context. Because of the large amount of information, section six will cover the discovery of the theory, section seven articulation of the theory with reference to literature, leaving section eight to discuss validation and confirmation of the theory.

\subsection{Analysis of the Meaning of Empowerment}

When analysing definitions of the meaning of empowerment the most common concept that arose was that of knowledge. The phrase that 'knowledge was power' was specifically articulated by Robin and the notion of knowing, seeking knowledge and learning resulting in an increase of power was articulated by three other participants. The second most common concept was that of giving. The idea that something was given by one and therefore gained by another during an interaction was common to four of the six participant definitions. These four participants defined empowerment from a global or holistic perspective that included the 
origin of the required conditions. The other two participants described empowerment from an individual position that defined individual abilities without including the origins of how or where the abilities may have originated.

The individual abilities articulated by all participants included confidence and being able to: speak out, know, seek facts, make decisions and be self determined. From this initial exploratory analysis a basic picture of movement and exchange involving an interaction, of giving and of change in an individual initiated by, or because of, an interaction was formulated ( Fig 6.1).

Other aspects of empowerment that arose from the definitions given by participants included:-

- The notion that one could be given knowledge or could get it by watching a role model and by reflecting on an experience.

- That being given responsibility increased knowledge and also increased confidence.

- That basic knowledge could be added to during an interaction or experience.

- That the giving over of power from one who holds it to one that doesn't can occur during an interaction .

- Abilities that led to or resulted in being empowered were; self efficacy or believing in one's own ability to do something; being capable; being confident; being able to speak up or speak out knowledgeably; being able to make decisions.

The attitudes and abilities demonstrated by those that empowered others during an interaction or experience were; the belief in the ability of the other; the ability to evaluate the knowledge and skills of the other; communication skills; the ability to share / give knowledge and experience; the ability to encourage someone to develop awareness of their own power. These attitudes and abilities helped the learner to feel confident, respected, and able to make choices.

The model that came from initial analysis was sketched as a series of actions and included conditions and consequences of an interaction.(Fig.6.1) 
Figure 6.1 Skeletal theoretical model from definitions of empowerment

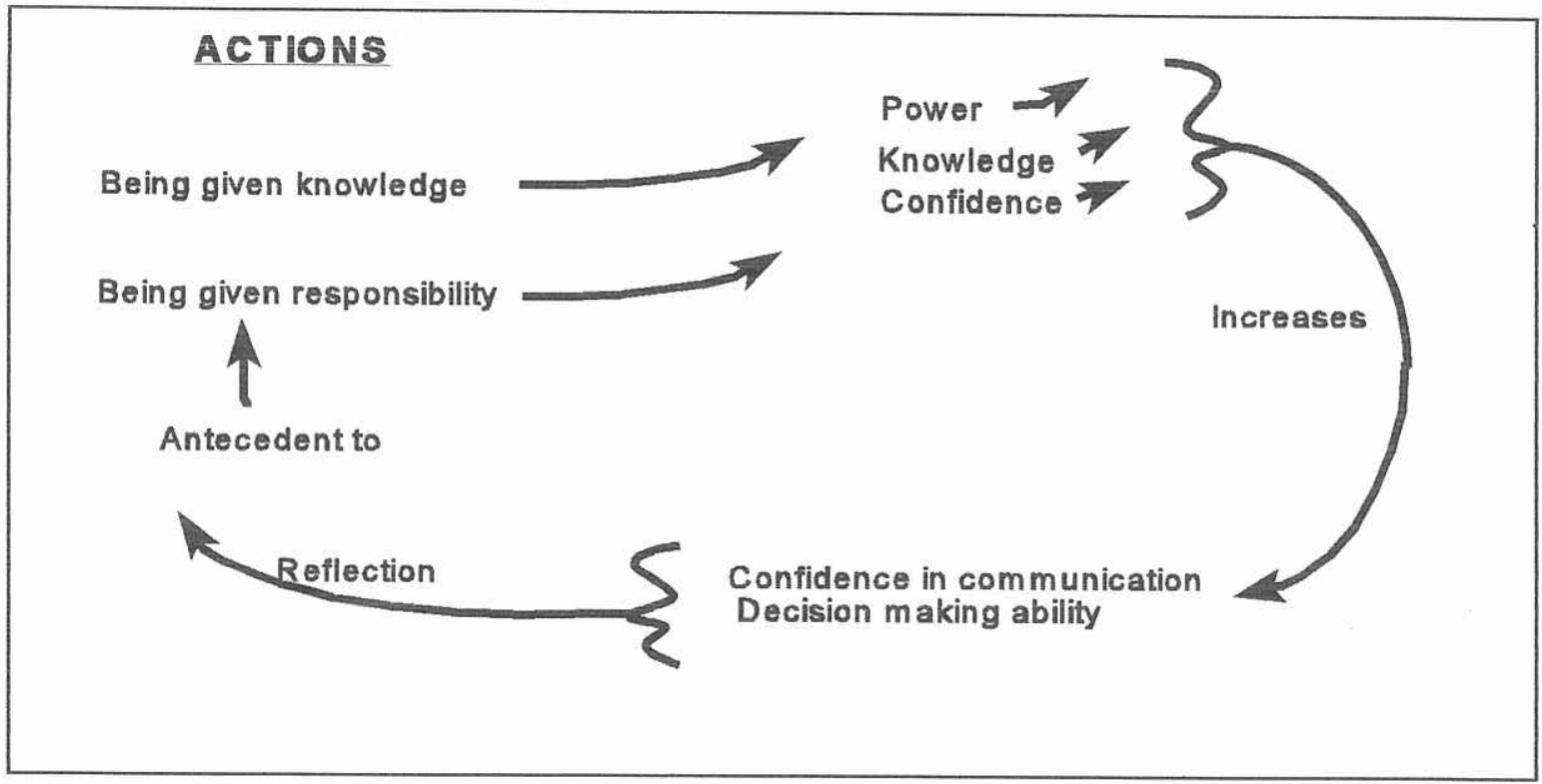

The skeletal theoretical model (Fig.6.1) shows that student feelings of power, knowledge and confidence increase when responsibility, role modeling and knowledge are given by a teacher/nurse. Being given responsibility and knowledge increases belief in self and self confidence which in turn enhances communication and decision making abilities. Belief in self, ability to communicate and ability to make decisions are required before (antecedent to) a teacher/nurse gives a student responsibility which can lead to their increased knowledge.

\subsection{Initial Analysis of First Interviews}

As first interview data was collected, general holistic initial impressions provided data for a theoretical model in my attempt to link, and make sense of the information given by the participants about their experiences. This informal analysis resulted in the development of a more complex primary model and the grouping of some concepts into temporary hypothetical categories.

Seven categories with explanatory concepts arose from this initial work. All focused on conditions of the student / teacher interaction.

\section{Category 1: Student needs}

The student needs: to be ready to learn; to know what to ask; to be knowledgeable; to be prepared; to have a positive attitude; to have belief in self and to have self confidence. 


\section{Category 2: Student antecedents}

Antecedents to a student being given responsibility are: confidence; communication skills; knowing what he/she needs to learn or needs to know.

\section{Category 3: Teacher attitude}

The student is given increased confidence from the teaching interaction. When the teacher is: helpful; trained; able to anticipate and answer questions when the student asks; able to give over power; has knowledge; is approachable; and acts as a positive role model.

\section{Category 4: Teaching strategies}

The teacher uses strategies of: working with a student; assisting problem solving; affirming; leading; praising; supporting; encouraging.

\section{Category 5: Teacher antecedents}

Teacher antecedents to giving a student responsibility are: a desire and ability to teach and evaluate; communication skills; confidence; knowledge and the ability to power share by giving the student relevant experience and knowledge.

\section{Category 6: Relationship feels like}

The interactional relationship that is empowering feels like: side by side; equal; learning together; partnership; and includes: not being put down; not being patronized.

\section{Category 7: Interactional gains}

From an empowering interaction the student gains: experience; opportunity for reflection; understanding which leads to better learning; learning in context; new knowledge that is added to what is already known; and learning from a role model.

A model of these categories (Fig 6.2) gave diagrammatic representation to the active or sequential nature of the conditions defined during this process which incorporated the first skeletal model. 


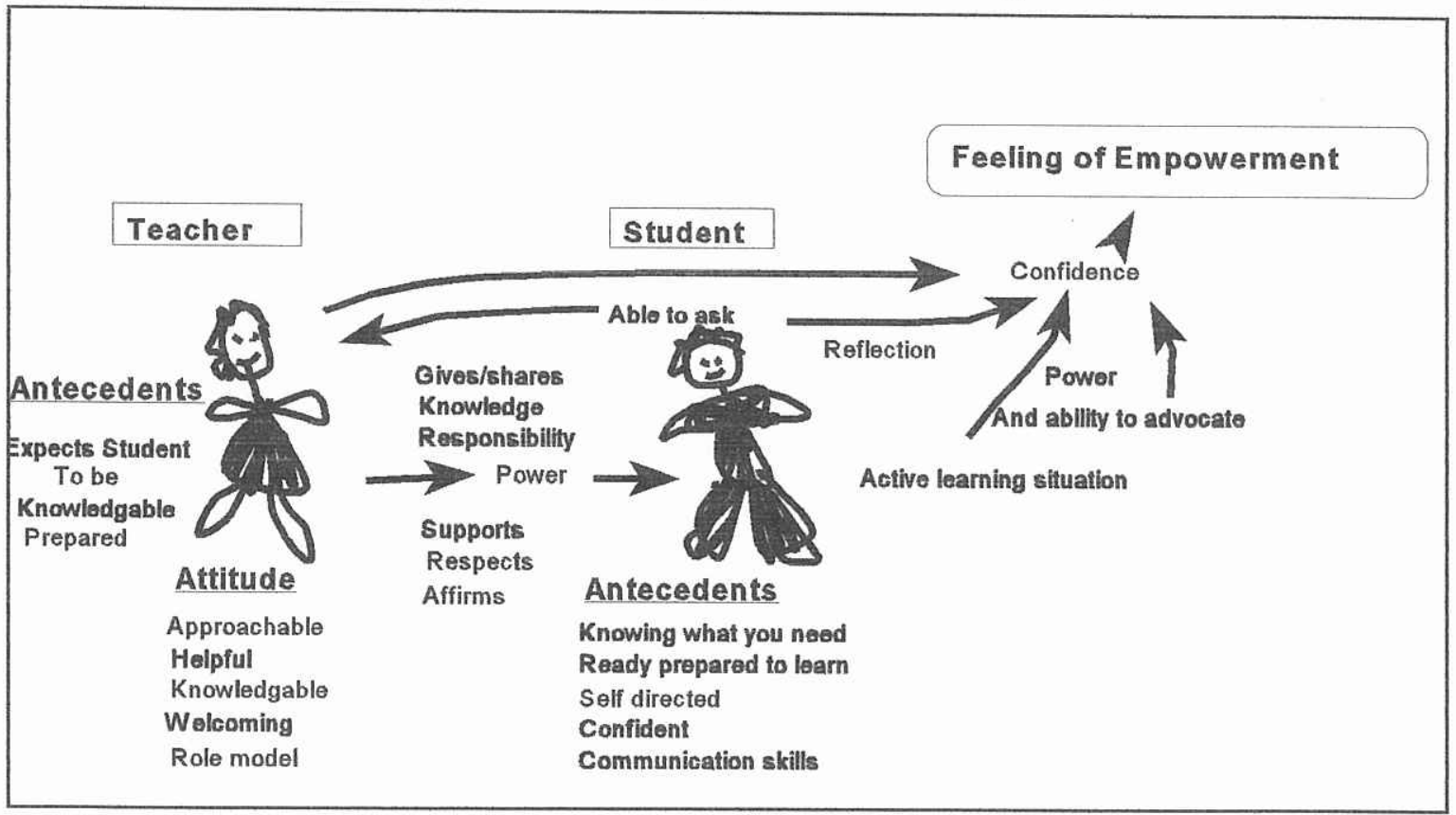

\subsection{Concepts and Categories}

Following the completion of the two scheduled individual interviews, complete line by line analysis of interview transcripts to elicit a full range of concepts according to the method described by Corbin and Strauss (1990), was undertaken. Coding into relevant concepts then clustering concepts into categories was then addressed. Using this method I sought to test hypothetical categories, generate new categories and determine relationships between categories. As the analysis progressed category structure was refined until no further unique categories were identified. By using this method of category generation all data was accounted for and the 'whole story' of the phenomena was described. The function of this analysis focused on the verification, confirmation or rejection of categories as well as the elaboration of key concepts.

\subsubsection{Analysis of Empowering Interactions}

Information initially elicited focused on the positive empowering moment or interaction. However, as previously indicated many examples of disempowering interactions were also shared by the participants either at the first interview or during the second meeting. Therefore when analysing transcripts it became apparent that it was not possible to merely analyse the exemplars in isolation from the total interview transcript or full story to get a picture of 
empowerment. Because of the complexity of the phenomenon, questions asked whilst clarifying relevant information from participants about each exemplar also gave rich data and so helped explain the phenomenon under study. When transcripts were analysed line by line to develop concepts each transcript was therefore taken as a whole. The following subsections present the concept analysis of each of these transcripts.

Literature explaining the significance of categories and an overall analysis of the focus or story from each participant is also introduced.

\subsubsection{Constant Comparative Analysis}

\subsubsection{Glenis}

During her interviews Glenis described how learning in year one had been the basis for learning in year two and how tutors had given her confidence and belief in herself. Glenis believed that the overt curriculum at Whitireia meant that students knew what was expected and that this knowledge led to success through which she developed belief in her ability to learn. Tutors were said to support and respect students and to be available. Glenis described that the flow on from students being supported by tutors, was that students developed the ability to support others (patients, tutors or peers). Glenis also described an interaction with a tutor in a clinical setting where the tutor was the nurse expert who guided by example, praise, suggestion and action. This situation occurred when Glenis was in her initial 'Year one' hospital placement and was being assessed on her ability to give appropriate hygiene cares to an elderly client. While concentrating on one aspect of care she was unable to focus on what else was happening to the patient she was showering. The tutor however calmly took care of the secondary situation without making Glenis feel incapable or inadequate. (Empowering interactions section 5.5.1) This approach encouraged Glenis's continued participation and made it seem possible for Glenis to develop a more complex level of nursing expertise in the future.

The exemplars given by Glenis included that action / interaction and reflection led to empowerment from a learning experience.

Concepts and categories that were determined from transcript analysis of interviews with Glenis were as follows: (The number of the category relates to the hypothetical categories defined in section 6.3:) 


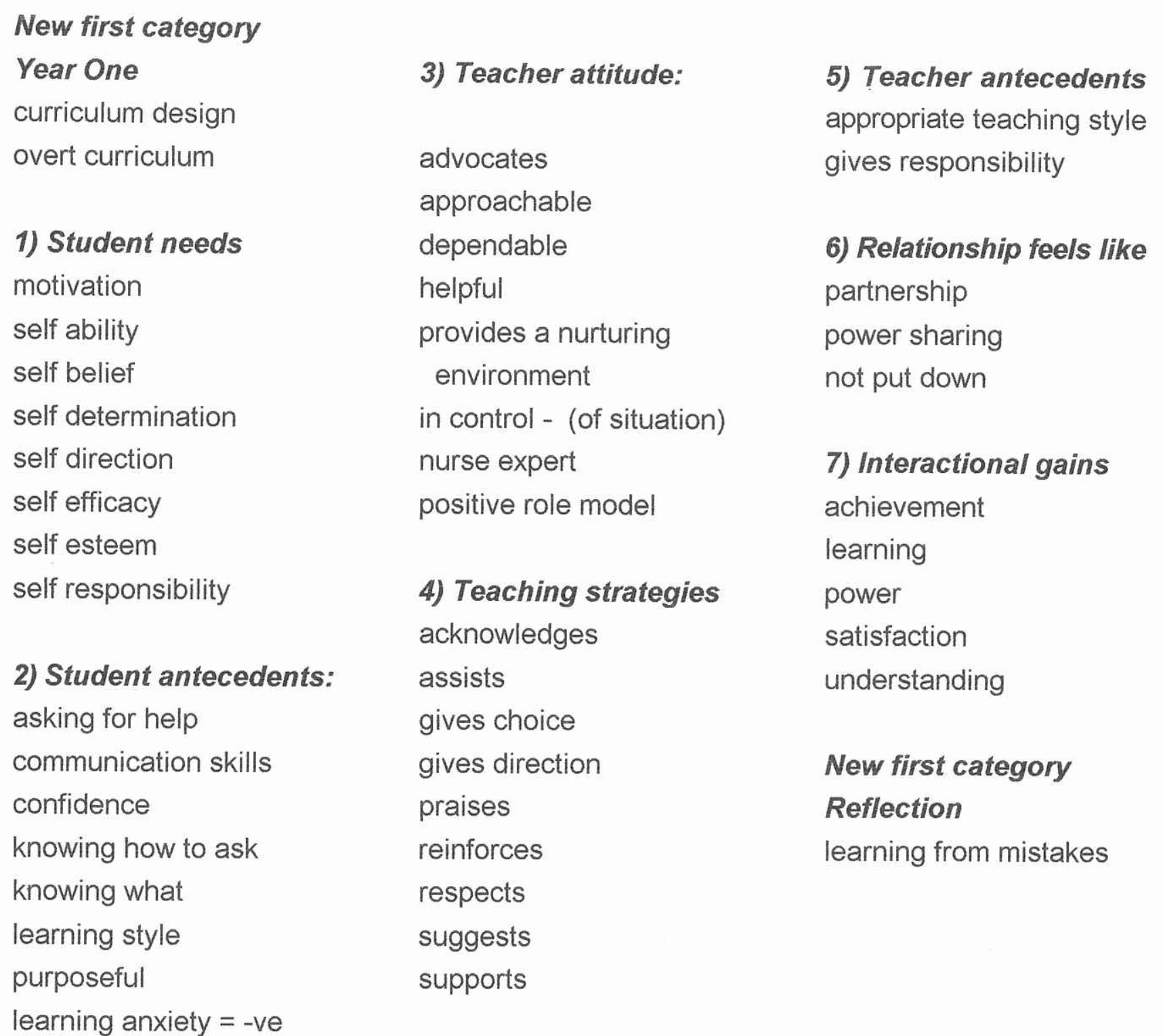

As can be seen from this analysis all the preceding seven categories from section 6.3 are accounted for and some new concepts within these increase the descriptive understanding of these categories. Concepts that belong to the new categories are placed at the beginning and end of the previously defined categories because this is where they fit in context. They do not seem to fit with, or belong to, categories that have already been defined. Broadly, these are concepts related to the first year of the programme at Polytechnic which have been placed as an initial category Year One and to the concept of reflection. It was hypothesed that learning from mistakes may occur whilst reflecting after an event. Therefore Reflection has been redefined as a category and placed at the end of the action process, with learning from mistakes a concept within it. 
Prior to the line by line analysis of transcripts I had been concerned that most of the empowering interactions described by participants had occurred during clinical placements. None of the participants, even when specifically asked, could think of exemplars that were classroom situated. However, after the analysis of Glenis's interview transcript the position of the Polytechnic within the empowering process became more evident. Glenis clearly described her perception of how the curriculum supported and assisted the process of empowerment. She believed that knowledge, skills, and attitudes including self awareness and self belief of success supported by the tutors in level one of the programme prepared her for level two experiential learning. Self belief as a concept was fully discussed by Glenis and the importance of self belief as a required antecedent to a positive empowering experience was mooted by her.

Glenis's exemplars assisted in confirming and strengthening category development and introduced the new category of student learning in level one. Glenis's story also initiated my enquiry into the place of self belief in empowering interactions and into the environment that supports empowering interactions. Following analysis of this transcript literature on self efficacy (Bandura 1986 ) the learning environment (Heron 1992 ) and the place of reflection in learning (Boud and Walker 1990, Bevis 1991, Reed and Procter 1993) was consulted to assist in theory development. The notion of empowerment through learning from mistakes was at this stage not clearly situated within the phenomenon of empowerment.

\subsubsection{Elisapeta}

Elisapeta initially described an empowering interaction that was recognisable because it followed on from a situation of prolonged disempowerent. Elisapeta articulated an awareness of the importance of hard work and preparation in the Polytechnic context prior to clinical placement. Elisapeta also described the effects of performance anxiety when she was watched in an 'assessing way' by a nurse expert in clinical placements. During the interview Elisapeta clearly articulated how the environment affected her learning and how she was sensitive to variations of body language, environmental milieu and signals of 'non acceptance'. When the 'milieu' (Boud and Walker 1990) did not feel safe Elisapeta described her tendency not to ask for what she needed in order for her to learn. Performance anxiety was described as causing mistakes and then feelings of failure. However when she was coached and supported, and when the person with power believed in her ability, learning and empowerment could occur. Elisapeta was then able to take initiative and performed beyond her initially perceived capabilities. Elisapeta stated that she needed feedback, support, guidance and belief in her ability from a nurse expert as pre conditions or antecedents before a learning experience was potentially empowering. 
Concepts and categories that were determined from transcript analysis of interviews with Elisapeta were:

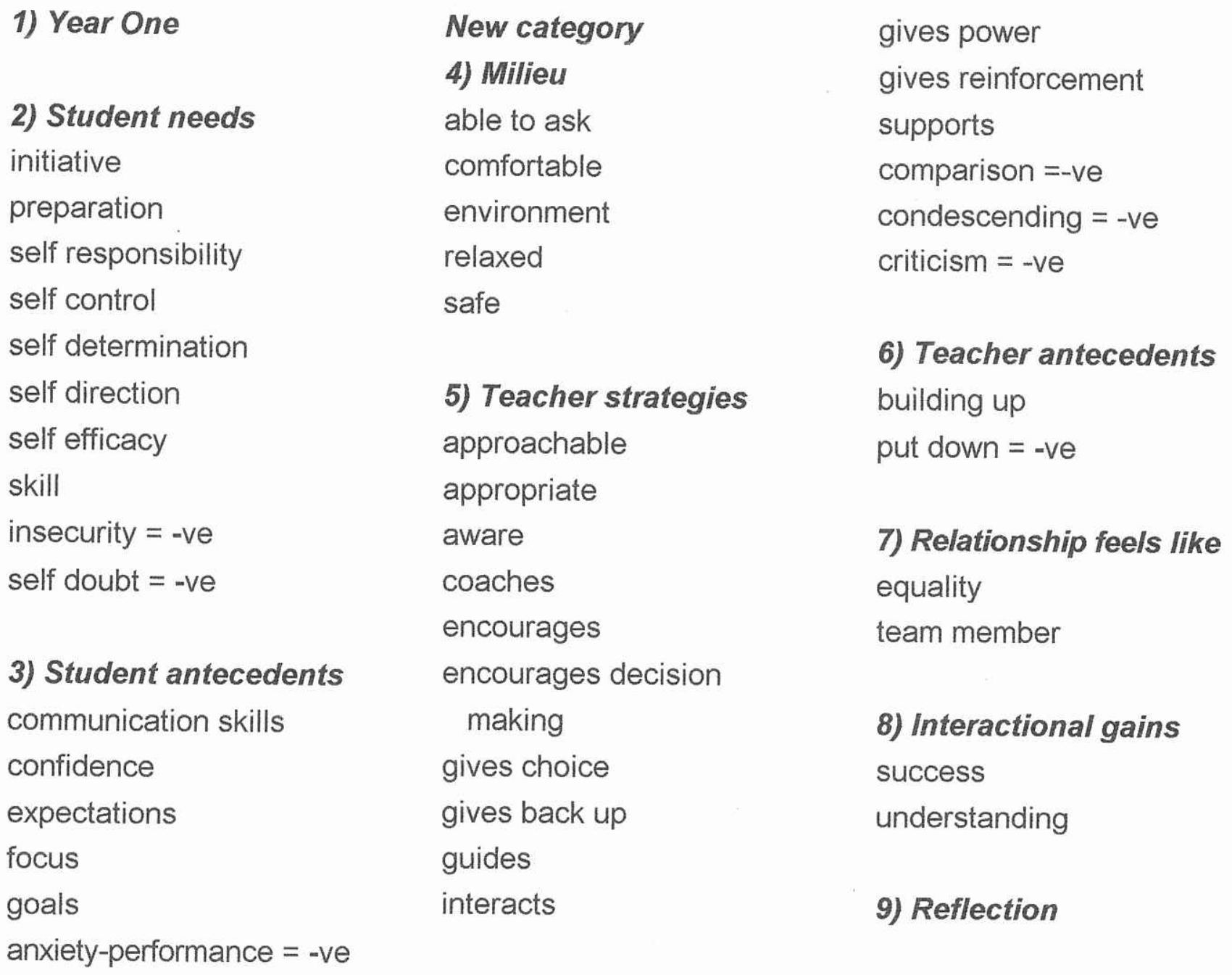

From analysis of this transcript the seven initial categories were confirmed and further concepts were added to them. In this instance negative concepts were placed within existing categories. For example insecurity and self doubt were considered as being negative to Student needs (2). Performance anxiety was determined as being negative to Student antecedents (3) and Teacher strategies (5) of criticism, comparison of students, condescending manner and student 'put downs' (Teacher antecedents 6) negated student learning and ultimate empowerment. Descriptions of how the environment was perceived and how feelings gained from the people and the place affected the ability to have meaningful experiences that empowered learning led to the development of a new fourth category of 'Milieu', that was placed between Student antecedents (3) and Teacher strategies (5). The categories of Year one (1) and Reflection (9) did not surface in this transcript analysis. 
Elisapeta described what appeared to be a disproportionately high number of disempowering experiences compared to other participants and as Elisapeta was the only participant who identified as Maori, the question of racism arose. The opportunity was taken at an appropriate time and context after the feedback discussion, to ask Elisapeta if she considered that racism had ever been a factor in her experiences in clinical learning situations. Without hesitation this notion was affirmed and Elisapeta went on to describe how she was often sent to placements with a peer who was also a Maori student who had a 'pakeha' name. Elisapeta recountered that what happened when the two students arrived was that people seemed confused and mixed their names up because of their physical appearances. Elisapeta put this down to the fact that she was lighter in skin colour that her peer. Elisapeta felt that assumptions were made prior to her arrival in a clinical area based on her identifiable name and she considered that further assumptions were made about ability based on body size ( less able if larger), clothes ( less able if not 'well dressed' ), name (if it identified ethnicity), and skin colour.

Elisapeta stated that :

After about a week attitudes changed if I had proved myself, but I have to do things twice as well to be as good as the others ( pakeha students).

As discussed earlier Elisapeta was very aware of, and acutely affected by what was happening in the general environment and when she felt unsafe she became anxious and less willing to risk being assertive in order to get the experience she required. In one instance the experience Elisapeta was assigned included pushing an infant up and down the corridor in a pram (perambulator), instead of being given responsibility for care of a patient at her level of competency. The story she told demonstrated that in spite of preparatory learning of skills and abilities, the person with power in this clinical situation had control over what happened for her as a student and therefore what learning experience was possible. During this data analysis the place of self efficacy in this situation was of interest to me as were the personal values, attitudes and behaviours of individuals with power. The need for education prior to teaching students of nursing (Atkins and Williams 1995), attitude change (Bowman 1993) for nurses, and the value of teaching cultural safety (Ramsden 1993)and issues related to the Treaty of Waitangi in nursing education programmes ( Ramsden and Spoonley 1993) were confirmed. The experiences described by Elisapeta highlighted the need for students to be given experience that was relevant to the knowledge level and competency of the individual student. Appropriate experiential learning that provided a challenge also surfaced as being essential to the empowering learning experience. Literature by Boud and Walker (1990) was perused to help explain the category of milieu. 
Literature that discussed victim blaming in nursing (Bowman 1993 Choy 1991), Inclusion (Pearpoint and Forest 1994) and Cultural Competence (Pierce 1993) was also consulted.

\subsubsection{Liam}

Liam described how self motivation to work hard during year one resulted in success and this motivated and encouraged him to do more work in a positive cycle of learning that resulted in increased self efficacy. He saw nurse experts as role models and stated that application of theory in practical situations helped him to learn. Liam described how, with support from tutors he was able to learn from his mistakes and that tutor guidance and constructive feedback allowed his tunnel vision to be expanded and encouraged him to learn from reflecting on his practice.

Empowerment for Liam was about openness and knowledge sharing, information sharing and power being given to him. Liam described a patient focus to his nursing practice that included encouraging people to speak up for themselves, acting to provide information so that others could make informed choices, encouraging questioning and acting as advocate (section 5.5.1).

Empowering learning situations for Liam required relationships between student and expert nurse of equality and sharing, described as symbiotic with each person bringing something to the interaction. Being able to ask and feeling safe in a supportive environment was also important for Liam and he knew that if the learning environment was relaxed and comfortable he was more able to be vulnerable and open to learning. Liam described how, in clinical situations, a position of trust was conferred by a nurse expert when an appropriate experience of responsibility was given to the student. When respect, opportunity, and supportive back up was provided, Liam considered that when power was given to him by the expert he was then able to empower a client.

The concepts that arose from the full analysis of Liam's interview transcripts were:

\section{1) Level one}

ability

knowledge

self efficacy

self directed

\section{2)student needs}

ability to plan

capable

competence

\section{3) Student antecedents}

awareness

confidence

motivation

vulnerability 


4) Milieu
comfortable
enjoyable
learning environment
manner 'way of being'
nurturing environment
relaxed environment
5)Teacher strategies
acknowledges
approachable
assists
available
discusses
encourages
facilitates
gives responsibility
gives choice
gives direction
helpful

\begin{tabular}{|c|c|}
\hline & learning how \\
\hline is in control of situation & learning through practice \\
\hline nurse expert & supporting patients rights \\
\hline \multicolumn{2}{|l|}{ praises } \\
\hline professional role & 7)Relationship feels like \\
\hline respects & equality \\
\hline shares power & partnership \\
\hline suggests & working relationship \\
\hline supports & symbiotic relationship \\
\hline \multicolumn{2}{|l|}{ teaches } \\
\hline trusts the student & 8) Interactional gains \\
\hline \multirow[t]{2}{*}{ validates } & excitement \\
\hline & learning satisfaction \\
\hline New category & power \\
\hline 6) Praxis & success \\
\hline \multicolumn{2}{|l|}{ advocacy } \\
\hline experience & 9) Reflection leads to \\
\hline goal achievement & consciousness raising \\
\hline informed decision making & learning through failure \\
\hline learning what & challenges thinking \\
\hline
\end{tabular}

Analysis of Liam's interview transcripts assisted in the clarification of the interaction and the Milieu(4) that best enhanced student learning. The link between his own empowerment, and then consequent empowerment of a client, also arose from his experience. This experiential learning space has been redefined in the category of Praxis (6). Praxis is considered to be the synthesis of theory and action in an experience when new situations are faced that allow enquiry orientated learning to take place (Bevis 1991). In this context the teacher provides the situated possibility but the student is the person who provides the knowledge and ability and engages in praxis during the experience.

At this stage of the analysis I considered that the designation of Teacher attitudes as a category was too narrow and too assumptive as it was usually based on the attitude or manner of more than one teacher affecting the student experience. Therefore the category of Teacher attitude (previous 3) was collapsed into that of Milieu (4). Teacher antecedents (previous 5) also seemed to be difficult to support at this point, as many of the concepts within this category could also fit within Teacher strategies (5) and within the new category 
of Praxis (6). Therefore the Teacher antecedent category was collapsed and concepts from it were placed in Praxis (6) and Teacher strategies (5) as appropriate.

The place of Reflection (9) and how it influenced the thoughts, self efficacy and feelings that a student might take to another learning situation became apparent after reading and analysing Liam's transcript. Prior to this I had thought that reflection was important as a strategy to use following an empowering situation. I had considered that reflection would assist the student to remember a positive experience, and would in this way, also help to increase self efficacy.

Liam's experience added a new dimension to reflection. Liam had felt disempowered in an interaction during which feedback was given in a destructive manner making him feel less able, and less competent than he had considered to be the case. With subsequent intervention from a teacher who interacted with him in a facilitative way, the outcome was that he did not continue to take on the feedback as a total picture of himself. He did not continue to generalise but was able to perceive the incident as one thing that had happened specific to that particular situation. This intervention appeared to assist Liam to make the change from a position of passive learned helplessness to proactive learned optimism ( Seligman 1991). Analysis of Liam's experience clarified the role of the teacher in assisting in reflection on practice and how, when reflection was facilitated through dialogue and rationalising a specific situation, the student could learn from the experience. When the student learnt in this way they appeared to regain a sense of control over their learning and were therefore more confident to approach the next learning experience.

\subsubsection{Meredith}

During her interviews Meredith discussed her learning history, current feelings and experiences of learning within the nursing programme. Meredith considered that issues originating in previous educational situations still impacted on her current learning. Meredith discussed a history of withdrawal from learning situations because of a 'fear of failure'. Not being heard and lack of discussion about things that concerned or affected her with perceived authority figures resulted in disempowerment for Meredith. Lack of answers that satisfied her led to her becoming annoyed and angry. Meredith stated that her needs were not met when she was not listened to by others. Meredith felt empowered by equality, by being part of a working team, by being supported, listened to, allowed and encouraged to express opinions and ideas, by being backed up and by being able to check things out with expert nursing staff. Learning for Meredith was often achieved through her individual endeavours with 
knowledge being gained by her reading of relevant books and asking others, only when she felt safe.

Meredith felt disempowered when as a result of asking, clarification did not occur because the interaction was ended in the nurse expert pulling rank and Meredith being put down. When made to feel powerless Meredith tended to withdraw and be silent which resulted in her not completing and so ultimately not succeeding.

Meredith was not comfortable with the notion of empowerment and discussions of power, as these reminded her of past unequal adult / child relationships. Meredith preferred active learning and gained little from reflection as she tended to block out what had happened for her in teaching / learning situations, and not dwell on it.

The concepts and categories that arose from Meredith's transcripts were :

\section{1) Level one}

\section{2)Student needs}

ability

knowing what is needed

knowledge

self knowledge

self direction

boredom $=-$ ve

3) Student antecedents

confidence

goals

preparation

avoidance $=-$ ve

4) Milieu

able to ask

able to speak

able to question

being heard

safe

\section{5) Teacher strategies}

approachable

appropriate experience

allows challenge

backs up

discusses

explains

facilitates

guides

listens

is open

gives constructive

criticism

gives power

gives rationale

gives recognition

gives responsibility

respects

supports success

values student perception

pulls power $=-$ ve

puts down $=-$ ve

pulling rank $=-v e$

\section{6) Praxis}

action

active learning

interaction

learning experience

7) Relationship feels like

equality

inclusion

team participant

\section{8) Interaction gives}

experience

power

satisfaction

understanding

lack of power = -ve

annoyance $=-$ ve

frustration $=-v e$

\section{9) Reflection}

avoided 
Analysis of the transcripts of interviews with Meredith again confirmed categories and concepts from previous analyses. Meredith also provided insight into how a student may be disempowered by not having a relevant experience or by being treated in a manner that disempowered by not providing the answers needed during communication between student and teacher.

The exemplars and experiences described by Meredith served to elucidate the issues of power and power balances in interactions. The need for nurse experts to satisfy a students need to the satisfaction of the student, rather than allowing the person with power to decide how much information was enough, was highlighted. Issues of adult versus child as learner arose during the analysis of these transcripts as well as the ways in which the conditions that encourage adult learning differ from those that may be acceptable for children.

The work of Knowles $(1970,1984)$ describes an andragogy of adult learning as opposed to the child education pedagogies. The notion of 'facilitation' of learning rather than 'teaching' of knowledge was also sparked by this transcript. The work of Heron (1992, Hunter et al 1994) on facilitated learning served as a source for further development of these ideas.

Although disempowerment occurred for Meredith due to inadequate learning situations, the interactional assumptions in empowering situations were also clarified by her interviews. Meredith described herself during the interviews to be feeling less able as a learner than when she entered the course which I considered may demonstrate how learning experiences and patterns of behaviour can be repeated if beliefs and attitudes that underpin them are not adequately addressed. The importance of individual self efficacy and success was also highlighted, as were questions of the consequence of lack of reflection.

Meredith was able to act as an advocate for her peers but at times appeared to put the learning needs of others before her own. This may well be a demonstration of her socialisation and the dilemma that many women in nursing have trouble coming to terms with, when changing from always meeting the needs of others to asking for their own needs to be met (Jolley and Brykczynska 1993). The importance of experiential learning, especially for an active learner as Meredith identified herself to be, as well as the need to apply theory to practical situations in a vocational education context led me to review experiential learning in education ( Boud and Walker 1990, Bevis 1991).

When comparing the picture told by Liam of how 'failure' was turned into a positive learning experience, Meredith's experience could be said to give the opposite view. Meredith made a choice of not reflecting or entering into reflective dialogue with others about what 
happened for her during learning situations. I wondered if this may have been a factor in her exiting the course, as without the making positive of disempowering experiences lack of self efficacy may have disallowed her to feel competent enough to persist with further clinical learning experiences. The question is, whether facilitated reflection can alter the perception of the learner and change a disempowering interaction into an empowering one, or not. If the answer is in the affirmative it would support the need for teachers to visit, talk and encourage students during clinical experience and would also strengthen the need for Paper 215 'The Caring Relationship in Nursing' that encourages students to discuss exemplars from practice with a teacher and their peer group in a safe environment.

\subsubsection{Robyn}

Robyn willingly shared a great deal of information that included her opinions concerning communication, learning interactions and her experiences in the education system. She discussed teaching and learning styles and what had and had not worked for her. Robyn was thoughtful and reflective of her learning experiences. She identified herself as being creative and as needing to establish meanings in order to understand. Robyn was self aware, self directed and knew what she needed to know and how to go about getting relevant knowledge. She was very aware of relationships and power balances and had studied transactional analysis. This appeared to have increased her understanding of how those with power relate to those without power. Robyn was also aware of the links between personal and professional roles.

Robyn considered that preparation for learning was important. Preparation for Robyn in the Polytechnic situation included reading and thinking about the topic before lectures and tutorials. In the clinical setting it meant prior revision of the knowledge and competencies required, then using an expert nurse as a role model before practising herself. Robyn's descriptions led to further clarification of the concept of Praxis (6) as the application of theory to the practical situation, or practical experiential learning following from learning knowledge and skills, gained at Polytechnic. Robyn appreciated this sequence of events and found it a valuable way for her to learn.

For Robyn empowerment depended on student and teacher information sharing. The ability for her to have choice in her learning was important. Robyn considered that nurse experts need to facilitate learning by giving students a decision making role that is appropriate to their level of knowledge, and by involving students in decisions that affect their learning. Robyn elucidated the importance of working with expert nurses who had been trained to be preceptors and teachers of nursing students in clinical situations. Robyn, like Liam, gave an 
exemplar of a situation that could have had a disempowering consequence but did not because of the way she controlled it. Whereas Liam's outcome was determined by the intervention of another, Robyn's experiential outcome was determined by her own decision to be assertive or proactive. In this instance Robyn took control to ensure that the outcome of her learning experience was positive. Robyn chose not to talk to a tutor, who she thought would make her feel as if she had made an irreversible error, she chose instead to talk to a nurse expert from the clinical area who supported her to learn from her experience. In making this choice Robyn avoided becoming powerless by avoiding people that may have labeled her and put her down because of errors of judgement made innocently as part of the learning process.

The concepts that arose from the full analysis of Robyn's interview transcripts were:

\begin{tabular}{|c|c|c|}
\hline 1) Year one & $\begin{array}{l}\text { safe } \\
\text { secure }\end{array}$ & $\begin{array}{l}\text { preceptor -trained } \\
\text { professional }\end{array}$ \\
\hline 2)Student needs & & respects \\
\hline ability & 5) Teacher strategies & role model \\
\hline knowledge & affirms & supports \\
\hline self awareness & answers questions & understands \\
\hline self awareness & appropriate & values \\
\hline self direction & aware & put down $=-v e$ \\
\hline self efficacy & discusses & power pull = -ve \\
\hline \multirow[t]{2}{*}{ skill } & encourages & \\
\hline & expectations & 6) Praxis \\
\hline 3) Student antecedents & explains & action learning \\
\hline communication & genuine & application \\
\hline confidence & gives rationale & challenge \\
\hline decision making & gives responsibility & checking out \\
\hline goals & gives guidance & choice \\
\hline learning style & gives feedback & experiential learning \\
\hline motivation & helps & learning process \\
\hline \multirow[t]{2}{*}{ questioning } & honest & practical learning \\
\hline & knowledge shares & theory to practice \\
\hline 4) Milieu & listens & teaching in context \\
\hline able to ask & makes links-overt & \\
\hline comfortable & non biased & 7) relationship feels like \\
\hline enjoyable & not comparing to & equality \\
\hline relaxed & nurse expert & partnership \\
\hline
\end{tabular}


peer

symbiotic relationship

team member

working with
8) Interaction gives

power

self growth
9) Reflection

learning from mistakes

Following the concept analysis from Robyn's interview transcripts my thoughts turned to how easy it is for an expert to either empower or disempower a student. I questioned as to whether disempowerment occurs because the nurse expert is not themselves empowered and to gain some power does so by disempowering the student nurse. If, in some instances, there was an element of horizontal violence being practiced by expert nurses. I wondered if what had happened to participants was mainly to do with power and how individuals respond to those with power. How those with power chose, or not, to include others or to share their power was given my consideration. My reading turned again to Heron (1992) and his analysis of how the person with power needs to be secure in self before they can share power in an authentic manner. How, if this is not the case, the use of power can become manipulative or is not really shared. Other ideas that I gave consideration to included what I had learnt from research carried out by my peers and myself in 1993. One of the conclusions we arrived at, when analysing the tutor / student relationship, was that when we needed to be liked, nurses and teachers could rescue those they perceive as 'needy' then persecute or victimize them if they did not behave as we expected. This treatment of students served to encourage continued dependance and so maintain the reliance on the teacher rather than supporting student independence (Pearson et al 1996).

Robyn reminded me that students need prior preparation, self ability and strategies such as communication skills and assertion skills before the event so that they can facilitate their own learning. These skills help to maintain a person in a healthy interaction rather than in a dependant role ( Choy 1990)

\subsubsection{Robin}

During his interviews Robin described low self efficacy and low esteem during his years of schooling. He also described his fear of failure at course entry, but high level of confidence in himself. Robin appreciated that he was able to learn the theory at Polytechnic then go out to clinical and apply what he had learnt. Robin described situations where he provided information and educated others in order to empower them, and how he acted as advocate for his clients, sometimes going beyond acceptable boundaries of student practice. For example on one occasion he informed relatives of surgical procedures unaware that this was 
not his role but the role of the surgeon (section 5.5.1). Robin was however able to learn from these experiences and felt more able once he did know what the boundaries of his practice should be. His definitions of empowering clients served as comparisons to the developed model .

The concepts that arose from the full analysis of Robin's interview transcripts were:

\section{1) Year one}

anxiety

confidence

\section{2) student needs}

ability

able to ask

information

initiative

knowledge

\section{3) Student antecedents}

communication

decision making

honesty

interest

questioning

self efficacy

skill

4)Milieu
comfortable
guidelines
safe

5) Teacher strategies

appropriate

assists

authoritative

backs up

discusses

explains

facilitates

gives assurance

gives responsibility

guides

helps

nurse expert

praises

respects

role model

supports

\section{6) Praxis}

advocacy

application

experiential learning

information sharing

knowledge sharing

learning

practical experience

7) Relationship feels like

power sharing

\section{8) Interaction gives}

empowerment

\section{9) Reflection}

learning from mistakes

insight

The concepts of power and motive arose following Robins interviews which prompted me to read further about facilitation (Hunter et al 1994). This analysis also highlighted for me the importance of giving students prior knowledge and information that they can use in the clinical situation. Robin's interviews also emphasised the importance of providing guidelines about roles, responsibilities and ethics either as part of the preparation or as the initial orientation to a new clinical area, rather than expecting students to learn through the traditional apprenticeship model that includes covert socialisation practices (Mingay 1993). 


\subsection{Concept Comparison}

Following the generation of concepts from interview data, comparisons between the six concept lists were made to determine which concepts were most common or recurring. During this process categories evolved as concepts based on the same property were grouped together. This analysis was then used to verify that categories and concepts had not been lost or artificially enhanced during the constant comparative analytical process.

During this process the frequency of a concept was used as a guide to its importance - or its place in the analysis and formulation of the theory and model. It became clear however that what had been developed during comparative analysis described the complexities of the action in greater detail. The frequency comparison process served only to confirm the more general categories and concepts that had been refined through the previous comparative analysis.

\section{Categories for empowerment in learning from frequency of concepts :}

- THE STUDENT -gets prepared has self: belief; efficacy; determination; esteem; direction; responsibility; knowledge; awareness; control. Has: appropriate knowledge; (knowing what, knowing how) understanding; ability to apply theory to practice; ability to make links. Is: assertive; able; confident; questioning; engendering of trust; initiative taking. Has needs met through: interaction; active/practical learning; being given responsibility; being trusted; being given choice.

- THE LEARNING PROCESS: Is inhibited by: anxiety (performance and assessment). Is enhanced by: achievement and success; learning from mistakes (practice and experiential,); constructive feedback; reflection (self and/or tutor initiated). Leads to: satisfaction; enjoyment; interest; further motivation; excitement. Requires an environment described as: safe; comfortable; nurturing; relaxed.

- THE TUTOR/ CLINICIAN/ BUDDYI PRECEPTOR Is: professional; a nurse expert; a role model. With Attitude/Manner/ 'Way of being'- that is: approachable; available; flexible; positive; supportive; open; genuine; vulnerable; honest in interactions; respectful; authoritative, not authoritarian; adult to adult. Has insight into: student role and ability. Is: trained to teach; in control of situations; power sharing/giving; not putting down; acknowledging; acting as an advocate (patients rights/students rights); knowledge sharing. Provides: experiential learning opportunity and has expectations of the student. Recognises ability, gives appropriate level of responsibility. Is: affirming; helpful ; praising; validating; valuing; directive; guiding; 
explaining; coaching; facilitating; providing of back up; giving of assurance; suggesting; giving of constructive criticism / feedback. Helps student to make links between theory and practice.

\section{- THE COMMUNICATION / INTERACTION BETWEEN STUDENT AND TEACHER.} Needs to include relevant information, guidelines and appropriate discussion. Student needs to be: heard; listened to; able to ask; able to challenge; able to question. In a relationship described as: a partnership; symbiotic; peer; inclusive. That feels like the student is a team member with full participant in care provision, or has equality within a working relationship.

When exemplars that described disempowerment were analysed the phenomenon appeared to be related to the interaction during the experiential learning practice. Therefore the phenomena could not be described as a separate entity because various situations or conditions seemed to influence the actual interaction and the perceived outcome for the student. Disempowerment was placed as a category within the whole interaction as it appeared that one of the consequences or outcomes of the interaction was empowerment or with different conditions disempowerment could occur. The conditions that appeared to set up the feeling or perception of disempowerment were as follows.

\section{- DISEMPOWERMENT OCCURS WHEN THE TEACHER OR PERSON WITH POWER}

IS: non professional; condescending; does not allow student real experience that provides valid learning; compares students to others; labels; puts down; patronises. When challenges or questions asked are: personalized with the teacher being defensive. When power is pulled to stop a student questioning or when adult to child or parent to child interactions are a feature of the interaction. When destructive criticism is given the student feels a lack of power and does not learn from the experience. The outcome of this lack of learning results in decreased levels of confidence in self and lowered self efficacy as a nursing student.

This analysis confirmed that the interaction between the student and teacher was pivotal to the learning situation being empowering.

At this stage the secondary model of the process of empowerment was developed by including all identified categories and the main concepts within them. 
Figure 6.3 Secondary Model developed from analysis of all interview data

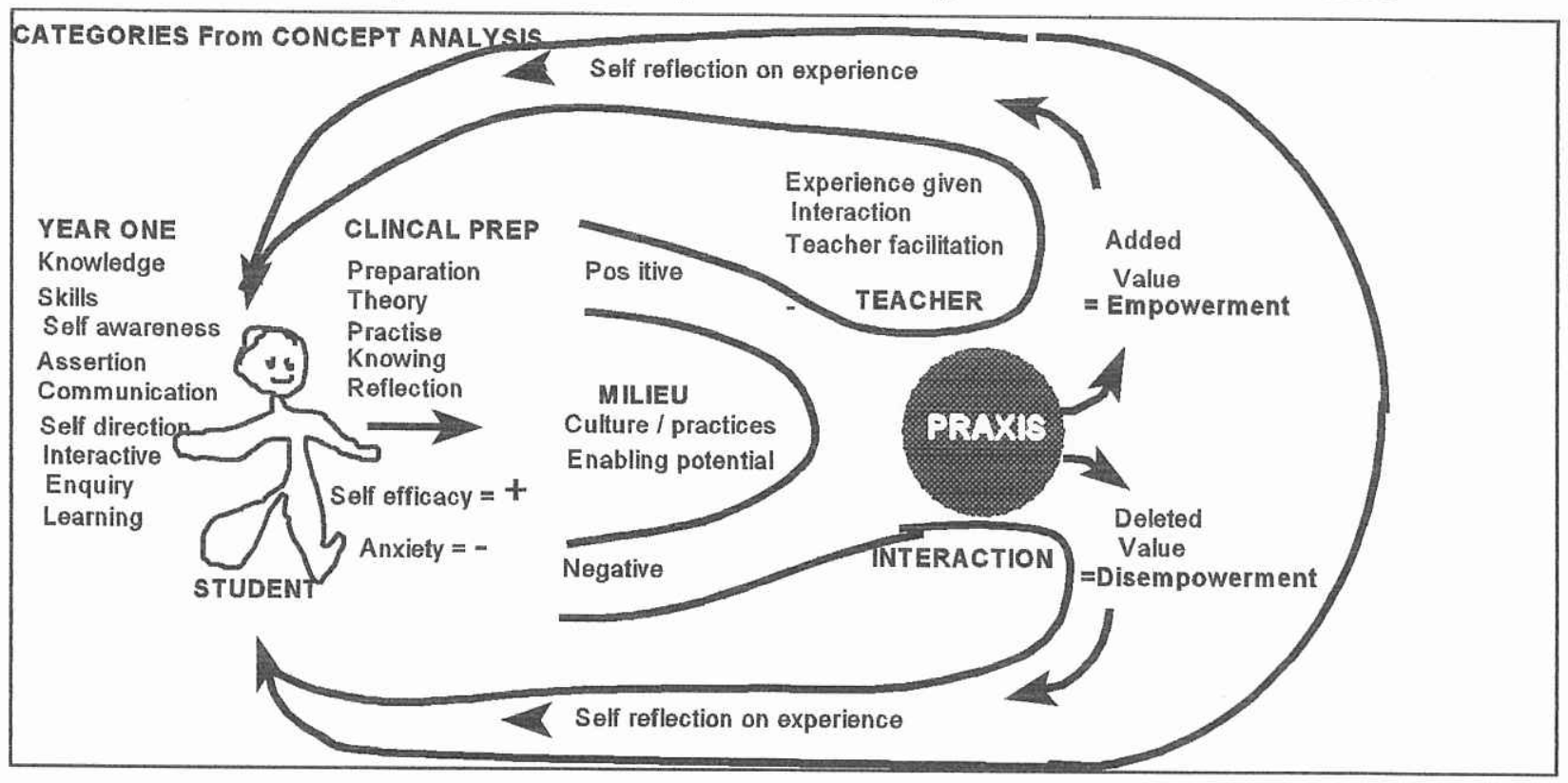

\subsection{Conclusion}

In this section data analysis of interview transcripts that served to generate concepts and categories was presented. The analytical process that culminated in the development of a theoretical model (Fig 6.3)was also described. Following this stage further literature served to expand and clarify the model. The literature, initially referred to in section 6 . will be discussed in depth in section 7 . 


\section{Articulating the theory}

\subsection{Theory Development through Reference to Literature}

This section discusses the literature that was considered whilst developing the theory during line by line concept analysis of individual interview transcripts.(Section 6)

During interviews participants were asked how they felt about their learning ability at course entry and at the time of interview. The rationale for this question was to elicit basic information about, and initiate discussion of, student learning. Interest in differences in self perception of learning ability prompted my exploration of self belief or the concept of 'learner self efficacy'.

\subsubsection{The Place of Self Efficacy}

Bandura (1986) proposed a social cognitive theory he named the Social Foundations of Thought and Action within which he described and discussed the concept of self efficacy. Perceived self efficacy is defined by Bandura (1986) as

peoples judgements of their capabilities to organize and execute courses of action required to attain designated types of performances. It is concerned not with the skills one has, but with the judgements of what one can do with whatever skills one possesses. ( $p$ 391)

Bandura (1986) proposed that conceptions of personal efficacy are important because self referent thought serves to mediate the relationship between knowledge and action. A person may not perform an action if they do not believe that they are capable of successful performance, in spite of knowing how and what to do.

In relation to nurse education competent functioning in a clinical situation requires skill competency, knowledge, and self belief of efficacy before a student is enabled to act effectively. In the current investigative context two different pre-conditions may effect performance. Knowledge and / or preparation may be lacking prior to the event, resulting in the student realistically perceiving lack of ability to act because of lack of competency, or the student may be knowledgeable and well prepared but not believe that they are capable of performing adequately in the clinical situation. The first of these situations requires the student to improve upon their preparation and / or knowledge, whereas the second, requires 
a change in the self belief of the individual before they can benefit from the learning experience offered.

I considered that if self efficacy had this potential to affect student clinical performance I needed to understand what brought about and influenced this self referent thought.

Bandura (1986) suggested that most self perceived outcomes flow from actions, or that success leads to belief in one's own ability.

In the current study some participants described how assessment success was one reason why they now felt confident and able. For example at course entry Glenis felt surprised that she had been accepted into the programme, but because of her success in her studies she felt that she could achieve to the highest level by midway through her second year. In Glenis's case I would consider that the outcome of her self efficacy had followed realistic appraisal of her proven ability.

Bandura (1986) stated that reasonably accurate appraisal of ones own capabilities is important to successful functioning and that we tend to avoid tasks or situations we believe exceed our capabilities and choose tasks we think we can handle. Over-estimations of capabilities can cause problems by undermining credibility and leading to failure. On the other hand, underestimation can be self limiting.

In this study the situation in which Robin found himself, when advocating for a client without knowing what the 'rules' of the situation were, could be viewed as an example of overestimation of capability. Alternatively, Meredith's withdrawal from school prior to sitting school certificate, and the nursing programme prior to the final year, in spite of successful completion of assessments, could be viewed as an underestimation of capability.

Bandura (1986) stated that the most functional estimations of ability are those that allow us to slightly exceed what we think we can do, or tasks that provide a realistic challenge and therefore provide motivation and progressive development of learning.

The aim of a planned education programme such as the current nursing programme at Whitireia is to provide a course of study that gradually builds on knowledge and competence so that students can demonstrate ability to achieve and be rewarded by ongoing success. 
Self knowledge about one's efficacy, whether accurate or faulty, is based on four main sources of information (Bandura 1986) that are all relevant to nursing education and specifically to the information given by participants in this investigation.

- The first information source is 'Performance Attainments', or assessment successes.

Robyn, Glenis, Liam and Elisapeta all discussed how success in assessments had given them more confidence and belief in their ability to succeed in the programme.

- The second source is 'Observing Others Performance'. (Bandura 1986)

Again several participants described how, by using the expert nurse as a role model they learned how to perform in the clinical situation. This way of learning is considered important in any educational process (Jolley and Brykczynska 1993) as well as specifically in the exploration of the concept of empowerment. As already stated I consider that students of nursing are more able to empower clients if they have been empowered themselves and have witnessed nurses and nurse educators who empower others in their nursing and teaching roles. Learning the skills, understanding and knowledge required of an autonomous nurse practitioner is very complex. Although much can be taught in simulations and clearly defined stages and processes, the power of observing how an expert nurse practitioner adapts to the context and individual needs of a specific client cannot be under-estimated when an expert nurse is a role model for a student nurse. An example given was the experience that Glenis reported when the actions of the expert nurse ${ }^{1}$ gave her a sense that she could learn the complex skills she observed with more knowledge and experience.

- The third source of information that impacts on personal efficacy is support, or 'verbal persuasion' from others who perceive capability ( Bandura 1986).

The strategy of supporting and verbally affirming students is used in many educational contexts. It is recognised and valued as a powerful teaching strategy at Whitireia Community Polytechnic where nurse lecturers have a strong belief that success is possible for every student (Pearson et al 1996). Clinical teaching situations are also supported by this strategy. Students are visited on a regular basis by a tutor as well as being assigned to a specific nurse in the area in which they are working. The aim is to give the student support,

${ }^{1}$ The term nurse expert will be used throughout to describe a tutor / lecturer, preceptor, buddy nurse or nurse teacher of students. The rationale for usage of this term being the identification of 'nurse expert' by participants as a precondition for an empowering teacher 
affirmation and the feedback needed to assist their successful performance. It was cited by participants that situations in which nurse experts praised what they had done, and that nurse experts' perceived that they were capable before they were given experiences relevant to their stage and ability were important to their learning. This support and provision of relevant experience provided a challenge and consequently increased the student knowledge base.

- The fourth source of self knowledge about one's self efficacy was described by Bandura (1986) as the influence of the physiological state of the individual on their capability.

This refers to the level of anxiety and tenseness present in the student that can influence performance and may be demonstrated by agitation or other physiological signs of fear. Bandura (1986) stated that

by conjuring up fear provoking thoughts about their ineptitude people can rouse themselves to elevated levels of distress that produce the very dysfunctions they fear ( p 401)

Elisapeta gave an example of this happening when talking generally about her learning ability and specifically about her anxiety concerning mathematics. Later Elisapeta described her actions in a clinical situation, when she was asked to calculate drugs and she stated that she had not been able to perform fast enough because she was anxious to a degree that caused her to fumble and make errors. Ottens (1984) referred to this situation in the context of academic anxiety and the consequential effect of self talk and how it can affect performance. Ottens (1984) stated that...

Math is an academic area in which low self efficacy often surfaces. The student avoids all tasks involving math, and on those occasions when confrontation with math is unavoidable the student expresses lack of self efficacy ("I can't do it "), rehearses for failure, and emits a stream of task disruptive inner speech. (p 56)

Other studies of student nurse learning have found that anxiety (Peirce 1991) or concern and fear (Jarvis 1993) are emotions that many student nurses experience when they are in clinical learning environments.

In light of these sources of influence on self efficacy I considered that I needed to further explore how, apart from altering and idealising all learning conditions (an impossibility), students could gain a different belief in themselves and perform to their level of actual competence. 
Bandura (1986) contended that the extent to which we alter our perceived efficacy through performance experiences will depend on the difficulty of the task, the amount of effort required to perform the task, the amount of assistance given by others, the circumstances, and the pattern of subsequent success or failure. Basically individuals learn from real performance, they are not fooled into believing they can do something if it is too easy, or if someone else does most of it for them. Success achieved with 'external aid' is said to carry less efficacy value for the individual because the success is likely to be credited to external factors rather than personal capabilities. Bandura (1986) also considered that effort is inversely related to capability, and when periodic failure occurs but continual improvement or learning gains are made over time due to persistent effort, it is more likely that perceived efficacy will be raised. This means that those who regard themselves as highly efficacious may ascribe a failure incident to insufficient effort, whereas those who regard themselves as generally inefficacious view the cause of a failure incident as stemming from their overall lack of ability. When some failure is encountered but continual improvement occurs (such as with current participants completion of the first year of the programme), an increase in self efficacy results.

These notions are linked to the notion of 'learned helplessness' ( Seligman 1991). Seligman proposed that learned helplessness can lead to a depressing or apathetic view of life and consequent lack of action that may result in failure, whereas the opposing feeling of power and control of ones life circumstances can lead to an optimistic and proactive view of life that is more likely to incorporate new challenges and successful outcomes. These two opposing positions can be viewed as two ends of a continuum. Seligman considered that three conditions: 'explanatory style'; 'stability of thought', and; 'generality of situation', affect the feeling of personal control or feeling of helplessness that an individual holds. These conditions also influence how we perceive our ability. Our perception of the amount of power we have stems from parental patterns of treatment of failure events which are subsequently reinforcement or altered through confirming or disconfirming life experiences.

\section{Seligman (1991) considered that:}

- 'Explanatory style' is important in the perception of failure, as explanations can either be internalised and failures ascribed to personal factors, or failure can be externalised and outside factors used to explain an event outcome.

- 'Stability of thought', is concerned with the enduring nature of the explanatory style, which depends on whether the individual perceives that they always fail at everything, or whether they believe that failure may happen occasionally.

- 'Generality of situation' is concerned with whether the cause of failure or success is perceived by the individual as operating in many situations, or in only a few. That is 
whether the individual perceives that they are inadequate at everything they attempt or whether perceived lack of ability only applies to specific skills.

Attributing ones failures to personal deficiencies of a general and enduring nature, can cause a more profound sense of self inefficacy. This may lead to those who hold a personal sense of self inefficacy becoming passive, as they feel that whatever they do will make no difference to the outcome of any event. This is the condition of 'learned helplessness' at one extreme end of a continuum, with the opposite end being 'learned optimism' (Seligman 1991). Learned optimism is characterised by failures being perceived by an individual as short term, specific set backs due to external causes. A person who perceives 'failure' in an optimistic light is more likely to remain confident and gain success in further achievements, but if they are totally optimistic they may tend to hold unrealistic expectations and not always learn from failure experiences.(Seligman 1991)

I consider that the position of greatest benefit for proactive learning is probably between 60 to 90 per cent on the optimistic side of the continuum.

I also consider that these ideas are strongly linked to the theory of external and internal locus of control as determined by Rotter (1966). The social learning theory of 'locus of control' refers specifically to an individuals source of control over events. Those who believe they have control over things that happen to them are determined to have 'internal locus of control', whereas those that believe forces such as luck, fate or powerful persons have control over what happens to them are determined to have external control (Rotter 1966). Internal locus of control allows individuals to achieve more, be more motivated and more resistant to manipulation, whereas individuals with external locus of control are more fatalistic and conforming to manipulation (Rotter 1966). Internal locus of control is supported by encouraging independent functioning, whereas external control is fostered by encouraging dependance authority figures. Dawson (1994) suggested that facilitation of internal control behaviours in nursing students would lead to empowerment in students and so in ultimately in practicing nurses.

I would contend that the individual who holds low levels of self efficacy is also likely to have an external locus of control and consequent to these states be passive in the pursuit of their own learning needs. I also consider that this passive position is the traditional situation of nurses trained in the apprenticeship, behavioural based curriculum mode. In traditional apprenticeship style training the student nurse could do little to influence their learning experience, and passivity and compliance were encouraged (Jolley and Brykczynska 1993). Whereas I consider that when nurses are educated to become critical thinking, autonomous 
practitioners they are more likely to hold higher levels of self efficacy, have internal locus of control and take a proactive stance towards their learning needs. Current nursing education undergraduate programmes aim to encourage students to be self aware, self assertive and proactive in their own and their client's best interests. In the Whitireia nursing programme independence in learning is an aim for students by the end of Year One (Pearson et al 1996).

Bandura (1986) determined that efficacy judgements could vary in several dimensions that have important performance implications. He also stated that generalising with respect to all or some activities and situations is important, and that the level of difficulty of the task and the strength of belief of the individual about their ability can affect performance. If from one failure a person generalises that they are not capable in any particular domain Bandura (1986) considered it would be more difficult to encourage their belief in any possible success because:

- if a task is perceived to be too easy the person does not gain increased self belief in their ability as they know that no new learning has occurred for them; or,

- If the strength of belief of inefficacy is weak, it is more readily changed with successful experiences, and if the belief in inefficacy is strong it is more difficult to change thought patterns in spite of some successes.

Application of these considerations to the present situation led me to contemplate that perhaps each individual student had a different level of self efficacy that could be increased or depleted depending on learning success. A student may enter the programme with low self efficacy ( as many participants described) and following success feel a stronger or increased level of self efficacy. If, however, a sense of failure was perceived by the student the level of self efficacy would be weakened or lowered. If the level dropped too far and was not replenished the student may withdraw from learning. Alternatively if the level was constantly strengthened or raised the student would feel more able to engage in further learning experiences.

Bandura (1986) also stated that self efficacy can be undermined by relinquishing personal control. He considered that in situations where control would carry responsibility above the 'comfort level' for the individual, some people would give up control to free themselves from performance demands. In other cases personal efficacy is undermined by others who have power over them.

When people are cast in subordinate roles or are assigned inferior labels implying limited competence, they perform activities at which they are skilled less well than 
when they do not bear the negative labels or the subordinate role designations.

(Bandura 1986 p 449)

I would consider that when students of nursing enter a new clinical environment the level of responsibility for a patient's life may be overwhelming if a student is not adequately supported. The traditional apprenticeship role of student nurse includes waiting for a nurse expert to assign a task, rather than for the student to have the opportunity to ask for the learning experience they may want or need. Although it is not appropriate for students to organise their own clinical experiences at the Year Two stage (Heron 1992) of this programme participant evidence suggested that greater learning was experienced when a nurse expert and the student were able to discuss learning goals and appropriate practice experience prior to the event. If there was dialogue about expectations and capabilities the likely result was that the nurse expert was more informed of the ability level of the student and therefore was able to assign safe, appropriate responsibility for client care. When this occurred the student could meet the challenges set and learn from their experience through successful practice. If however the student could not negotiate appropriate experience or was pre-assigned an inferior label, with consequent assignment of menial tasks (as was the case with Elisapeta) then less learning was possible, so reinforcing the student's and the nurse expert's perception of lack of student competence.

Bandura (1986) considered that low self efficacy occurred when performance requirements were ill defined, the persons ability level was underestimated and task demands produced errors. The results of this study confirm this, since statements about how the overt curriculum assisted them to learn in the Polytechnic situation through knowing exactly what was required, and at what level competency was expected. Whereas, in the clinical situation, where not all nurse experts had teaching skills, different messages and expectations left students in the situation of not knowing what was expected, resulting in inexperienced guesses that could, and on some occasions, did lead to mistakes being made.

Two participants discussed the above situation. Liam stated how having guidelines to provide client care helped him to know what to do and acted as a check for his practice that was backed up by a supportive nurse expert. Robin however, gave an example of not acting correctly in a clinical situation because he was left on his own and had not been given guidelines relevant to the situation he found himself handling.

These experiences could also be seen to arise from what is referred to by Carlson-Catalano (1992) as demonstrating the existence of a covert curriculum in nurse education, and by Jolley and Brykzcynska(1993) and Bevis (1988) as the hidden curricula. Carlson-Catalano 
(1992) Jolley and Brykczynska(1993) and Bevis (1988) considered that the covert or hidden curriculum encouraged the acceptance of the norm or status quo and was characterised by mechanistic learning and an emphasis on technical routines of care and conformity to the teachers view of nursing. This type of curriculum emphasised the values of service and hard work and tended to promote isolation, passivity and subordination (Carlson-Catalano 1992). An overt curriculum however is one in which the teacher consciously encourages activities that stimulate the exchange of ideas and analysis of problem situations, and so creates an environment of encouragement, motivation and sincere colleague ship.

Current participant information strongly supported the fact that it is the overt curriculum that leads to empowerment in learning.

The influence of formal school education on self efficacy was evident from information given by participants in this study. Many of them stated that they had low school achievement on course entry and most, as a consequence, had low perceptions of academic ability unless subsequent academic success had altered their perception (as was the case with Robyn). Bandura (1986) believed that self efficacy is developed in stages from birth, and that each life stage provides different challenges that could either effect efficacy in a positive way or have a negative effect, depending on outcomes of actions. School is cited by Bandura as the place were children gain social validation and cognitive efficacy and he considered it was possible for school to increase cognitive efficacy or to undermine the sense of personal efficacy that is needed for ongoing self development. Competitive rankings used in schools always lead to failure for some children, and recurring failure or low achievement have lasting effects on personal efficacy in future academic situations. (Bandura 1986)

Robyn clearly stated how school served to work against her learning success and how being treated as an individual and as an adult in subsequent tertiary educational contexts assisted her learning and confidence in her learning ability.

\subsubsection{Facilitation of Adult Learning}

Knowles (1970) discussed the difference between the philosophy and practice of school or child educational pedagogies and adult educational philosophy and practice. He termed this Andragogy, defined as

The art and science of helping adults learn. ( Knowles 1970 p 38)

Knowles (1984) contended that the pedagogical model assigned full responsibility to the teacher for making all decisions about what would be learned, how it would be learned and if it has been learned. He described adult learners as having a self concept of being 
responsible for their own life decisions, therefore they required acknowledgment as responsible and capable of self direction in any teaching/learning context. Knowles (1984) also contended that adults learn new knowledge, understanding, skills and attitudes most effectively when information is presented in real life contexts.

Knowles (1984) considered that the andragogical model he proposed was not an ideology but a system of alternative sets of assumptions that included pedagogical assumptions. The role of the teacher in the andragogical model is to provide conditions of learning where:

- The learners feel a need to learn.

- The learning environment is characterized by physical comfort, mutual trust and respect.

- Mutual helpfulness, freedom of expression and acceptance of differences exist.

- The learners perceive goals of a learning experience to be their own goals.

- The learners accept a share of the responsibility for planning and operating a learning experience and therefore have a commitment toward it.

- The learners actively participate in the learning process.

- The learning process is related to, and makes use of, the learners experience.

- Learners have a sense of progress toward their goals.

Knowles (1984) discussed how a pleasant learning environment improves learner productivity and how a climate of mutual respect is the most important condition for learning. He also stated that trust, support and caring are essential components of providing a satisfactory learning experience. Support of the need for caring in nurse education has been proposed by Diekelmann (1990), Bevis (1988) and Watson(1985,1988). As previously discussed Diekelmann proposed a curriculum that was focussed on meaningful dialogue. Watson (1988) stated that nursing had in the past neglected the moral context of health and human caring and proposed that

nurse education must attend to education of the whole person and recognize that learning is subjective, contextual, dialogue and values driven. ( $p 1$ )

All the above points made by Knowles $(1970,1984)$ are relevant to the current investigation. In fact many of the conditions Knowles described as being essential to successful learning were identified by participants in this study as being factors in their feeling empowered by a given learning experience. For example the student / teacher relationship and how a student is treated by a nurse expert or teacher when empowerment takes place was described by participants as being respectful, being treated as equal, being in partnership and being symbiotic. This evidence supports the theory proposed by Knowles as being an 
appropriate model for teaching, in that it enhances learner empowerment for this group of adult learners.

The idea of adult learners sharing the responsibility for planning and operating a learning experience has also been discussed by Heron (1992), who believed that the role of the teacher is to integrate the authority of the facilitator and the autonomy of the learner. Heron considered that the person with authority has three possible decision modes which were:

- Direction, which is deciding for others.

- Negotiating, or deciding with others.

- Delegation or handing over to others.

Heron contended that learners need to be guided to autonomy and that initially they require direction, guidelines or 'ground rules' to allow them to develop security and knowledge about the culture and milieu of the new learning situation. Following an initial period of 'direction' a 'co-operative' phase where learner and teacher work together should take place before 'autonomy' is given to the learner (Heron 1992).

Heron ( Hunter et al 1994) has also discussed these stages in terms of three forms of power. - Power over, which is deciding for others.

- Power with, or shared power, which he equates with deciding co-operatively and negotiating with others.

- Delegating power to, which is defined as handing over decisions to others to make autonomously.

Heron (1992) considered that the amount of direction, negotiation and autonomy possible is variable and depends on the context and experience of the learners, and that it is the role of the teacher as expert to decide the appropriate progression and degree of autonomy for the individual learner.

The role of the teacher of adult nursing students, is to provide appropriate learning experience that moves the learner towards autonomy (Heron 19921994 Knowles 1970 1984). According to my analysis the student needs to be prepared and committed to learn at the outset. The nurse expert needs to ensure that guidelines appropriate to the experience are given to the student, and then he or she needs to work co-operatively with the student to ensure that they are safe and able to work with a client, with some degree of autonomy. At different stages of their education different levels of direction, co-operation and autonomy are appropriate for different nursing students, depending on their knowledge, skills, attitude and ability. It is the teacher as expert nurse who decides the appropriate progression for the student, with a focus on increasing the level of self direction and autonomy over time. 
Heron (Hunter et al 1994) discussed that the expert 'facilitates', rather than teaches in this process, and that the Facilitator's role is ultimately one of redundancy.

Hunter Bailey and Taylor (1994) discussed facilitation as an art that has underlying values of respect, honour, accomplishment, fulfillment and integrity. The important factors are that facilitation is not about giving advice (unless it is asked for), but that it is about being with another person, accepting the world views of others and listening to others. Hunter et al (1994) also discussed the importance and need for the Facilitator to be aware of themselves and what they project onto others. Heron (Hunter et al 1994) defined Facilitation as

Empowering people to be self determining in the context of a relationship with other self determining people. So it's about the interaction between autonomy and co-operation in human beings, and enabling people to develop this, enjoy it and affirm more of it in their lives. ( $p$ 216)

Boud and Walker (1990) have conceptualised how experience based learning is an interaction between the learner and the learning milieu, that requires expert facilitation. They define the learning 'milieu' as more than the physical environment because:-

It embraces the formal requirements, the culture, procedures, practices and standards of particular institutions and societies, their immediate goals and expectations of any facilitator, as well as the personal characteristics of individuals who are part of it. ( $p$ 65)

Boud and Walker (1990) considered that important dynamics in the interaction involve what the learner brings to the milieu, and that it is the learner's involvement with the event that constitutes the learning experience. The learners intent, ability to notice what is going on whist interacting, and ability to intervene to change events so that their intent or learning goals are met, are all important factors in the interaction and outcome. The other important action within the learning experience is the ability to reflect on the experience and so to learn from it. Boud and Walker (1990) postulated that the Facilitator has a role in the preparation of the learner, support through the learning interaction and facilitation of meaningful reflection during and after the event.

To clarify the situation within the current context a diagrammatic representation of possible interactions within the learning milieu was developed. (Fig. 7.1) 
When placing current participant experience within Boud and Walker's (1990) theoretical framework I considered that if a student was disempowered by the learning experience either due to lack of preparation, incongruence of teacher / student intent or disempowering interaction, individual self reflection on the experience caused lack of confidence and lowered self efficacy. However, if a student was coached, assisted or facilitated in the reflective process, following the experience, the student appeared to be able to notice what contributed to the disempowering experience. This reflective intervention helped to create a different perception of the experience from which the student was more able to emerge having learned from the experience, and having gained insight as to how an empowering experience would subsequently be possible for them.

\subsection{Diagrammatic representation of possible actions within the learning milieu}

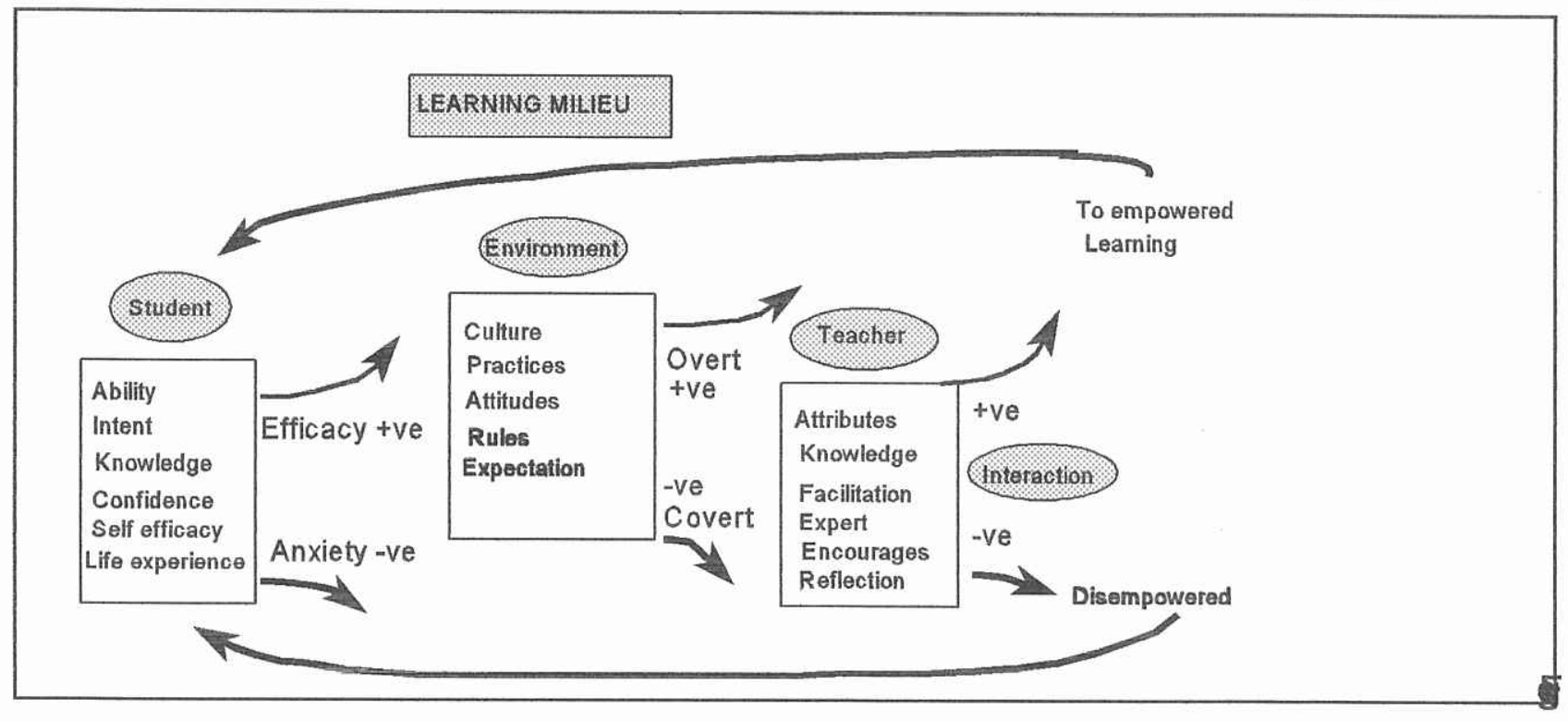

The key I consider is the facilitation of the whole process of learning. Students need individual facilitation to develop the skills required in order to be able to learn in a clinical environment. They require preparation both theoretically and clinically, with knowledge, practical skills and personal self awareness, self efficacy, esteem and confidence in order to fully participate in the learning experience. The experiential learning situation needs to be facilitated so that the student can negotiate the milieu and fully engage in praxis. Following the learning experience, facilitation of the reflective process is required to assist with further learning irrespective of whether 'empowerment' or 'disempowerment' was perceived to occur consequent to the actual event. Assisted reflection is more important, in fact crucial to meaning being made of the experience by the student, following a disempowering learning experience. 
I therefore contend that Heron's (1992) definition of the 'facilitators role' strongly supports the need for all nurse experts who teach student nurses to be educated in teaching methods and learning processes that work towards facilitating student learning.

Recent developments in this direction within a nursing education context have included 'preceptorship training' for nurse experts working in clinical situations (Peirce 1991, Caine 1994, Atkins and Williams 1994) as discussed below.

\subsubsection{The Role of the Preceptor}

Peirce (1991) stated that the role of the preceptor is usually a 'one on one', reality based clinical experience in which the expert nurse supervises the learning of the student nurse (Peirce 1991). According to Caine (1994) the preceptor role goes beyond orientation. Caine (1994) defines orientation as

the passive process of acquainting someone with the organizational and clinical settings and directing the new person towards the interests of the organization (p 59)

I would suggest that orientation is part of entree into the milieu, whereas Preceptorship provides a supported position for the student. According to Caine (1994) Preceptorship includes

an emphasis on independence in the clinical and organizational setting. In a preceptorship we think of a triad of individuals: the preceptor, the preceptee and the individual who puts them together. (p 59)

The benefits of the preceptorial learning experience are that the Preceptor has been educated to teach the student and is therefore more likely to be aware of student learning needs, student abilities and their skills at different educational levels. Atkins and Williams (1994) in a study in the USA on the role of the registered nurse as mentor found that mentoring or being a preceptor for undergraduate students was a complex and skilled activity that required educational preparation, support and recognition. The role of the preceptor was to support students, facilitate their learning, and work in partnership with them.

Peirce (1991), when engaged in a study of student nurses who worked with preceptors, considered that a preceptor was more likely than a 'buddy nurse' to provide the student nurse with relevant clinical experiences and was also more able to spend longer periods of 
quality time with the student than a buddy nurse or visiting teacher. Peirce found that the school, the hospital and the student all contributed to the clinical learning experience.

Many of the findings in the study conducted by Peirce (1991) are supported by participants in this current study. Participants in the current study compared the two hospitals where they were assigned and spoke positively about the one in which they worked with prepared preceptors. Robyn was especially forthcoming about the value of the one-on-one learning experience provided by a Preceptors, and the value of having an expert nurse preceptor as a role model, with whom she could work and communicate with, in a manner that facilitated her learning experiences.

This confirmed the findings of Peirce (1991) who also found that preceptorial experience supported student independence, involvement with other nurses and provided a safe situation in which to try new skills. Peirce also determined that planning of care that was supported by a preceptor gave the student a feeling of being organised to complete specific assignments as well as giving them the opportunity to interact positively with staff. That although students continued to have anxieties about their ability in clinical and worries that included harming the patient, not knowing what to do, being assessed, and making medication errors, they felt safer if they could discuss these issue with a preceptor to whom they could relate. Clinical days that students determined were 'bad', were those when insufficient time was spent with the preceptor, and when the student felt that there was lack of direction, observation of nursing care was the only practice possible, and when they were assigned to an 'inappropriate' patient (Peirce 1991). Students disliked the preceptor programme when: the preceptor was unsure of their role; the student was treated as a nurse aide rather than a student nurse; the student was not assigned to do what they were capable of; the preceptor did not orientate them; the preceptor did not seem to like them; the preceptor was not attentive to their needs and the preceptor made them feel helpless (Peirce 1991).

As previously stated many of the conditions found by Peirce (1991) were similar to findings in the current study, and although preceptor programmes are apparently more likely to overcome many of the difficulties that student nurses encounter during their clinical experience a preceptor programme does not always preclude learning difficulties for all students.

In the current study Elisapeta appeared to be the most disadvantaged student in the clinical situation. Enquiry led to the discussion of assumptions of capability on the part of clinical agency staff concerning students who were different from the 'norm' in terms of ethnicity, body size, dress and skin color. As discussed earlier, the idea that one person is of lesser 
ability than others is based on beliefs and assumptions rather than demonstrated competencies and as such is patronising, and in this case racist. When such assumptions are made they exclude the 'other' and so perpetuate the belief of lack of capability by agency staff because appropriate experience is not offered to the person about whom the assumptions are made.

\subsubsection{Beliefs, Attitudes and Behaviours}

Mingay (1993) stated that the transmission of values, attitudes and beliefs impacts on the delivery of health care and influences the relationships nurses have with one another. The hierarchical structures (previously described in the first section ) traditional in health care institutions can allow those with limited power to abuse those with slightly less power. Short et al (1993), cited Ashley, (1980) who suggested that nurses have developed hostility towards each other as a method of dealing with their relatively low status in the health workforce.

They have accepted the misogynous (women hating) beliefs about women and release tensions by demonstrating horizontal violence towards each other. ( $p 28$ )

Student nurses can be targets of such abuse from registered nurses who may also feel threatened by students who are currently gaining higher levels of education than they hold at a time when structural reforms have resulted in casualisation of the workforce and threats to their job security. This abuse can be termed horizontal violence or victim blaming. Victim blaming usually occurs however when a person with slightly greater power and knowledge 'rescues' a person who they perceive as needing their help. Ryan (1971) considered that victim blaming occurs in the nursing profession and stated that

Blaming the victim is an ideological process, which is to say that it is a set of ideas and concepts deriving from systematically motivated, but unintended, distortions of reality. ( $p$ 11)

Ryan (1971) contended that although 'blaming the victim' is not an intentional distortion it (as does horizontal violence) serves the class interests of those who practice it. In this context the class interests could be interpreted as the maintenance of dependance or the passive 'handmaiden' role of the nurse trained through a process of covert socialization (Mingay 1993) which supports traditional patterns of dominance within, and of the profession of nursing. Bowman (1993) has also discussed the concept of victim blaming and defined it as 
attributing blame for a negative outcome to an individual when it's determinants lie outside the individual's control. ( p 268)

Bowman's discussion focused on the problems nurses have in gaining power in the workplace in a system where nurses are constrained by their subservient relationship with the medical profession and with the institutions in which they are employed. McCurdy (1982) proposed that female nurses enter a hospital power system with sex role socialization handicaps, and that they may either sabotage nursing as a group to gain individual power, or exert power over subordinates when they feel powerless within the institutional hierarchy. Bowman (1993) suggested the solution lies within greater power sharing and collegiality amongst nurses, and suggested that this could be accomplished through the changing curricula in nursing education by developing greater political awareness and including feminist ideologies. Bowman (1993) further suggested that

nursing education can encourage resistance and foster agency in nurses. It can teach nurses to interrogate their practices and traditions, to confront their oppression, and to become more attuned to the voices of marginalized people. (p 273)

The philosophy behind this suggestion is that of assisting nurses to become more self aware and critical with respect to their own situation in society. Critical reflection undertaken by nurses engenders the need to confront the way marginalized persons have been kept out of professions such as nursing because they are different from the 'norm'. Suggestions as to how this change can be managed are to be found in ideologies of 'inclusion', 'education for diversity', and in New Zealand, 'cultural safety'.

Pearpoint and Forest (1994) believe that Inclusive education can overcome racism and sexism because within it is the conscious philosophy that no person is ineducable, that all people can learn, and that all learning is legitimate. They state that:-

Inclusive education therefore acknowledges that all people are diverse in their cultures and individualism. Inclusive education honors this diversity and attempts to find the most effective method for all students to fully participate and learn. (Pearpoint and Forest 1994, p 5)

Peirce (1993) proposed that in the USA, the need to address the challenge of cultural diversity in education requires culturally competent educators. Peirce (1993) citing Cross (1988) proposed stages of cultural competence on a continuum. 
- At the first, most primitive and least conscious level, persons and organisations seek to destroy a different culture out of fear and the belief that the other culture is inferior to their own.

- The second level is 'cultural incapacity', where ethnocentric views seek to assimilate differences and ignore the strengths of different cultures. This stage tends to blame and rescue those who are different.

- Awakening to one's own biases and prejudice in relating to difference is defined at the next level and termed 'cultural pre-competence'.

- 'Cultural competence' is characterised in terms of having respect for, and acceptance of difference, self monitoring regarding cultural bias, and sensitivity to the dynamics of difference in interpersonal, group or organisational interactions.

- 'Advanced cultural competence' is placed at the most positive end of the continuum where an advocacy and educative role, aiming towards taking responsibility for transformative change in society stance is assumed.

Peirce (1993) considered that 'critical education for diversity' can be supported by creating a climate, and structures, to support this goal, by modeling critical thinking through encouraging openness to inquiry, and through respect for other points of view. Dialogue, discovering self and others, challenging assumptions and building interpersonal communication skills and knowledge are also necessary for goal achievement (Peirce 1993).

In New Zealand nursing education curricula the concept of cultural safety has been included as a essential competency for all nurses registering from a three year undergraduate comprehensive education programme (Ramsden and Spoonley 1993). Teaching methods that assist competency development aim to provide the climate and structure of critical education for diversity proposed by Peirce (1993) at the advanced level. Teaching sessions however, have, on occasions become opportunities to attempt indoctrination of students with 'politically correct' ideologies without encouraging dialogue and openness to enquiry (Ramsden and Spoonley 1993). The need for nurses to understand how the monocultural nursing service has not met the needs of the Maori people is considered paramount in this education (Ramsden and Spoonley 1993). However, understanding the role of economic, political and cultural systems within New Zealand society is also an essential element of this educative content. A problem can occur if those teaching cultural competency are not at the upper or positive end of the continuum of cultural competence (Peirce 1993). If teachers demonstrate cultural competence they are more able to act as role models in critical thinking and encourage students to progress in a manner that can lead to personal valuing that will change their attitudes, beliefs, and so their behaviours. I contend that if teachers are not culturally competent attempts to indoctrinate students are more likely. 
The experience that Elisapeta described demonstrated how a nurse who did not demonstrate appropriate cultural competence could continue to act in what they may think are the best interests of 'the other', but in fact serve to maintain victim blaming or rescuing behaviours that did not assist 'the other' (Elisapeta) to become empowered.

Rescuing and persecution of students can also occur within the student nurse / nurse teacher interaction. Findings of a 1993 study of first year nursing students at Whitireia (Pearson et al 1996) involved teacher reflection on how student dependance may be maintained for the self gratification of the teacher, who rescued 'victims' and subsequently persecuted the student (victim) if they did not ultimately achieve independent learning. Teachers in this study, the majority of whom were products of hospital 'training' programmes, also considered that as nurses they probably acted in this manner towards clients / patients. Alterations in these patterns of behaviour were made through the development of critical social and self awareness, and of communication and assertion skills for both students and teachers. The aim in altering these negative patterns of interaction was to encourage both parties to maintain healthy positions in the 'Winner's triangle' which Choy (1990) believed could be maintained through self awareness, self assertion and competence in communication.

As previously discussed in Section 3, current ideology on which nurse education curricula are based state that the development of independent, autonomous critical thought is essential for competent nurse practitioners (Bevis 1991).

Critical thinking and the application of such ideas to practice, and the notion of 'praxis' are linked to the ideology of change through educational experience.

\subsubsection{Praxis}

As explained in Section 6, during the process of analysing the responses of the participants and developing the theory, the concepts and categories that included the interactions between the student and nurse expert were collapsed into the category of Praxis. This concept was chosen because the of the nature of the information given by participants and suggested to me that praxis was taking place during experiential learning. As previously stated Freire (1972) defined praxis as

reflection and action upon the world in order to transform it. ( $p$ 28)

Bevis (1991) described praxis as being 
one of the fundamental concepts necessary to understand practice fields such as nursing and teaching.

Bevis considered that there were four aspects that influence new curriculum directions in nursing which are:

- That it is connected with transforming society through critical and feminist theory;

- That it is guided by truth, justice and caring;

- That it reconstructs the social setting by changing traditions;

- That it is dynamic, fluid, and mutually constructed, demanding reflection between; elements in order to discover contradictions that require new constructive thinking.

Bevis (1991) further stated that to be viable to specific fields of practice, the characteristics of praxis needed to be reality based, phenomenological in occurrence, inquiry orientated, include reflective action, be able to alter both theory and practice, and be able to provide a guide to further practice. Bawden (1993) in his discussion proposed that praxis was

a three dimensional phenomenon - a dynamic system of learning, generated by the interactions between theory, practice and praxis. ( $p 2$ )

Where

no one element is prime, but each contributes to, and indeed participates in, the others. ( $p$ 2)

Bawden, referring to Reason and Heron's (1986) concept of the three kinds of knowledge that are used in experiential learning situations portrayed them in a triangular format. The knowledges portrayed were

- Propositional knowledge 'about' something defined as a THEORY for KNOWING, as one angle.

- Practical knowledge about 'doing' something represented as PRACTICE for DOING' as the second angle.

- Experiential knowledge which results in the transformation of personal experiences defined as PRAXIS for BEING, as the third angle.

Bawden contended that within the space formed by the triangle their was potential for these three dimensions to interact in dynamic and ever changing ways. Southwick (1993) applied Bawden's notions of praxis when writing the Whitireia nursing curriculum, which states. 
It is the transformative potential of the relational which we take from the Treaty and embed in our curriculum to illuminate the teaching /learning partnership, and the nurse/client relationship in nursing practice. (The curriculum philosophy, Appendix 3)

It was against this background that I considered the reality of the student interaction and learning experiences, and redefined them as both being part of the category of Praxis within the empowering process.

Freire (1972), Kemmis (1985), Boud Keogh and Walker (1985), Bevis (1988), Boud and Walker (1990), and Bawden, (1993) all discussed the importance of reflection as part of praxis.

\subsubsection{The Place of Reflection}

Boud Keogh and Walker (1985) considered that reflection was an essential element of praxis, as reflection allows an individual to construct new ways of doing things. Reflection in a professional learning context has been described by Schon (1987) as the way we develop new forms of understanding and action when familiar ways of doing and thinking fail. Schon proposed that students of a profession require practical learning experiences that

are reflective in that they aim at helping students learn to become proficient at a kind of reflection-in-action. ( $p$ 40)

This type of reflection I consider is the coaching or facilitation of student learning that is assisted by expert nurse practitioners working with students, during practice experience.

In the current study the preceptors and nurse experts that engaged in positive interactions with students in the practice setting encouraged students to think and reflect as they acted. Bevis (1991) contended that students of nursing need to be assisted to reflect on practice in order to make the links between technical and practical knowledge and reality during, and following experiential learning. Boud and Walker (1990) consider that reflection is essential to making the most of experiential learning in any context. They further proposed that the most useful strategies for learning through reflection are 'returning to experience', 'attending to feelings' and 're-evaluating the experience'. Boud and Walker (1990) considered that the

emphasis on reflection after the event attempted to provide a counterbalance to much current educational practice which does not leave sufficient time and opportunity for learners to process their experience before moving on. ( $p$ 61) 
Reed and Procter (1993) also supported the need for students of nursing to learn how to reflect and proposed that the keeping of a 'journal', where exemplars that include the feelings of the author during the experience is helpful. Street (1990) considered that a personal / professional journal provided valuable information about the development of professional practice and also on the process of reflection itself.

I consider that the participants in this study may have used reflection to assist their learning at three different times during the process of empowerment.

- Student participants used and were encouraged to use reflection (by the nurse expert, visiting tutor and in clinical tutorial groups) in order to understand and make links between theory and practice during the experiential learning process. This reflection assisted or formed part of Praxis.

The evidence for this reflection was when participants discussed the learning experience and how they had applied their technical and practical knowledge to new situations. Nurse experts who engaged in positive interactions with students answered and asked questions to help students consider new ways of doing things.

- Student participants self reflected on what they had learned and what had happened for them immediately following praxis, which lead them to consider that they had either been empowered or disempowered during the learning experience.

For participants who had been empowered the consequence of this reflection was an increase in self efficacy. For those who considered that they had been disempowered the consequence of this self reflection was a reduction in efficacy, in some cases generalised to more abilities than was deserved.

For example Liam's feelings following an assessment when he was told he had not performed well in all expected competencies. He generalised this feedback to include all his clinical competencies to the extent that he stated

I had a really hard time of it for a couple of weeks, two or three weeks.

Meredith who also felt disempowered after some experiences exited the programme in spite of her having successfully achieved in year two assessments. Elisapeta's feelings of efficacy lowered and she became more anxious in each new clinical situation as a consequence of each disempowering event.

- Student participants were assisted to reflect during interactions with visiting teachers and during tutorial sessions following their return to Polytechnic. This formalised 
reflection included the expectation that students bring an exemplar from their journal to class to where a lecturer facilitated discussion with their peer group.

I consider that this assisted reflection was most important as it enabled an alteration in the perception of the participant and allowed 'disempowering' experiences to become learning experiences. When this occurred, (as was the case with Liam in the above example) a sense of control over their situation was regained and high enough levels of self efficacy maintained in order for the student to want to engage in a further learning experience. If the student did not engage in assisted reflection following a disempowering experience as was the case with Meredith who avoided reflection, the consequence was a maintenance of the generalised state and a possible reduction in efficacy. In Elisapeta's case the assisted reflection that appeared to affect her self perceptions of ability the most occurred as a consequence of her engagement in this research study.

\subsection{The Tertiary Model}

Following consideration of the literature as discussed in the previous sub sections, and the concept and category analysis as described in Section 6, The Tertiary Theoretical model was proposed (Fig 7.2). This model intends to represent the active nature of the phenomenon of empowerment in the learning context as it was perceived and described by the participant group. In presenting this model my aim is to describe the complexity of each of the categories, how one impacts on another and how differing conditions may alter the outcome for the student at any different stage of the learning process.

\section{Fig 7.2 Tertiary Model of the Empowering Process}

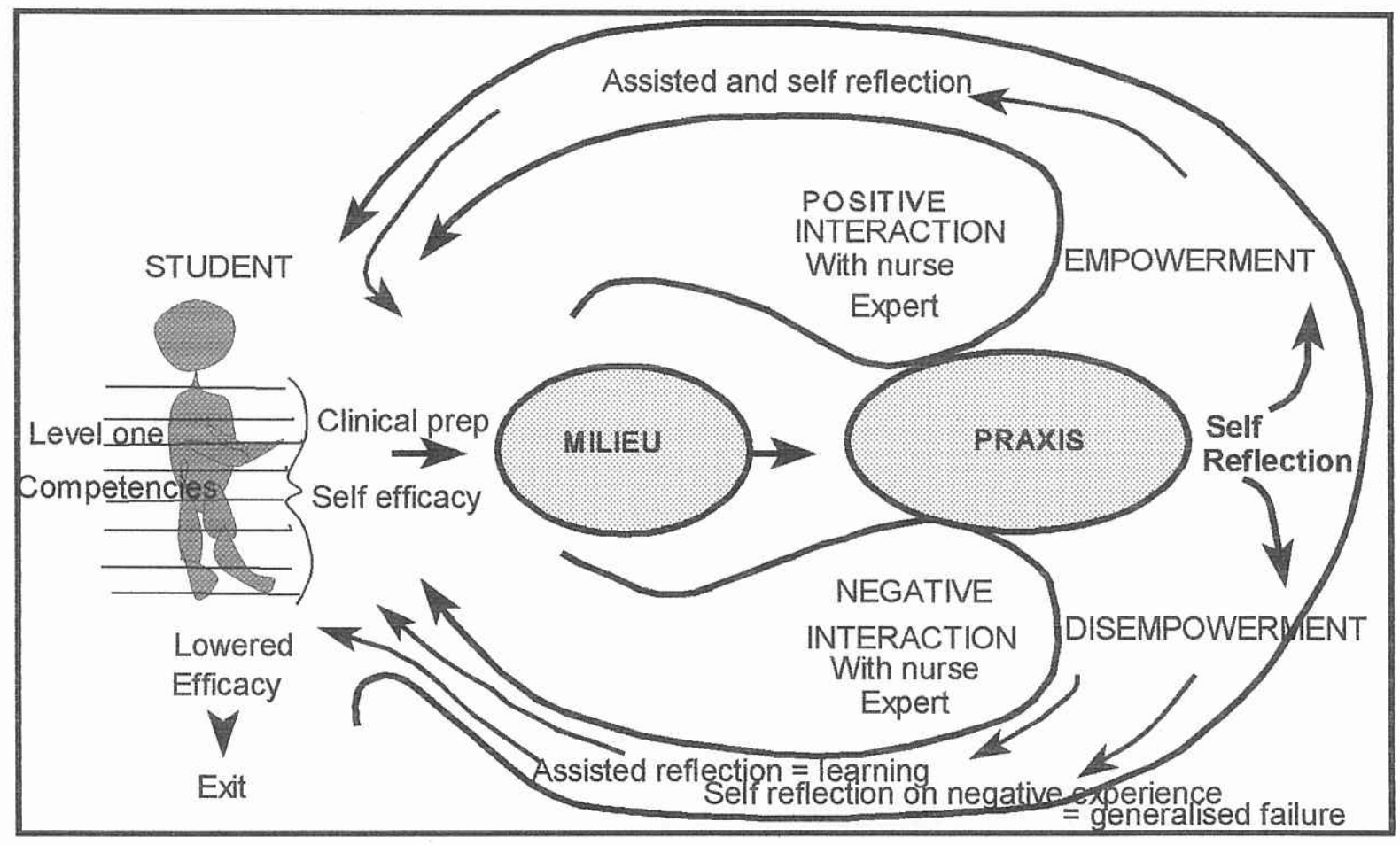


- The model shows the student (left) who is prepared for clinical placement by completing Year One papers including assessments and has therefore demonstrated appropriate competencies determined by success in assessments to allow learning success in Year Two of the programme.( Appendix 8)

- The student has individual levels of self efficacy based on previous learning success and failure accumulated from all learning experiences, but most recently influenced by their experiences in year one of the nursing programme. Motivation and desire to engage in and to make the most of each learning experience or what the student brings will also be influenced by personal interest, levels of optimism and self knowledge.

- Prior to embarking on a new clinical situation, the student is prepared by being given the relevant theoretical and practical knowledge by teachers at Polytechnic, with suitable clinical placements arranged between the Polytechnic and available agencies and institutions.

- The student then enters the clinical learning milieu where the culture, personnel, environment and consequent feelings of safety can influence the learning experience. If clear guidelines and overt expectations allow the student to become knowledgeable concerning what is expected, successful learning is more likely to occur. If, however, the student is left to learn by trial and error, he or she is given inappropriate experiences and is expected to learn by watching and trying to guess what is expected, successful or empowered learning, is less likely.

- The student is placed with a nurse expert who may or may not be educated in their teaching or preceptor role and may or may not have values, beliefs, attitudes and behaviours that will enhance the student learning or praxis experience. The student has the aim of bringing together the theoretical and practical components of their current knowledge levels into the reality based situation in order to make sense of, and to practice their current competencies whilst engaging in care of a client. Interactions, communication and the relationship with the nurse expert can enhance the likelihood of an empowering praxis experience, as the student is facilitated through an appropriate learning encounter. The interaction is dependant upon what both parties (student nurse and nurse expert) bring to the experience. However, the nurse expert has power and if this power is not shared with the student in an appropriate way that facilitates student learning the student can be disempowered. 
- If the nurse expert shares an appropriate level of power and treats the student with respect the student is more likely to feel empowered and leave the praxis experience, to reflect on success as empowerment.

- If reflection is further facilitated by a teacher, more will be learned from the experience, and greater connections between reality, theory and practice will be noticed and acted upon in further learning situations by the student. Self efficacy will also be increased and the student will be better prepared to enter into a further clinical learning experience.

- If, however, the student nurse / nurse expert interaction results in the student feeling disempowered, self reflection may result in the lowering of self efficacy to the extent that perceived failure may result in the student abandoning the course to avoid further failure. If facilitated reflection occurs, the student may be able to appreciate the factors which contributed to this one failure event, so limiting it to this specific instance. This may have the effect of halting generalisation of the failure paradigm to all other situations, and may allow the student to feel more powerful in terms of the control they have over their own learning through the knowledge they have gained from this failure event.

\subsection{Conclusion}

In this section literature used to articulate the theory and develop the tentative model was examined. Following the development of this model, testing it against the exemplars of empowerment and disempowerment was undertaken to ensure it's validity. The model was then presented to the participants for final validation. Section 8 will detail these processes. 


\section{Testing the theory}

In this section the theory is tested taking one exemplar from section 5.5 .1 and checking it against the theoretical model for 'fit'. I then describe how the model was presented to participants, and their responses to it. The final model is then presented, followed by participant suggestions as to how the theory should be used. The purpose of this process was to test the validity of the developed theory against the original data, and gain confirmation from research participant feedback.

\subsection{Comparison with exemplars of empowerment}

The exemplar given by Liam, described how during the time he was enrolled in the Year two nursing practice paper entitled 'Child bearing Families and Children' (paper 211) he was placed in a paediatric clinical setting to gain knowledge through experiential learning. Liam was assigned to work with a preceptor who gave him the responsibility for care of a young child (accompanied by the mother) with a non complex but potentially serious condition.

The preceptor initially assisted Liam's transition into the milieu by treating him with respect, and providing him with the agency protocols for client care.

His passage into praxis was further assisted by being given responsibility appropriate to his level of knowledge. Liam recalled that: 'she (the preceptor) treated me with a lot of respect and saw me as being capable and confident'. This had the effect of increasing his confidence and enabled him to work with his clients (mother and child) to his full capability. Once engaged in praxis, Liam used the technical skills of hygiene care, and taking and recording TPR (Temperature Pulse and Respirations). He also employed communication skills including completing necessary documentation, listening and responding in a manner appropriate to the client, asking for assistance, and learning from the information given. Liam appeared to demonstrate application of knowledge and theories gained during Polytechnic classes and during previous practical experiences. He considered that his role was 'to assist the young child to an improvement of health' (whaiora), and he concluded that this care involved more than just physical care and that it was 'about holistic care' of a client.

Liam termed the positive interaction he had with the preceptor as 'symbiotic'. He stated that it was 'very interactive', she'd listen, evaluate and give me the benefit of her experience', This enabled him to work in a 'symbiotic' manner with his clients (mother and child). 
Liam's exemplar demonstrated the need for knowledge skills and competencies learned at Polytechnic during the year one course and the year two preparation required by him prior to clinical placement. Liam appeared to have adequate self efficacy when entering the new learning milieu to respond to the positive affirmation of his perceived competence, as evaluated by the preceptor, who had been educated for her role as a teacher of nursing students.

Liam took the responsibility given and engaged in praxis which included the application of skills, knowledge and theory to practice. The positive interaction with the preceptor was pivotal to his feeling of comfort, successful practice, increased learning, and ability to reflect on the experience. Reflection on what he had learned, how he had empowered a client and engaged in praxis led him to consider that he had been empowered. Liam further engaged in assisted reflection on the learning experience in a tutorial for Paper 215 (The Caring Relationship) where students are encouraged to bring exemplars from clinical experience and to use them during facilitated discussion with peers. His participation in this research enquiry also provided the opportunity for further assisted reflection, enhancing Liam's increased efficacy and desire to engage in further practical learning experiences.

I consider that this exemplar, as one example of many, was adequately explained by the proposed theoretical model. All other exemplars were given similar consideration and the model has successfully provided an explanatory pathway of the conditions and consequences occurring in each of them. Therefore my conclusion is, that the tertiary model (Figure 7.2) is a valid explanation of the phenomenon of empowerment.

\subsection{Presentation of the theory to participants}

Following the development of the theory and model (Figure 7.2) a meeting was arranged with the participants to describe and explain the results, and to request feedback concerning whether or not they considered that the description and theory satisfactorily explained their experiences of empowerment.

During the presentation, participants asked for clarification as needed. Their questions included:

What is the difference between self confidence and self efficacy?

What was my hypothesis?

Did I have the model in my head before I started?

Did all of the participants have similar definitions of empowerment? Was their course empowering? 
My responses included explanations that often resulted in discussion amongst the group, as they clarified words and meanings for themselves, and assisted each other to new levels of understanding. Discussion also included the reasons why some nurses practice horizontal violence towards students and how many (nurses in health care institutions) are currently feeling threatened by the changes in Health Funding and nursing education that has resulted in their perceptions of devaluation of their qualification and potential status reduction and/or future redundancy. The socialisation of nurses who were trained in hospitals and the hierarchical management structures of hospitals were also discussed. Students recalled the confusion they had encountered when attempting to negotiate the milieu. For example, abbreviations used in hospitals such as SOB which is used to refer to 'Shortness of Breath' rather than the popular lay meaning that they were more familiar with. They determined that this was an example of staff maintaining power over those (students and patients) who did not know the language.

Following the presentation, responses to the model and theory were generally positive. Comments were:

I'm impressed our discussions came up with this.

It's a good model

You've done quite a bit of analysing

Makes you realise that you are more in control than you think. That its up to you ( the student)

At the conclusion of this meeting participants were asked to reflect upon the information given and write down their comments and thoughts in their own time. Some participants responded immediately and others gave me information over the course of a few days to a few weeks. This feedback also included, informal verbal discussion, and one formal verbal consultation. Some participants provided written feedback followed by verbal responses after further reflection. Full responses are as follows:

Robyn wrote: I found the model to be well established with good ideas about the interaction between students, preceptors and tutors. The topic 'self efficacy' made me feel that the individuality a student brings to the scenario is just as relevant as the outcome of negative and positive empowerment. I also felt supported in this idea by the other members of the study group (participants).

Robin wrote: The presentation opened my mind towards some disempowering situations I have been involved in. This allowed me to let go of the situation and not dwell on my mistakes. So now I look on the situation as a learning experience. The model clarified the 
circle or cycle of positive and negative interactions involving empowerment. This has benefited me personally as I feel I can now improve on my self efficacy. The model presented was simple, easy to understand and is applicable to nursing situations.

Glenis stated that she was not sure what to write other than that : The model has given me new meaning to the word (empowerment) and explained for me what it was that I experienced. However, during a subsequent informal meeting and discussion between Glenis, Robin and myself, Glenis described how she was currently working with a nurse in a clinical placement who was potentially disempowering in her interactions. Glenis described how she reflected on the model and then reframed the current situation in a way that prevented her from becoming disempowered. She then wrote that: Every interaction with people is an exchange of energy. So if your interactions are with someone who is condescending, just say 'Thank You' and keep your energy and theirs. So that in the end you have your energy and theirs and they have no energy. You win !!!

Liam wrote: The method or flow chart (fig 7.2) was really helpful in grasping the model / thesis. What could be a complex verbal presentation was simplified by using the flow chart /diagram. Jan appears to have successfully sifted out the superfluous data and found common links in the gathered data from her subjects.

Meredith wrote: Well presented flow chart, easy to comprehend, well explained, clear and defined. Easy for the student and the preceptor to see where each is coming from. A little understanding from both sides can only enhance quality of learning (and) give extra confidence with the knowledge. If a disempowerment occurred, it is a learning experience but at the same time to keep you feeling good when an empowered situation occurs. One can learn from repetitive cycles (if we keep them in mind)

P.S. Just remember to keep one's feet on the ground and head out of the clouds.

Elisapeta discussed the model and its impact on her a few weeks following the presentation, after spending three weeks in a clinical placement. During this meeting I perceived that Elisapeta (who at previous interview had described brief moments of empowerment which were contrasted with times of prolonged disempowerment), appeared confident and different from earlier meetings. She was smiling more, holding herself higher and making more eye contact during conversation. I asked Elisapeta what had been happening for her, then asked her thoughts about the model. Elisapeta's response was: I liked the model a lot, it was clearly laid out and helped explain disempowerment. When I was out in clinical this time, in a surgical ward I kept the levels in my head. I could visualize it and it showed a path. It gave me support as it showed me what goes on for everyone and I felt supported as it was 'not 
only me' that things (disempowerment) had happened to. It ( the model) gave me more confidence and during my recent clinical I thought 'I don't care if it goes wrong as I'm going to get there' (to empowerment). I think that the levels ( of self efficacy) are small steps and when you are empowered you go up a little bit and when you are disempowered you go down a little bit. I remembered my goal and the steps in my head and that gave me more confidence to reach my goal.

Given this feedback I considered that the theory I had developed had been validated by the participants, and that the research process per se also had the intended emancipatory impact of enabling the participants to understand themselves and their world in a manner that allowed them to become empowered and to transform their own learning experiences.

The final model was therefore a confirmation of the tertiary model ( Fig. 7.2)

\subsection{How the theory and model should be used}

As part of the presentation feedback I asked participants how the theoretical information could be used to maximize student empowerment. Participants responded in the following ways:

Robin suggested that I: Introduce the model to tutors and students in first, second and third year as it was introduced to respondents.

Glenis wrote: The model and explanation would benefit the year one students in that they could learn through this a different way to look at problems faced in life and also in the way they relate to others.

Meredith wrote: Repeat it in year one to year three. Give each student a copy and remind them to read it before each clinical experience. Encourage, encourage, encourage...

Robyn wrote: I think that if this is explained to students at the end of the first year and then again in the beginning of nursing research in the second year to reinforce that students have a say in how the events in clinicals turn out and how research is relevant to confirming already suspected ideas. That is, students clinical can be controlled by disinterested staff nurses. If students are able to have this idea in the back of their heads they will be aware that they do not have to tolerate nurses that are not interested in training students and because of this tutors will back up their decisions. 
Elisapeta considered that the model may not be understood by Year one students if they had not attended clinicals and thought that it would be best explained before or just after the first clinical placement in year two. Elisapeta also felt strongly that the model should be included in the curriculum documentation.

Liam wrote: It equips and prepares the student by giving information on how the empowering I disempowering process may occur, and enables the student to at least have an idea on the role they play, and how to best be a part of empowering their patients. It also highlights areas to be aware of ( own personal baggage).

\subsection{Postscript to participant feedback}

Since receiving this feedback I have presented the model and theory to my year one Lecturer colleagues and to year one students, following Lecturer recommendation. The student presentation was part of a two day Power/ powerlessness workshop which is presented to Year One student nurses prior to their first placement in health institutions.

During the process of presentation to colleagues and year one students refinements to the Tertiary model (Fig. 7.2) have been made resulting in the development of The Theoretical Model shown below (Figure 8.1). The developmental changes have included visually clarifying the competencies, knowledge, attributes and self efficacy that the student brings to an experiential learning situation, placing self reflection more closely linked to praxis and diagrammatically representing praxis in triangular form, to more adequately represent the curriculum philosophy (Appendix 3).

\subsection{The Theory of the Process of Empowerment}

The theory is diagrammatically represented in Figure 8.1 where the student, who is the primary actor is located at the centre of three concentric circles. The student (center) brings her / his life and previous learning experiences to this new learning experience. The circle closest to the student represents year one competencies that the student has accumulated. Added to these, and surrounding, or part of them are the preparatory competencies and knowledges appropriate to the clinical placement setting. Around year one competencies and clinical preparation (and highly influential to student performance) is the concept of self efficacy, or the perception of the student as to how able they are to practice what they know. Levels of self efficacy are represented by dotted lines which portray that these levels are changeable or fluctuating and vary for individual students at different times, depending on previous learning experiences. These potentially varied conditions are taken by the student into the clinical placement or milieu where the student encounters staff and clients and an environment and culture that may or may not assist the student to know what is expected 
and/or possible. The student interacts within the setting with a nurse expert who facilitates student praxis. Praxis is represented by a triangle that encloses the potentially dynamic space. It is possible for the interaction with the nurse expert to be positive or negative. Following praxis the student self reflects on the experience and determines whether the learning experience was empowering or disempowering. The paths taken are indicated by the arrows. If the upper 'empowerment' path is taken, whether or not there is engagement in assisted reflection self efficacy levels will be increased and another learning cycle will be ventured. If the lower path of 'disempowerment' is taken the student may either disengage or exit. If the student continues and engages in assisted reflection they will regain, or maintain efficacy levels sufficiently high to allow a further learning cycle to be attempted. he diagrammatic representation is of one cycle of a learning experience. Many cycles will occur for a student within a programme of learning.

\section{Figure 8.1 The Theoretical Model of the Process of Empowerment}

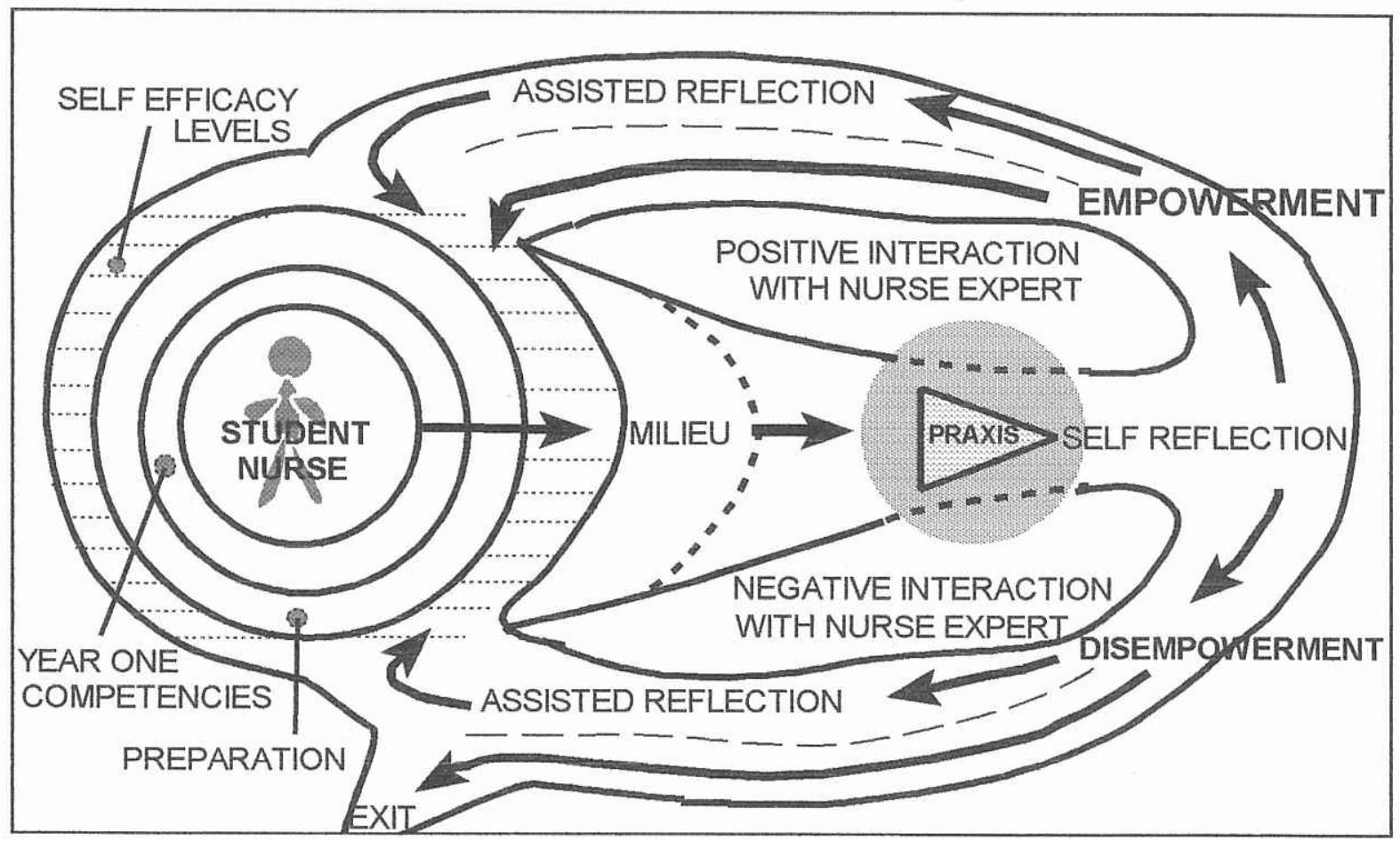

\subsection{Conclusion}

In this section theory validity was checked by comparison against one exemplar, and participant response to the theoretical model presented. Recommendations made by participants for dissemination of the theory and the Theoretical Model of the Process of Empowerment were also presented. The final section(9) will conclude the thesis. 


\section{Conclusion}

To conclude I will evaluate the aims of the study, briefly reiterate the research process and findings, then discuss the implications of the findings for practice, and end, by making suggestions for further research.

\subsection{Research Purpose, Aims and Answers}

To conclude this process I will complete the research cycle and return to the introduction, to examine whether of not I have met the intended outcomes for the study. My original statement included the intention: To explore, articulate and make visible the conceptual process or phenomenon of Empowerment, as perceived by students of nursing. I stated that the need for this study arose from the fact that the curriculum that currently shapes the teaching of nursing students at Whitireia Community Polytechnic has the intention of empowering students so that they enter the nursing profession capable of emancipatory practice.

A main question therefore could be :

\section{Do students enrolled in The Bachelor of Nursing programme at Whitireia gain empowerment?}

My findings were, that the current Bachelor of Nursing programme at Whitireia has the potential to empower students and that by year two, students have had empowering learning experiences and are able to empower clients and advocate for others. Empowerment for participants occurred foremost in the clinical practice setting, and empowering teaching / learning experiences were conditional upon the student working with a nurse expert who facilitated the student's engagement in praxis.

The stated questions on which I sought clarification were:

- What do students enrolled in this Nursing Programme understand by the term empowerment?

- What, in the view of the participants, assists them to become empowered?

- What, in the view of the participants, impedes their empowerment?

- What, in the view of the participants, could improve / enhance the development of their empowerment?

The first question was answered by the analysis of participant responses to the question 


\section{What do students understand by the term empowerment?}

Findings were, that empowerment involved an interactional exchange or transfer from one person with greater knowledge and power, to another with less. Students perceived an increase of power and confidence when an appropriate responsibility and learning experience was given to them by a nurse expert. The consequence of an interaction that facilitated learning was that the student gained further knowledge and belief in his or her ability to practice which they defined as 'empowerment'.

The second question What assists students of nursing to become empowered? was answered through analysis of exemplars and interview transcripts which resulted in the discovery and articulation of a theory that is represented in 'The theoretical model of the Process of Empowerment' (Section 8.4 and Figure 8.1).

To reiterate the explanation of the theory ${ }^{2}$ : Student participants voiced the need for knowledge skills and competencies learned at Polytechnic during the year one course, and the need for preparatory knowledge and competencies from the relevant year two paper, prior to clinical placement.

It was also found that a level of self efficacy sufficient to allow a student to be proactive in the search for knowledge and learning experience when entering a new learning milieu was essential.

The milieu, encompassed people, the culture (beliefs, values, policies) and the environmental setting for the student's learning experience. When open communication and adequate orientation was part of the culture, student learning was facilitated.

Within the milieu it was found to be important that a nurse expert engaged in a positive interaction with a student and that the nurse expert was willing and able to evaluate competence, and provide an appropriate learning experience for the student. When these conditions were met the resulting learning experience increased the student's knowledge. Nurse experts who were 'preceptors' or had been educated for the teaching role, were considered by students to provide a higher number of positive interactions that resulted in empowerment.

\footnotetext{
${ }^{2}$ Categories that were determined essential to the empowerment process are in bold font
} 
To become empowered it was necessary for the student to be prepared, to accept the responsibility given by a nurse expert, and to engage in praxis. Praxis included the application of theoretical and practical knowledge, combined with reflection-in-action which allowed for transformative, or new 'ways of being' during the practice experience.

Reflection on what was learned during and immediately following praxis was essential for a student to gain a sense of empowerment.

For an empowered student, increased efficacy subsequent to self and / or assisted refection resulted in a desire to engage in further practical learning experiences.

The third question What, in the view of the participants, impedes their empowerment? was also answered by the theory ( Section 8.4, Figure 8.1) which described the following conditions that were likely to contribute to disempowerment.

Impediments to empowerment, named as the condition of disempowerment, were more likely to result when the student entered a clinical milieu with lack of a belief in their own ability, or low self efficacy.

Students also had difficulty becoming empowered if they encountered an antagonistic milieu where they were not given the necessary orientation and information. These milieu conditions could result in errors being made by the student due to lack of information, or, through a high degree of anxiety resulting in poor performance.

A negative interaction with a nurse expert could result in disempowerment due to the assignment of inappropriate learning tasks that prevented the student from engaging in praxis thus negating the possibility of learning. Lack of learning leading to disempowerment was also possible if a clinical placement was inappropriate for the learning needs and goals of the student.

Negative interactions also included the student encountering racism, patronization, disrespectful treatment, or lack of control over their learning. These conditions could reduce or preclude the student from achieving through rendering them passive (learned helplessness) and therefore less able to access the experiences they required to meet their learning goals. 
Self reflection alone, following a disempowering experience resulted in failure to learn from events and led to feelings of general inefficacy. However, this situation could be redeemed if reflection was assisted by a nurse expert in a manner that allowed the student to understand the nature of the sequence of events and to reflect on strategies they could use to gain a sense of control in a future similar situation.

Desire to engage in assisted reflection seemed essential to negate diempowerment. As Pickford (1995) stated.

If you have made mistakes... there is always another chance for you...you may have a fresh start any moment you choose, for this thing we call 'failure' is not the falling down, but the staying down.(30/12/95)

It would appear that students need help from their teachers to prevent the 'staying down', and that a successful strategy is assisted reflection following the learning experience.

Responses to the fourth question What, in the view of the participants, could improve / enhance the development of their empowerment? were sought from the participants following presentation of the theory and theoretical model.

It was recommended by participants following their general agreement with the theory, that the model and theory should be presented to all students of nursing at Whitireia at various stages during their educational programme, but preferably prior to and/or immediately following initial clinical experience in year one. This was considered a strategy that could enhance student empowerment through the student gaining knowledge concerning the range of competencies, abilities and attitudes they required in order to facilitate their own learning. It was also suggested that the theory and theoretical model should be presented to Nurse Lecturers at Whitireia Community Polytechnic and Preceptors in health care institutions. The intention being that nurse experts they could then gain a greater understanding of the effect of their interactions upon students.

Given these findings I consider that the aims and goals of this enquiry were adequately met. The findings have been validated through the use of emancipatory research methodology. Empowerment as a consequence of the research process has also been achieved for the participants and for myself. 


\subsection{Personal Empowerment through Praxis}

I consider that I have become further empowered by this research process through my engagement in the process itself, and through my interaction with participants. This has resulted in a huge personal knowledge gain. I also consider that this process has itself been one of research as praxis ( Lather 1986). The model of empowerment (Fig. 8.1) can also be used to describe my journey.

I commenced this study with my personal life experience, my knowledge obtained from completed university courses, my nursing and my teaching practice. I prepared myself for praxis by reading, thinking and preparing the plan of my intended journey. I felt sufficiently efficacious about research to enable my engagment in the process. I entered the research milieu as a novice, having only modest knowledge of the culture, and followed the policies by gaining approval for my study from the University and Polytechnic research and ethics committees.

I negotiated the milieu by asking for information from knowledgeable and experienced people who were approachable. I had a clearly focused goal of what I wanted to find and had planned how I intended to go about it.

I interacted with persons who enabled me and my learning, my colleagues, supervisors, partner, peers, whose interest, respect and support for my study facilitated me to fully engage in research praxis.

In response to my request for student participants an appropriate number (six) volunteered to participate. The participants continued to engage in ongoing formal and informal contact with me throughout the study. This constant contact encouraged me to reflect continually on the research purpose, process and ethics of the study, in order that I might maintain integrity in my teaching and research.

All interactions experienced with participants, supervisors, colleagues, librarians and year one students were positive and respectful. This enabled me to successfully engage in my study programme. Support for my experiential learning has ultimately led to my own empowerment. I have gained an increase in knowledge and competence in research which has strengthened my efficacy in this domain and led me to aspire to continue to engage in research in the future. 
The achievements of this study are two fold. Firstly I have detailed the journey or process of empowerment occurring for this group of nursing students. Secondly I have developed a model that I could use to describe my own Action Research process or Research Praxis. As Mezirow (1989) described.

In the reflection-decision-action-reflection cycle, reflection often comes to mean reflection on the consequences of disciplined inquiry, so that learning and action research become moments in the same process. ( preface $\mathrm{xx}$ )

\subsection{Implications for Practice}

As I stated in section 4.5.4., Hutchinson (1990) considered that generalization is not possible in grounded theory research, however Corbin and Strauss (1990) contended that generalization could be partially achieved through the process of abstraction. The more abstract the concepts the wider the application of the theory in that Grounded Theory Research allowed for

generalization insofar as it specifies conditions that are linked through interaction / action with definite consequences. ( $p$ 14)

I consider that generalizability is partially possible for the theory developed during this research because other people who share common circumstances may perceive and identify with the pattern described in the model and theory( Hutchinson 1990). As I have previously stated, I was able to usefully apply the model to my own action research process in order to clarify the conditions essential to the process, and teachers of students in other practice disciplines have also verbalised agreement with it.

Therefore I believe that the theoretical model has the potential to be used or applied to teaching/ learning situations that involve experiential learning. I consider because it is an appropriate and useful analytical tool for teacher education ( pre, primary, secondary and tertiary school) and education or research that aims to be emancipatory in nature.

However, the main implications for the development and articulation of this theory were, that because it arose from grounded theory and was based on the world view of the student I participants it is their 'truth'. As consumers of a vocational education programme and practitioners of the future I consider there is a moral obligation for those of us who are involved in nursing education to take heed of how, why and when, we as teachers impact on the learning of the student nurse. The theory which has been developed highlights areas of 
teaching practice that either enhance or impede the success of students learning from practice experiences. As participants have recommended students and teachers should be exposed to this knowledge in order that they may gain further insight and understanding into the roles each play during the empowering teaching / learning process.

The theory has made visible a curriculum in action and identified how intent may be exploited by actors and their conditions of 'ignorance' when they translate or interpret the curriculum into their 'way of being' or personal philosophy. As Baer-Doyle (1988) contended it is our personal philosophy or epistemology, that has been developed from life events, that determines how we act and what we view as important.

The interactions between nurse experts and participants in this study demonstrated how history can shape nurse expert actions. What has been revealed is not only how students are empowered but also how difficult it is for nurses who have either been 'trained' and / or are working in a hierarchical institution to learn or maintain emancipatory or 'critical thinking' skills and behaviours that could challenge the status quo.

As Freire (1994) contended, only through understanding based on discussion or dialogue is it possible to understand the thought of the oppressed - or how hegemony persists. Freire citing Fromm considered that the knowledge that can move the oppressed 'outside themselves' is an educational practice

that is a kind of historic-sociocultural and political psychoanalysis. ( $p$ 105)

It would appear that students enrolled in a nursing education programme that has emancipatory or 'critical social' theories included as a philosophical basis (Diekelmann 1988,1991, Bevis 1988, Watson 1988, Bevis and Watson 1989, Clare 1991, Southwick 1994) do develop an awareness and behaviours that can bring about social change. The aim of assisting students to develop these 'ways of being' is so future nurse practitioners are able to advocate for themselves and their clients. The challenge is therefore to encourage nurse practitioners currently engaged in the Health Care System to develop awareness of their own situation and that of others in order that they can be supported to overcome hegemony, racism, horizontal violence and other forms of oppression practiced in the current Health Care System.

The caution is, that care needs to be taken to ensure that those educating nurses for change are not 'dogmatic activists' driven 
to 'fill' the 'empty' awareness of educands with content whose learning process he

or she as educator already knows to be important and indispensable to the educands. (Freire 1994 p 115)

For if this 'banking model' of education (Freire 1972) occurs we again set up an environment that is not safe for people within it to engage in emancipatory dialogue.

\subsection{Recommendations for Practice}

Because student nurses are empowered in their learning through praxis, the role of nurse experts in supporting praxis is the focus of the following recommendations.

The role of the educator in the 'school' setting is to understand the importance of, and ensure the adequate preparation of students prior to practice placement.

- It is recommended that nurse educators in this programme maintain the current year one course of teaching, to ensure development of student competencies in Appendix 8 , that form the basis of year two competency development ( Appendix 9).

The role of the Nurse Expert involved with student nurse education in practice settings is to facilitate appropriate learning experiences for the student nurse.

- It is recommended that preceptor programmes are extended to all clinical areas that student nurses are placed and that preceptorial programmes include historicsociocultural and political psychoanalytic awareness to overcome hegemonic practice.

The role of all registered nurses who interact with student nurses during their education is to facilitate student learning.

- It is recommended that all nurses who interacted with student nurses gain heightened awareness of the impact that their 'way of being' has on students and work towards developing strategies that ensure a culture of critical reflective practice, that has transformative potential. Linked to this recommendation is the need for these nurse experts to have personal philosophical congruence with the curriculum philosophy of the nursing programme with which they engage. For as Clare (1993) stated

nursing education does not simply process students or process knowledge, it helps create and legitimise forms of consciousness that reinforce existing hegemonic structure. ( $p$ 1034)

The need for reflection during and following learning experiences cannot be understated for both nurse experts and students. 
- It is therefore recommended that processes and strategies that develop ongoing reflection in nursing education and practice be encouraged.

\subsection{Suggestions for Future Research}

Suggestions for further research to explain gaps and concepts of importance to this study include

- Research on how students of nursing use reflection as a tool. The rationale being that it was not possible to adequately describe the place of assisted reflection, following empowerment, in the current study. Further exploration into refection-in-action, self reflection and assisted reflection would be of value to explain and situate this learning strategy within nursing education.

- How self efficacy can be influenced would also be of immense interest and importance in understanding the place of self efficacy in student nurse education. Research that illuminates whether this concept is linked to intrinsic / extrinsic locus of control and how/ if self beliefs can or should be altered would be of interest to educationalist.

- Empowerment of students within an educational institutional setting would also be elucidated by future research. This may be addressed by replicating the current study methodology with year one students or by a research study using different methodologies.

Suggestions for further research that would further validate the theory developed during this research could include

- A study using similar methodology with nursing student participants enrolled in year one and year three at Whitireia Community Polytechnic, to see how students at different levels of the same programme perceive the phenomena of empowerment.

- A study using similar methodology with a different cohort of year two students.

As previously stated I consider that the theory may be able to be applied to other educational disciplines that include experiential learning, this would be confirmed through research that tests the theory with groups of students in other disciplines, such as teacher education.

Further claims were made as to the usefulness of the theory in the action research process, again the most valid way that this could be confirmed would be through researched application to studies using Action Research methodologies.

Suggestions for other related research studies would include 
- A post presentation ( of the theory to students, as recommended by participants) study of 1997 year two students and comparison of the empowering experiences of this group to the findings in this study .

- A follow up of student / participants from this study during their experiences as novice graduates in order to determine socialisation patterns and emancipatory nursing practice, as compared to a control group, who had been educated in the same programme but had not been involved with the research study.

\subsection{Concluding Remarks}

I consider that this research process has been one of empowerment for both researcher and participants. Gibson (1991) determined that

in a broad sense empowerment was a process of helping people assert control over their own lives. ( $p$ 354)

This research has enabled those engaged in it to explore, examine and gain a sense of control over their learning experiences and by so doing has led to a generalised feeling of empowerment. 


\section{References}

Atkins S and Williams A (1994) Registered Nurses' experiences of mentoring undergraduate nursing students. Journal of Advanced Nursing, 21, 1006-1015

Allen D (1990) The Curriculum Revolution: Radical Re-Visioning of Nursing Education. Journal of Nursing Education, 29(7) 312-316

Anderson G (1990) Fundamentals of Educational Research, The Falmer Press, Great Britain Apple M (1990) Ideology and Curriculum, Great Britain, Routledge

Ashley J (1980) Power in Structured Misogyny. Advances in Nursing Science, 2(3), 3-22

Baer-Doyle T (1988) To Learn or to Know-What is the Quest? In Middleton S and Jones A Editors, Women and Education in Aotearoa, Allen and Unwin, Wellington.

Bandura A (1986) Social Foundations of Thought and Action: a Social Cognitive Theory, Prentice - Hall, New Jersey:

Banister P, Burman E, Parker I, Taylor M, and Tindall C (1994) Qualitative Methods in Psychology: A Research Guide. Open University Press, UK

Bawden R (1993) Praxis: The essence of systems for being. In Viskovic A, Editor, Research and Development in Higher Education (HERDSA) conference proceedings, 14,1-7

Bowman A (1993) Victim Blaming in Nursing. Nursing Outlook, 41(6), 268-273

Belenky M, Clinchy B, Goldberger N, and Tarule J (1986) Women's ways of knowing: The development of self, voice, and mind. Basic Books, New York

Bell J (1987) Doing Your Research Project. Open University Press, Milton Keynes

Benner P (1984) From Novice to Expert : Excellence and Power in Clinical Nursing Practice. Addison-Wesley Publishing Company, California

Bevis E (1988) New Directions for a New Age. In N.L.N. Curriculum Revolution: Mandate for Change. National League for Nursing Press, New York

Bevis E and Watson J (1989) Toward the caring Curriculum: A new pedagogy for Nursing. National League for Nursing, New York

Bevis E (1991) Educative Teaching for Critical Thinking Professional Nurses: A Perception of Curriculum. Seminar, Auckland Technical Institute, Auckland, NZ

Bevis E and Murray $\mathrm{J}(1990)$ The Essence of the Curriculum Revolution: Emancipatory Teaching. Journal of Nursing Education, 29(7), 326-331 
Boud D, Keogh R and Walker D (1985) Turning Experience into Learning. Kogan Page, London

Boud D and Walker D (1990) Making the Most of Experience. Studies in Continuing Education, 12( 2) 61-79

Bowers B (1988) Grounded Theory. In Sarter B. Editor, Paths to Knowledge: Innovative research methods for Nursing. National League for Nursing Press, New York.

Boyd V (1991) Bicultural Development in Nursing. RPIEN National Action Group Guidelines.

Burchfield R (1986) The New Zealand Pocket Oxford Dictionary: Oxford University Press, Auckland

Caine R (1994) Empowering Nurses Through Mentoring. MEDSURG Nursing, 3(1) 59-61

Carlson-Catalano J (1992) Empowering Nurses for Professional Practice. Nursing Outlook, 40(3), 193-142

Carr W and Kemmis S (1986) Becoming Critical :Education, Knowledge and Action Research. Deakin University Press, Australia

Choy A (1990) The Winner's Triangle. Transactional Analysis Journal, 20(1) 40-46

Clare J (1991) Transforming Health Care: Does Nursing Theory have anything to Offer ? Nursing Praxis In New Zealand, 6(2), 5-9

Clare J (1993) A challenge to the rhetoric of emancipation: recreating a professional culture. Journal of Advanced Nursing, 18, 1033-1038

Clay T (1992) Education and Empowerment: Securing Nursing's Future. International Nursing Review, 39(1), 15-18

Collins W (1987) Collins COBUILD English Language Dictionary, Collins ELT, London

Corbin J (1986) Qualitative data analysis for Grounded Theory. From Practice to Grounded Theory. Chenitz W and Swanson J, Editors, Addison-Wesley Publishing Company Inc., California

Corbin J and Strauss A (1990) Grounded Theory Research: Procedures, Canons, and Evaluative Criteria. Qualitative Sociology, 13(1), 3-21

Cross T (1988) Cultural Competence Continuum. Focal Point, 39(1)

Dawson M (1994) Using Locus of Control to Empower Student Nurses to be Professional. Nursing Forum, 29(4), 10-15

Denzin N and Lincoln Y (1994) Handbook of Qualitative Research. Sage Publications, Thousand Oaks 
Denzin N (1978) The Research Act., 2nd edition, McGraw-Hill, New York

Deshler D and Selner D (1991) Transformative Research: In search of definition. Convergence, 24(3), 9-23

Diekelmann N (1988) Curriculum Revolution: A Theoretical and Philosophical Mandate for Change. In N.L.N. Curriculum Revolution: Mandate for Change. National League for Nursing Press, New York

Diekelmann N (1990) Nursing Education: Caring, Dialogue and Practice. Journal of Nursing Education, 29(7), 300-305

Diekelmann N (1991) The Emancipatory Power of the Narrative. In N.L.N. Curriculum Revolution: Community Building and Activism. National League for Nursing Press, New York

Diekelmann N (1993) Behavioural Pedagogy: A Heideggarian Hermeneutical Analysis of the Lived Experiences of Students and teachers in Baccalaureate Nursing Education. Journal of Nursing Education, 32(6), 244-250

Doyal L and Gough I (1991) A Theory of Human Need. McMillan Education Ltd., London Durie M (1994) Whaiora : Maori Health Development. Oxford University Press, Auckland

Elley W and Irving J (1972) A Socio-Economic Index for New Zealand: based on levels of Education and Income from the 1966 Census. New Zealand Journal Of Educational Studies, $7(2) 153-164$

Freire P (1972) Pedagogy of the Oppressed. Ramos M, Translator, Penguin Books, Great Britain

Freire P (1994) Pedagogy of Hope. Barr R Translator, Continuum, New York

Freire P and Shor I (1987) A Pedagogy for Liberation. MacMillan Education Ltd., London

French P and Cross D (1992) An interpersonal-epistemological curriculum model for nurse education. Journal of Advanced Nursing, 17, 83-89

Gallocher-Shearer S (1995) The Development of Nursing within a Dualistic Framework: does Caring a have a place? Whitireia Nursing Journal, 2, 38-43

Gibson C (1991) A Concept Analysis of Empowerment. Journal of Advanced Nursing, 16, 354-361

Glaser B (!978) Theoretical Sensitivity. The Sociological Press, California

Glaser B and Strauss A (1967) The Discovery of Grounded Theory. Aldine Publications, Chicago 
Glesne C and Peshkin A (1992) Becoming Qualitative Researchers. Longman Publishing Group, New York

Guba E and Lincoln Y (1994) Competing Paradigms in Qualitative Research. In Denzin N and Lincoln Y, Handbook of Qualitative Research. Sage Publications, Thousand Oaks

Habermas J (1971) Knowledge and Human Interests. Shapiro J, translator, Beacon Press, Boston

Reason P and Heron J (1986) Research with people:The Paradigm of Cooperative Experiential Inquiry. Person-centred review, 1, 457-476

Heron J (1992) The Politics of Facilitation: Balancing Facilitator Authority and learner autonomy. In Mulligan J and Griffin C, Editors, Empowerment through Experiential Learning., Kogan Page, United Kingdom

Hitchcock G and Hughes D (1989) Interviewing, asking questions and conversations. Research and the teacher: A qualitative Introduction to school-based research. Routledge, London

Hokanson Hawks J (1992) Empowerment in Nursing Education: concept analysis and application to Philosophy, learning and instruction. Journal of Advanced Nursing, 17, 609-618

Holly C, Millar G and Skelly A (1994) Empowering Environments for Caring. Journal of the New York State Nurses Association, 25(2), 3

Hunter D Bailey A and Taylor B (1994) The Art of Facilitation. Tandem Press, Auckland

Hutchinson S (1990) Education and Grounded Theory. In Shermann R and Rodman B, Editors, Focus and methods. The Falmer Press, London

Jackson $\mathrm{H}$ (1994) The Curriculum revolution: What do all those Buzz Words really mean? Nursing Praxis in New Zealand, 9 (2), 25-31

Jarvis A (1993) Student Nurse Learning From Practice: A Grounded Theory Study. Unpublished, M.Ed Thesis, University of Waikato

Jayaratne T (1981) The Value of Qualitative Methodology for Feminist Research. In Bowles C and Duelli-Klien R Editors, Theories of Women's Studies II. Women's Studies, University of California, Berkeley

Jolley M and Brykczynska G (1993) Hidden Curricula in Nursing Education In Jolley M and Brykczynska G Editors, Nursing: its Hidden Agendas. Edward Arnold, London.

Jolley M (1993) Out of the Past. In Jolley M and Brykczynska G, Editors, Nursing: its Hidden Agendas. Edward Arnold, London

Kemmis S (1985) Action Research and the Politics of Reflection. In Boud D Keogh R and Walker, Editors, Reflection: Turning Experience into Learning, Kogan Page, London 
Kieffer C (1984) Citizen Empowerment: A Developmental Perspective. Prevention in Human Services, 3, 9-36

Knowles M ( 1984) The Adult Learner : A Neglected Species. Gulf Publishing Company, Texas

Knowles M (1970) The Modern Practice of Adult Education : Andragogy versus Pedagogy. Association Press, New York

Labonte R (1994) Health Promotion and Empowerment: Reflections on Professional Practice Health Education Quarterly, 21(2), 253-268

Lather P (1986) Research as Praxis. Harvard Educational Review, 56 (3), 257-277

Lather P (1992) Critical frames in educational research: Feminist and post - structural perspectives. Theory into Practice, 31(2), 87-99

MacLean B (1992) Technical curriculum models : are they appropriate for the nursing profession. Journal of Advanced Nursing, 17, 871-876

Manthey M (1992) Issues in Practice; Empowerment for Teachers and students. Nurse Educator, 17(4), 6-7

Marcus G (1994) What Comes (Just) After "Post" ? The case of Ethnography. In Denzin N and Lincoln Y Editors, Handbook of Qualitative Research.: Sage Publications, Thousand Oaks

McCurdy J (1982) Power is a Nursing Issue. In Muff J Editor, Socialisation, Sexism, Stereotyping: Women's Issues in Nursing. C.V. Mosby, USA

McLeod W, Editor (1984) The Collins Thesaurus. Collins, London

Mercer C (1994) Curriculum Crossroads: Which Direction should Nursing take ? Nursing Praxis in New Zealand, 9(2), 4-10

Mezirow J (1989) Fostering Critical Reflection in Adulthood: a guide to transformative and Emancipatory Learning. Jossey-Bass Publishers, San Francisco

Middleton S (1993) Educating Feminists : Life Histories and Pedagogy. Teachers College Press, New York

Mingay J (1993) A Sociologists View: the handmaiden's theory. In Jolley M and Brykczynska G, Editors, Nursing: its Hidden Agendas. Edward Arnold, London

Ministry of Education (1990) Derivation of Elley-Irving Codes from Census Occupations. Unpublished, Ministry of Education, Wellington

Moccia P (1988) Curriculum Revolution: An Agenda for Change. In Curriculum Revolution: Mandate for Change. National League for Nursing Press, New York. 
Morse J (1994) Designing Funded Qualitative Research. In Denzin N and Lincoln Y Editors Handbook of Qualitative Research. Sage Publications, Thousand Oaks

Mulgan R (1989) Maori, Pakeha and Democracy. Oxford University Press, Auckland

Norrish S (19950 The World Health Organisation Directive on Primary Health Care: a case study examination of its implications for nursing practice. Whitireia Nursing Journal, 2, 60-67

Orange C (1987) The Treaty of Waitangi. Allen and Unwin New Zealand Ltd., Wellington

Orsman E and Orsman H (1994) The New Zealand Dictionary. New House Publishers, Auckland

Ottens A (1984) Coping with Academic Anxiety. The Rosen Publishing Group Inc.,New York

Parumoana Community Polytechnic (1987) He Matapuna. The Bicultural Partnership in Polytechnics. Unpublished Professional Development paper, Whitireia Community Polytechnic, Porirua City

Pearpoint $\mathrm{J}$ and Forest (1994) Inclusive Educational Practice at Whitireia Community Polytechnic, Whitireia Community Polytechnic, Porirua City

Pearson J, Joyce M, Khull J, MacDonald S, Norrish S, Southwick M, Wilks T (1996) Beginning the Journey to self reflective practice: A study of teaching and learning in the first year of the Diploma in Nursing programme at Whitireia Community Polytechnic. Unpublished research report, Whitireia Community Polytechnic, Porirua City

Peirce A (1991) Preceptorial Student's View of their Clinical Experience. Journal of Nursing Education. 30 (6) 244-250

Perry A (1993) Hidden Curricula in Nursing Education. In Jolley M and Brykczynska G, Editors, Nursing and Its Agendas. Edward Arnold, London

Pickford M (1995) In Wilson Schaef A, Calendar for Women who do too Much. Jossey-Bass, San Francisco

Pierce G(1993) The Centrality of Critical Thinking in Educating for Diversity. Paper presented at the Annual Conference on Critical Thinking and Educational Reform (13th Sonoma, CA, August 1-4 1993)

Ramsden I (1993) Korero Whakaruruhau. Unpublished Research report into Culturally acceptable standards of Health service delivery to Maori, Health Department, Wellington

Ramsden I and Spoonley P (1993) The Cultural Safety Debate in Nursing Education in Aotearoa. New Zealand Annual Review of Education, 3, 161-168

Rappaport J (1984) Studies in Empowerment : Introduction to the Issue. Prevention in Human Services, 3, 1-7 
Rather M (1994) Schooling for Oppression: A Critical Hermeneutical Analysis of the lived Experience of the Returning RN Student. Journal of Nursing Education, 33 (6), 263-272

Reed J and Procter S (1993) Nurse Education: A Reflective Approach. Edward Arnold, London

Rogers C (1983) Freedom to Learn in the 1980's. Charles E. Merrill Publishing Co., Toronto

Rotter J (1966) Generalized expectancies for internal versus external control of reinforcement. Psychological Monographs: general and Applied, 80(609),1-28

Ryan W (1971) Blaming the Victim. Pantheon Books, New York.

Sandelowski M (1995) Sample size in Qualitative Research. Research In Nursing and Health, 18, 179-183

Schon D (1987) Educating the Reflective Practitioner. California: Jossey -Bass Inc.

Scott S (1985) Feminist Research and Qualitative Methods: A discussion of some of the issues. In Burgess R, Editor, Issues in Educational Research. The Falmer Press, London

Seligman M.(1991) Learned Optimism. Alfred A Knopf, New York

Shaw S (1986) Nursing and Primary Health Care in New Zealand. The New Zealand Nursing Journal, May, 22-25

Short S, Sharman E, Speedy S (1993) Sociology for Nurses. MacMillan Education Australia PTY Ltd, Melbourne

Skelton R (1994) Nursing and Empowerment: Concepts and Strategies. Journal of Advanced Nursing, 19, 415-423

Southwick M (1994) Making the Treaty Count : A New Curriculum for the Whitireia Nursing Centre of Learning. Whitireia Nursing Journal ,1, 7-16

Southwick M(1994) Learning to Walk the Talk. Critical reflections on Curriculum Development at Whitireia Community Polytechnic from 1985 - 1993. Nursing Praxis in New Zealand, 9 ( 2) 4-10

Stern P (1980) Grounded Theory Methodology: It's Uses and Processes. Image, 12 (1) 20-23

Stevens P, Schlade A, Chalk B, and Slevin O, (1993) Understanding Research. Champion Press Ltd., Edinburgh

Street A (1990) The practice of Journalling for Teachers, Nurses, Adult Educators and Other professionals. Deakin University, Australia

Tones K (1991) Health promotion, Empowerment and the Psychology of Control. Journal of the Institute of Health Education, 29(1), 17-26 
Tripp D (1990) Socially Critical Action Research. Theory into Practice, 29(3), 158-166

Walker R (1985) Doing Research: A handbook for teachers. Routledge, London.

Watson J (1988) A Case Study: Curriculum in Transition. In N.L.N Curriculum Revolution: Mandate for Change. National League for Nursing Press, New York

Watson J (1985) Human Science and Human Care: A Theory of Nursing. Appleton-CenturyCrofts, Norwalk, C.T.

Weiler K (1988) Women Teaching for Change: Gender, Class and Power. Bergin and Garvey Publishers Inc., Massachusetts

Wheeler C and Chinn P (1991) Peace and Power: A handbook of Feminist Process. National League for Nursing Press, New York

White J (1996) Ontological and Epistemological Assumptions. Paper presented to Course on Qualitative Research, Health Research Council , Auckland, Feb 12-16

Whitireia Community Polytechnic (1993) Bachelor of Nursing Curriculum. Unpublished, Whitireia Community Polytechnic, Porirua City

World Health Organisation (1978) Primary Health Care, Report of the International Conference on Primary Health Care, Alma Ata, 6-12 September, 1978, WHO, Geneva

World Health Organisation (1986) Ottawa Charter for Health Promotion, An International Conference on Health Promotion, November.17-21,1986, WHO, Geneva

Zerwekh J (1990) Empowerment of Nursing Students. Nurse Educator, 15(1), 23 and 35 
Appendices 


\section{TE TIRITI O WAITANGI}

Ko Wikitoria, te Kuini o Ingarani, i tana mahara atawai ki nga Rangatira me nga Hapu o Nu Tirani i tana hiahia hoki kia tohungia ki a ratou o ratou mau tonu hoki te Rongo ki a ratou me te ata noho hoki kua wakaaro ia he mea tika kia tukua mai tetahi Rangatira hei kai wakarite ki nga tangata maori o Nu Tirani. Kia wakaaetia e nga Rangatira maori te Kawanatanga o te Kuini ki nga wahi katoa o te Wenua nei me nga Motu. Na te mea hoki he tokomaha ke nga tangata o tona iwi kua noho ki tenei wenua, a e haere mai nei. Na ko te kuini e hiahia ana kia wakaritea te Kawanatanga kia kaua ai nga kino e puta mai ki te tangata Maori ki te pakeha e noho ture kore ana.

$\mathrm{Na}$, kua pai te Kuini kia tukua a ahau a Wiremu Hopihona he Kapitana i te Roiara Nawi hei Kawana mo nga wahi katoa o Nu Tirani e tukua aianei, amua ki te Kuini e mea atu ana ia ki nga Rangatira o te wakaminenga o nga hapu o Nu Tirani me era Tangatira atu enei ture ka korerotia nei.

\section{KO TE TUATAHI}

Ko nga Rangatira o te Wakaminenga me nga Rangatira katoa hoki kihai i uru ki taua wakaminenga ka tuku rawa atu ki te Kuini o Ingarani ake tonu atu te Kawanatanga katoa o o ratou wenua.

\section{KO TE TUARUA}

Ko te Kuini o Ingarani ka wakarite ka wakaae ki nga Rangatira ki nga hapu, ki nga tangata katoa o $\mathrm{Nu}$ Tirani te tino rangatiratanga o o ratou wenua o ratou kainga me o ratou taonga katoa. Otiia ko nga Rangatira o te Wakaminenga me nga Rangatira katoa atu ka tuku ki te Kuini to hokonga o era wahi wenua e pai ai te tangata nona te wenua, ki te ritenga o te utu e wakaritea ai e ratou ko te kai hoko e meatia nei e te Kuini kei kaihoko mona.

KO TE TUATORU

Hei wakaritenga mai hoki tenei mo te wakaaetanga ki te kawanatanga o te Kuini. Ka tiakina e te Kuini o Ingarani nga tangata maori katoa o Nu Tirani ka tukua ki a ratou nga tikanga katoa rite tahi ki ana mea ki nga tangata o Ingarani.

\section{(Signed) WILLIAM HOBSON}

Consul and Lieutenant-Governor

Na ko matou ko nga Rangatira o te Wakaminenga o nga hapu o $\mathrm{Nu}$ Tirani ka huihui nei ki Waitangi, ko matou hoki ko nga Rangatira o Nu Tirani ka kite nei i te ritenga o enei kupu, ka tangohia, ka wakaaetia katoatia e matou, koia ka tohungia ai o matou ingoa o matou tohu.

Ka meatia tenei ki Waitangi i te ono o nga ra o Pepuere i te tau ko tahi mano, e waru rau, e wa tekau o to tatou Ariki.

Ko nga Rangatira o te wakaminenga.
TREATY OF WAITANGI

Appendix 1

Her Majesty Victoria Queen of the United Kingdom of Great Britain and Ireland regarding with Her Royal Favour the Native Chiefs and Tribes of New Zealand and anxious to protect their just Rights and Property and to secure to them the enjoyment of Peace and Good Order has deemed it necessary in consequence of the great number of Her Majesty's Subjects who have already settled in New Zealand and the rapid extension of Emigration both from Europe and Australia which is still in progress to constitute and appoint a functionary properly authorised to treat with the Aborigines of New Zealand for the recognition of Her Majesty's Sovereign authority over the whole or any part of those islands Her Majesty therefore being desirous to establish a settled form of Civil Government with a view to avert the evil consequences which must result from the absence of the necessary Laws and Institutions alike to the native population and to Her subjects has been graciously pleased to empower and to authorise me William Hobson a Captain in Her Majesty's Royal Navy Consul and Lieutenant Governor of such parts of New Zealand as may be or hereafter shall be ceded to her Majesty to invite the confederated and independent Chiefs of New Zealand to concur in the following Articles and Conditions.

\section{ARTICLE THE FIRST}

The Chiefs of the Confederation of the United Tribes of New Zealand and the separate and independent Chiefs who have not become members of the Confederation cede to Her Majesty the Queen of England absolutely and without reservation all the rights and powers of Sovereignty which the said Confederation or Individual Chiefs respectively exercise or possess, or may be supposed to exercise or to possess over their respective Territories as the sole Sovereigns thereof.

\section{ARTICLE THE SECOND}

Her Majesty the Queen of England confirms and guarantees to the Chiefs and Tribes of New Zealand to the respective families and individuals thereof the full exclusive and undisturbed possession of their Lands and Estates Forests Fisheries and other properties which they may collectively or individually possess so long as it is their wish and desire to retain the same in their possession; but the Chiefs of the United Tribes and the individual Chiefs yield to her Majesty the exclusive right of Preemption over such lands as the proprietors thereof may be disposed to alienate at such prices as may be agreed upon between the respective Proprietors and persons appointed by Her Majesty to treat with them in that behalf.

\section{ARTICLE THE THIRD}

In consideration thereof Her Majesty the Queen of England extends to the Natives of New Zealand Her royal protection and imparts to them all the Rights and Privileges of British Subjects. WILLIAM HOBSON Lieutenant Governor

Now therefore We the Chiefs of the Confederation of the United Tribes of New Zealand being assembled in Congress at Victoria in Waitangi and We the Separate and Independent Chiefs of New Zealand claiming authority over the Tribes Territories which are specified after our respected names, having been made fully to understand the Provisions of the foregoing Treaty, accept and enter into the same in the full spirit and meaning thereof: in witness of which we have attached our signatures or marks at the places and the dates respectively specified.

Done at Waitangi this Sixth day of February in the year of Our Lord One thousand eight hundred and forty. 


\section{Appendix 2}

\section{CHARTER}

\section{PURPOSE STATEMENT}

Council and staff see the purpose of Whitireia Community Polytechnic is to provide high quality learning opportunities and a sense of belonging for all people in supportive and caring ways which are:

Non-sexist

Non-racist

Sensitive and responsive to the uniqueness of each person's special needs

Responsive to the changing multicultural community

In accordance with the Treaty of Waitangi

\section{VALUES STATEMENT}

Council and staff are committed to the following values:

\section{EQUTTY}

Providing significant learning, power-sharing and success for those who have lacked such opportunities. IDENTITY

Creating an environment where people feel they belong because their uniqueness is valued and promoted. RESPONSIVENESS

Being flexible, creative and open to change, to better meet individual and community needs.

MANAAKI

Encouraging the sharing of views, learning and resources, where individual self-esteem (mana) and group harmony result from caring about others.

\section{SUCCESS}

Being an effective organisation which leads in its field, demonstrating a clear sense of purpose and striving for excellence.

\section{GOALS}

\section{OVER-RIDING STATEMENT}

All Goals and Policies developed will be consistent with the Treaty of Waitangi and ensure the opportunity for Maori people to achieve their social and economic potential as an equal party to the Treaty.

\section{GOAL 1}

To provide a comprehensive range (introductory to degree level) of high quality, accessible, appropriately recognised, vocational and non-vocational learning opportunities which have been developed by consulting widely with relevant industry, occupational and other constituent groups.

\section{GOAL 2}

To provide a learning environment (including high quality teaching and a range of learning services) which enhances the possibility of success for every student - as of right.

\section{GOAL 3}

To actively promote equity of educational opportunity particularly for traditionally disadvantaged groups.

\section{GOAL 4}

To be accountable for the efficient and effective use of resources allocated.

\section{GOAL 5}

To increase available funding resources. 


\section{Appendix 3}

\section{THE CURRICULUM PHILOSOPHY}

\section{INTRODUCTION}

The epistemological beliefs espoused in this curriculum arise from individual and collective critical reflection on past experience. Out of the discourse emerges a renewed commitment to two fundamental principles. Firstly, that health and well-being are an inherent right of all people in our community. Secondly, that through the development of specialised knowledge (research) nurses make a unique contribution to the health of their communities through their nursing practice.

In seeking to embed these principles in our curriculum we have chosen to use the Treaty of Waitangi as a central organising conceptual framework. The justification for using this framework arises out of our belief that the Treaty provides us with a powerful metaphor of PARTNERSHIP by illuminating relational boundedness and the transformative possibilities which occur in the spaces created within this boundedness. The Treaty of Waitangi articulates the nature of the relationship between the founding peoples of New Zealand, by first naming them, and then describing the rights and obligations of each to the other. This is what we refer to as relational boundedness. It is the space between the "one" and the "other" that creates the dialectical tension through which relational possibilities are transformed into action. Even more fundamental than this, we would argue that when "one" and "other" engage in the dialectic each creates both "self" and "other".

Critically reflecting on the historical relationship between the Crown and Maori gives us important insights into how the health and well-being of people within our society has been managed over time, and provides strategies by which barriers to health and well-being may be better addressed in the future. Deep understanding of the relational; that is, recognition of the dialectic between "one" and "other", is a fundamental basis for nursing practice. We believe that an understanding of the relational possibilities illuminates the transformative potential of the teaching/learning relationship, and the nurse/client relationship.

Our beliefs about the significance of the concept of partnership to the teaching/learning, and nurse/client relationship are articulated through the understanding we have of the way the Articles of the Treaty create the possibility of partnership within the New Zealand context.

\section{THE TREATY OF WAITANGI}

\section{ARTICLE THE FIRST}

\section{KAWANATANGA/GOVERNORSHIP}

The first article of the Treaty of Waitangi is the basis for the claim that the Treaty is the cornerstone of New Zealand nationhood. Social existence is dependent on the organisation of mutual relations of human beings and classes of human beings in community. By signing the Treaty, Maori people mandated to the Crown the authority to secure an ordered social system within which Maori people and those represented by the Crown could live together in community. Over time, the authority of the Crown has been transferred to a western liberal parliamentary democratic system of government.

In an uncritical climate this ordered system becomes a dominant ideology by representing itself as the 'natural order', thus "assuming a cultural ascendancy" which enables this world view to reproduce itself overtime. (Fay. 1987. p 138) This process is what Gramsci described as hegemonic oppression in which;

\section{"...those who govern and disproportionably possess its goods are thought to have a right to do so."} (Gramsci. 1971. P. 181-182)

The greatest source of a government's power and authority lies in the hegemonic belief held by those who are governed, that governments act in their best interest. It is this process which obscures the real nature of power relations within any social system. What makes the New Zealand context unique is that by using the Treaty of Waitangi as their reference, Maori have consistently challenged this hegemonic process. By their resolve to maintain their mana motuhake, Maori challenge the legitimacy of a social order based on a "single world view" reality. By creating the possibility that "knowledge" may derive from more than a single world view Maori become an archetypal model for the claim that there may be many ways of knowing. 
From the literature, and our own experience of teaching to culturally and socially diverse students we believe that a single world view approach to teaching and learning deriving solely from an empirical/behaviourist paradigm is not only educationally inadequate but also morally indefensible. In acknowledging the possibility of a bicultural world view, we can also extrapolate that there are many world views, many ways of knowing, that inform us. To provide a framework where these different forms of knowing are explicit and open for conscious reflection we have used Habermas' three categories of knowledge-constitutive interests which he argues are integral to human existence. These three categories he identified as "technical", "practical" and "emancipatory". (Habermas, J., 1971).

Each of these knowledge interests articulate essential ways of knowing which is integral to nursing practice.

Technical knowledge interests derive from empirical analytic inquiry and is;,...".typically instrumental knowledge taking the form of scientific explanations. "(Carr \& Kemmis. 1986. p 135) These explanations provide nurses with essential knowledge of the psycho biophysical, as well as an understanding of instrumental methodologies and process which are integral aspects of nursing practice.

Practical knowledge interests derive from the hermeneutic or interpretive paradigm. Typically it takes the form of phenomenological inquiry which explores and articulates the meaning of the lived experience for self and others.

"It is distinguished from technical cognitive interest in that it aims not at comprehension of an objective reality but at the maintenance of the intersubjectivity of mutual understanding." (Habermas, J., 1971. p 176).

It is through the insights gained from the phenomenological paradigm that nurses are able to articulate the core value of caring in nursing practice.

Emancipatory knowledge interest arises from a critical paradigm. Habermas argued that the interpretive paradigm was an insufficient explanation because it ignored the way people's understanding of their lived experience was itself shaped by the social structures and constraints. (Carr \& Kemmis ibid.) Emancipatory knowledge is possible when people engage in a discourse which challenges dogma and received wisdoms.

"Discourse helps test the truth claims of opinions (and norms) which the speakers no longer take for granted. In discourse the force of the argument is the only permissible compulsion, whereas cooperative search for truth is the only permissible motive." (Habermas, J., 1971. p 168).

In the context of the relational, when "undistorted" communication occurs people can realise their potential to fully act as autonomous rational decision makers. It is the inclusion of emancipatory knowledge that moves us past the didactic limitations of power and powerlessness, and into a dialectic model of empowerment from which transformative partnership can emerge.

It is this illuminated concept of partnership which links the emancipatory potential of the Treaty of Waitangi with the emancipatory potential of the teaching/learning relationship, and the emancipatory potential of the nurse/client relationship.

\section{TECHNICAL KNOWLEDGE AND NURSING}

Critically reflecting on the limitations of positivist science as a 'single world view' enables us to articulate both the relationship of science within the curriculum, and the nature of power relations existing between "teachers" and "learners".

Like most industrially developed countries, New Zealand has gained much from the application of knowledge gained from positivist science. However as Carr and Kemmis (1986) argue;

"Science had become an ideology culturally produced and socially supported unexamined way of seeing the world which shapes and guides social action." ( 1 1 321)

In developing our curriculum we have recognised that a "single world view" based on an empirical behaviourist approach to teaching and learning is an inadequate basis to prepare students for nursing practice. There are two major limitations to curricula which rely solely on an empirical approach. 
The first serious limitation is that empirical explanations are themselves limited. Again to quote Carr and Kemmis;

"... to claim that the label "Knowledge" can only be ascribed to that which is founded in 'reality' as apprehended by the senses, (is in effect to say) that value judgements, since they cannot be founded on empirical knowledge, cannot be given the status of valid knowledge. (ibid. pp 61-621).

We would argue that one of the important outcomes of this curriculum is in fact to produce beginner nurse practitioners who are able to make sound value judgements in relation to client care. To rely solely on an empirical behaviourist paradigm would be to create a serious paradox between what we teach and what we intended to achieve. Bevis (1989) has lucidly argued that when nursing curricula depend on a behaviourist approach, illegitimate and hidden curricula are employed to circumvent the inadequacies of explanations deriving from this empirical paradigm.

The second limitation to behaviourist curricula is that they become what Freire has described as a "banking" model of education. (Freire, P. 1972) That is to say a model of education in which the teacher has all the 'knowledge' which they 'deposit' in students who are deemed to have no knowledge. It is this model of education which has been challenged by many critics on the grounds that it has become one of the principle mechanisms by which dominant ideology is reproduced by obscuring the nature of the power relations in the teaching/learning context.

(eg Freire, P. 1972, Gramsci, A. 1971, Bourdieu, P. 1973, Apple, M. 1979.)

It is these insights, along with their lived experience which has in recent years caused Maori to question the adequacies of the education system to meet their needs and aspirations. Similarly, authors such as Belenky, M. et al (1986) have challenged this model of education from a feminist perspective. And this same challenge has been raised by nurses who have questioned the adequacies of this model of education to prepare students for nursing practice. (Bevis, E. \& Watson, J. 1989, Perry, J \& Moss, C. 1989, Clare,J. 1991. Dixon, A. 1991.)

In addressing this limitation we acknowledge our obligations and responsibilities of Kawanatanga in this curriculum. The curriculum describes the "ordered system", and states under what authority actions are taken in order that accountability may be defined.

The boundedness of the concept of Kawanatanga as it relates to the role of the "teacher" in this curriculum, arises from the interpretation of Governorship as authoritative responsibility and obligation to "students" rather than authoritarian privilege. From this stance, Tutors model the way "governance" translates into a social contract of competency for the professional responsibilities and obligations of safe nursing practice.

In this curriculum technical interests are reflected in a strong Bioscience focus and technical nursing skills.

\section{ARTICLE THE SECOND AND FOURTH}

\section{TINO RANGATIRATANGA/AUTONOMY}

At the very least the second article of the Treaty articulates the right of Maori to maintain their separate identity as Maori. The Crown guaranteed to protect those institutions, customs and artefacts by which Maori express and know themselves as Maori. We have interpreted Tino Rangatiratanga to mean the right to be self governing and self determining, and use the term "Autonomy" to represent this meaning.

Hoagland (1988) describes the Kantian view of autonomy as the need for people to rise above their nature and through the use of pure reasoning determine what to do and by exercising their will do their duty. Fay (1987) presents the existentialist view of autonomy as defined by Sartre as the freedom from the illusion that our actions are dependent on external forces or other people. According to this view of autonomy we are condemned to freedom. The autonomous person knows that they alone are responsible for the decisions they make from an infinite range of possibilities. (p 201)

A third sense of how the term autonomy has been defined is that suggest by Rousseau. He argued that autonomy represented moral liberty. That is, the autonomous person is one who acts on the basis of ones best judgement as to what one should do. A person is self determining in the sense that who one is and what one does is as a result of ones own voluntary discretion. (Fay. 1987. p 76).

Hoagland challenges the Kantian view of autonomy as freedom from ones emotions, and the radical autonomy of the existentialists, and appears to argue a view of autonomy similar to the Rousseau explanation. 
She proposes that autonomy may be defined as the self conscious sense of ourselves as moral agents. She extends the concept of autonomy (self governing) to include the idea of autonomous individuals in community by coining the term "auto koenony", that is self in community. Auto (self) and koenonia (community, or any group whose members have something in common).

"The self in community involves making choices, it involves us having a self conscious sense of ourselves as moral agents in a community of other self conscious moral agents."

(Hoagland. 1988. p 451.)

This idea of self in community is expanded upon by Fay who argues that:

"Collective autonomy involves a group of people determining on the basis of rational reflection the sorts of policies and practices it will follow and then acting in accordance with them." (Fay. 1987. p 77)

In relating these different perspectives back to the Treaty, we argue that autonomy expressed as Tino Rangatiratanga, is the possibility Maori people have to critically reflect on what it is to be Maori within the context of the dialectic tension between Kawanatanga, and Tino Rangatiratanga.

It is in the space between Kawanatanga and Tino Rangatiratanga that all of the relational possibilities can be realised. It is from the Treaty that we take this model of the way "partnership" can emerge from a transformative relationship in which "self and "other" are mutually constitutive.

In his discussion of Buber's conceptualisation of the I-Thou relational, Geering captures the essence of this potential.

"In the beginning there is neither I nor Thou but the primal relation we may call I-Thou. It is out of such a relation that the I grows to become a self conscious reality. Moreover, it is only through a Thou that a person develops a clear sense of selfidentity: and this happens to one as an act of grace."

(Geering. 1983. p 27)

We would argue that the Treaty provides an opportunity for this relational possibility to exist between Maori and non Maori, and to symbolically represent the transformative potential of all relationships.

If it is an act of grace to recognise that the "I" needs the "other" in order to know "self" then it is the act of an autonomous, self conscious moral being to accept responsibility for what they bring to the relational.

Understanding the shared meanings of people's lived experience, and the choices they make, forms the basis for Habermas' claim that this constitutes a practical knowledge interest.

\section{PRACTICAL KNOWLEDGE INTERESTS AND NURSING}

If technical knowledge enables us to develop universal laws of probability, then practical knowledge enables us to understand through interpretive theory the meanings people make of their lived experience.

"Lived experience is the way people encounter situations in terms of their own personal concerns, background meanings, temporality, habitual, cultural bodies, emotions and reflective thought. "

(Benner \& Wrubel. 1989. p 410)

The significance of practical knowledge to nursing practice is that through the use of interpretive methodologies such as phenomenology, nurses are able to surface the central caring value of nursing practice. Patterson \& Zderad (1976), Watson (1985), Benner \& Wrubel (1989), and Bishop \& Scudder (1991) have all provided examples of thick descriptions of the way caring is critically and fundamentally a process involving the relational between nurse and client.

Nursing begins with a moral disposition "to care". Using an ontological interpretation of caring as a fundamental human way of being in the world, Bishop and Scudder (1991) draw a Heidegarrian distinction between caring that creates dependency and "authentic caring".

"... authentic care occurs when the care giver will 'leap ahead' in his existential (sic) potentiality-for-Being, not in order to take away his "care" but rather to give it back to him authentically. Thus, in authentic care the other is helped to care for his or her own being." (Bishop \& Scudder. 1991. p 57) 
The significance of the distinction between caring which is dependency creating and caring which is authentic, is that dependency creating care inevitably involves a "power-over" relationship. Authentic care is "an act of grace", in that the power in the relational is an enabling power, a "power-to".

We would argue that a prerequisite for understanding the full potential of what it means "to care" is the development of an autonomous self as defined by Hoagland. That is that "authentic caring" can only be undertaken by people who have developed a self conscious sense of themselves as moral agents. It is our contention that authentic caring for self precedes the possibility of authentic caring for others. Within this curriculum students are guided through a reflective process of exploring their own lived experience, in relation to others. From this platform, students begin the exploration of the meaning of authentic caring for self and others, for the I-Thou within a nursing context, using the knowledge from the interpretive paradigm to inform them.

While knowledge from the interpretive paradigm is a necessary aspect of nursing knowledge, it is no more sufficient an explanation of the complexities of nursing practice than knowledge from the technical paradigm. To argue that the one or the other is a better foundation for nursing practice is to deny ourselves the opportunity to use both kinds of knowledge. The transformative power of the relational is diminished when it is represented as a reductionist argument of either/or. That is to say that neither the knowledge from the technical, nor the interpretive is sufficient to explain the relational.

In relation to the Treaty this point is most aptly put in a submission to the Waitangi Tribunal from the Manakau claim:

".. As things are, the local tribes have no status. Continually they feel it to be pressed upon them that they have only two options- to capitulate to Western ways, which they refuse to do, or cling to past ways in the belief that they contain fixed and uncompromising truths freed from the challenge of change. We believe there is a better option." (Cited by William Renwick. 1990. p 42).

In relation to an educational curriculum, Bawden argues that this reductionist logic has become a

".. conflict around the relative importance of knowing versus doing. It has indeed become an issue of competitive exclusion-Knowing has become divorced from doing and vice versa, and indeed has been placed in opposition to it. (Bawden. 1993. p 1)

Within Nursing this same argument takes the form of the a debate between "theory" versus "practice", and between the "ethic of efficiency" and the "ethic of caring".

What is required to move beyond this sterile binary trap is a way of conceptualising the relationship between Kawanatanga and Tino Rangatiratanga, between knowing and doing, and between theory and practice.

We believe the third article of the Treaty moves us beyond the binary trap of either/or, and enables us to explore the "other options", the other potentialities.

In this curriculum practical interests are reflected in the emphases on personal growth and communication skills, and an acknowledgment of the significance of the meaning that individuals have of their own lived experience.

\section{ARTICLE THE THIRD}

\section{KIA RITE TAHI/EMPOWERMENT}

The third article brings the concept of Kawanatanga into relationship with Tino Rangatiratanga. It articulates two obligations of the Crown to Maori, and by inference suggests the responsibility of Maori to the Crown. The first obligation was that the Crown would protect Maori people. We interpret this obligation from a deontological perspective of non maleficence, that is an obligation to do no harm. The second obligation was that the Crown would invest Maori people with the same rights of citizenship as all other people within the Crowns jurisdiction. This second obligation we interpret as a right of inclusion.

The significance of defining protection and inclusion is that it places some boundaries on the nature of the relationship formed by the two parties to the Treaty. The notions of protection and inclusion oblige the Crown to remain in the partnership with Maori. At the same time it may be argued that by accepting the rights of citizenship, Maori also accept the responsibility to participate, and thereby setting some limits to their autonomy. 
The three articles of the Treaty of Waitangi create the possibility of a partnership between the founding peoples of New Zealand. Our understanding of the partnership between Maori and non Maori acknowledges past power relations of dominance and subordination, and the effects that this history has had on the way we express ourselves as New Zealanders. In the past we would argue that the denial of the significance of the Treaty by Tau Iwi has led to injustices and social inequities for the Tangata Whenua. A relationship built on hegemonic privilege is oppressive to all in the relationship because it limits human potential.

When we begin to understand through critical reflection that the Treaty enables both 'partners' to define themselves in relation to the other, then the whole concept of partnership becomes one of emancipatory potential. This potential occurs when people are able to engage in what Habermas defined as the undistorted communication of discourse.

When discourse occurs all of the dialectical possibilities are attendant in a relational in which authentic self engages with authentic other to act. Empowerment is achieved when this emancipatory potential is realised.

\section{EMANCIPATORY KNOWLEDGE INTERESTS AND NURSING}

Bawden argues that the reductionist trap can be avoided through the realisation that the relationship is triangular not binary. In his formulation the triangle is defined at each apex by 'theory", "practice" and "praxis".

"As a Trinity (these concepts) reflect a set of interrelated processes where no one element is prime, but each contributes to, and indeed participates in the others in affecting their very essences and creating a dynamic learning system." (Bawden. 1993. p 2.)

Similarly, Bishop and Scudder reconceptualise Buber's I-Thou, I-It from a binary dialogue to a "triadic dialogue", by including the "It" world into the relational between the "I and Thou".

"Triadic dialogue is constituted by the relationship of two partners to the events in the world, as well as their relationship to each other:" (Bishop \& Scudder. 1991. p 83)

We would argue then that emancipatory knowledge within the curriculum enables tutors and students to engage in dialogue which surfaces the contradictions between "theory" and "practice", by reflecting on their own understanding and experience in such a way that new questions and therefore possibilities emerge. According to Perry and Moss (1989) this becomes a transformative process because "ideal-real" dichotomies are able to be made explicit and therefore open to critique. It is this transformative potential which Freire (1972) calls praxis and which we derive from the Treaty partnership as empowerment.

It is this transformative potential of the relational which we take from the Treaty and embed in our curriculum to illuminate the teaching/learning partnership, and the nurse/client relationship in nursing practice.

In this curriculum emancipatory interests are reflected in the strong emphasis on critiquing Maori access to health, and sociological concepts relating to disadvantage, which create structural barriers to full and equitable access to health care. 


\section{REFERENCES}

Apple, M. W. (1979). Ideology and curriculum. Routledge and Kegan Paul.

Bawden, R. (1993). Praxis: The essence of systems for being. In Alison R. Viskovic, (Ed.), Research and development in higher education (pp 1-7). HERDSA (Inc).

Belenky, M. F., Clinchy, B. M., Goldberger, N. R., \& Tarule, J. M. (1986). Women's ways of knowing: The development of self, voice, and mind. NY: Basic Books.

Benner, P. \& Wrubel, J. (1989). The primacy of caring: stress and coping in health and illness. California: Addison-Wesley.

Bevis, E. (1988). New directions for a new age. Curriculum revolution: mandate for change. N.Y.: National League for Nursing.

Bevis, E. \& Watson, J. (1989). Towards a caring curriculum: A new pedagogy for nursing. N.Y: National League for Nursing.

Bishop, A., \& Scudder, J. (1991). Nursing: The practice of caring. N.Y.: National League for Nursing.

Bourdieu, P. (1973). Cultural Reproduction and Social Reproduction. In Richard Brown (Ed.), Knowledge, education and cultural change. Tavistock.

Buber, M. (1970). I and thou, Trans. W. Kaufmann, T \& T Clark, Edinburgh.

Carr, W., \& Kemmis, S. (1986). Becoming critical: Education, knowledge and action research. Victoria, Australia: Deakin University Press.

Clare, J. (1991). Transforming health care: Does nursing theory have anything to offer? Nursing Praxis in New Zealand. $\underline{6}(2): 5-9$.

Dixon, A. (1991). Bachelor of Nursing and Midwifery curriculum. Otago Polytechnic.

Fay, B. (1987). Critical social science. Oxford: Polity Press.

Freire, P. (1972). The pedagogy of the oppressed. N.Y.: The Seabury Press.

Geering, L. (1983). The world of the relation: An introduction to Martin Buber's I and Thou. Victoria University Press.

Gramsci, A. (1971). Selections from the prison notebooks. Q. Hoare and Geoffrey Nowell-Smith (Eds.). N.Y.: International Publishers.

Habermas, J. (1971). Knowledge and human interest. (Trans. J. Shapiro). Boston: Beacon Press.

Hoagland, S. L. (1988). Lesbian ethics: Towards new value. Institute of Lesbian Studies. Palo Alto, California.

Paterson, J. G., \& Zderad, L. T. (1976). Humanistic nursing. N.Y.: Wiley.

Perry, J., \& Moss, C. (1989). Generating alternatives in nursing: Turning curriculum into a living process. The Australia Journal of Advanced Nursing. $\underline{6}$ (2):33-40.

Renwick, W. (1990). The Treaty Now. Government Print Publications.

Watson, J. (1985). The moral failure of the patriarchy. Nursing Outlook. $\underline{38}$ (2):62-66. 
This research project is being undertaken as the basis for my thesis, which forms part of the requirements for my M.Ed degree.

I am interested in the concept of empowerment in education and specifically in the empowerment of nursing students in the educational settings of Polytechnic and clinical .

The aim of the study is to gain contextual meaning and understanding of the process of empowerment by:

- Exploring the concept of empowerment through a review of nursing, educational and associated Treaty of Waitangi literature.

- Gathering data from participants using individual interviews to elicit exemplars, and holding group meetings to discuss and clarify interpretations.

- Data analysis using interpretative methods to identify meaning or meanings of empowerment .

- Developing a theory to explain the enhancement of empowerment for nursing students.

- Making recommendations, based on research findings that will clarify contexts and interactions that facilitate the development of empowerment.

To meet the second objective ( bold italics) I will need to individually interview five to ten of your group about empowerment and moments in your learning when you felt you were empowered by a teaching/ learning interaction. The interviews will be audio taped, transcribed by myself and returned to you for checking of content and meaning prior to analysis / interpretation by myself.

I will need to have two interviews (taking up to an hour) and two group meetings (of up to an hour) with those of you who wish to be involved. I aim that the group meetings would be discussions that help clarify issues and help shape the project as it develops, that is, include participants in the research process.

I will ensure that the information given remains confidential, and to value and be aware of other pressures that you have on your time and energy.

If you wish to participate could you please fill out the section below and I will get in touch with you as soon as possible to arrange our next meeting (first interview)

Name.

Address.

Phone

Consent to participate in this project (signature) 
These are the main questions I will explore with you at our interview.

I am giving the questions to you prior to our discussion to give you some time to think about the answers.

I am interested in your thoughts, opinions, and experiences, whatever they may be.

1) Would you please tell me about your educational history? That is, your schooling and other educational experiences you, ve had proir to coming into the nursing degree course.

2) How did you spend your time prior to comimg on the course ? ie. Child care, employment school etc

3) What were your perceptions of your learning ability prior to coming into the course ?

4) What are your perceptions about your learning ability at this stage of the course ?

5) What does the word 'empowerment' mean to you ?

6) What does empowerment mean as it applies to your teaching/ learning experiences ?

7) Can you describe a teaching / learning situation you've had that made you feel empowered, at any time during your nursing course?

Ie: -Would you be able to tell me, or record:

Who were the people in the interaction? ( eg. self and tutor, clinician, peer etc.)

What was the subject / task of learning?

When did it take place?

Where did it take place? (eg. classroom, nursing lab, clinical situation)

How did it occur, or what actually happened? (in as much detail as you can remember)

Why did this interaction feel empowering?

What were you thinking about at the time?

What did you feel at the time, and/ or after?

What did you find most memorable about this interaction/experience?

Is there anything else you would like to discuss / tell be about this area of your learning ?

Would you just let me record your age group ? 17 - 20, 20- 25, 25-30, 30-35, over 35

The enthnic group with whch you identify? 
Interview schedule for second interview November 141995

Just want to check back with you after you've had the opportunity to read through the transcript and think some more about empowerment in your teaching and learning

1) Have you any further experiences / examples of teaching /learning experiences that you've had that made you feel empowered, that you want to tell me about? *

Ie: -Would you be able to tell me,

Who were the people in the interaction? ( eg. self and tutor, clinician, peer etc.)

What was the subject / task of learning ?

When did it take place?

Where did it take place? (eg. classroom, nursing lab, clinical situation )

How did it occur, or what actually happened? (in as much detail as you can remember)

Why did this interaction feel empowering?

What were you thinking about at the time?

What did you feel at the time, and/ or after?

What did you find most memorable about this interaction/experience?

* If none I will ask about disempowering experiences

If some then ask

2) Have you ever felt disempowered ? If yes when, why

3) Is there anything else you would like to discuss / tell be about this area of your learning

4) Would you just let me record your age group ? $17-20,20-25,25-30,30-35$, over 35 ?

5)The enthnic group with whch you identify?

6) Just for interests sake, what made you decide / why did you agree to take part in this research?

Following transcription of the tape I will send you a copy then I would like to meet with you in the new teaching year to let you know what I have come up with.

Would you prefer to meet with me by yourself or in a group ? 
Level one of the Bachelor in Nursing course runs for 32 weeks. This time is divided into three 10 week trimesters with a one week break between trimesters.

The content of the course is arranged into various subject papers. Some run for one trimester whilst others run for the whole year.

\section{Key (1) Trimester 1 papers \\ (2) Trimester 2 papers \\ (3) Trimester 3 papers \\ (4) Full year papers}

Nursing Knowledge 101 (1) Provides the introduction to the body of knowledge which, shaped and shapes the profession of nursing.

Nursing Research 102 (1) Provides the introduction to the relationship between knowledge and nursing practice and research. Issues of ethics and research methods are also introduced.

Treaty of Waitangi 103 (1) Provides a knowledge and understanding of the Treaty of Waitangi. This enables students to appreciate wellness and whaiora from a bicultural perspective.

Introduction to Bicultural Studies 104 (1) Explores the concept of culture form the students world view Provides a beginning knowledge of the world of Maori to non-Maori students. Facilitates the development of attributes which enable students to be culturally safe within Bicultural environments .

Nursing Practice 105 (4) Introduces the concepts and contexts of nursing within a humanistic framework. It also develops beginning professional expertise in the fundamental skills of nursing.

Bioscience 107 (4) Studies the structure and functioning of the human body at various levels of complexity. The importance of homeostasis to body function is explored.

Lifespan 111/112 (2) \& (3) These papers focus on the development of knowledge and understanding of the principles and theories of human growth, health and lifestyle, decision making and the New Zealand Health Goals. Students begin to assess health status and develop holistic nursing skills as they relate to people across the lifespan.

Paper 111 (2) Focuses on the child to adolescent part of the lifespan and provides a foundation for students to individualise care for children and families

Paper 112 (3) Focuses on the adolescent to older adult part of the lifespan and again provides a foundation for students to individualise care for persons in these stages of the lifespan.

Sociology 113 (1) Provides a conceptual framework to expand students knowledge of social structures and institutions and their application to nursing practice.

The Caring Relationship 115 (4) Facilitates an increase in self-awareness and the development of healing behaviours on both a personal and professional level.

Health Behaviour 117 (1) Provides information about wellness and the application of knowledge from behavioural sciences to nursing practice.

Level two of the Bachelor in Nursing course runs for 32 weeks. This time is divided into two sixteen week semesters with a one week break between.

The content of the course is arranged into various subject papers. Some run for one semester whilst others run for the whole year.
Key (1) Semester 1 papers
(2) Semester 2 papers
(3) Full year papers

Nursing knowledge 201 (1) This paper is designed to give the student the opportunity to identify knowledge which informs nursing practice. This includes nursing theory, ethical and legal responsibilities. 
Nursing Research 202 (2) The purpose of this paper is to provide a clear understanding of the relationship between nursing practice, nursing knowledge and nursing research. Questioning of current nursing knowledge and developing discrimination in reading research is also included in this paper.

Cultural Safety in Nursing Practice 204 (3) This paper will enable students to consolidate the learning achieved in level one and aims to increase awareness of and assist in promoting the health status of Maori people. The paper will enable students to develop confidence in applying skills, knowledge and attitudes to situations they will encounter in their nursing practice, and to deliver care that is culturally safe.

Bioscience 207 (3) This paper builds on the knowledge developed in the 100 level Bioscience paper. It is designed to enable students to develop an understanding of altered physiological changes that occur as a result of developmental alterations, illness and adaptive or compensatory changes.

Sociology of Health Care 213 (3) This paper builds on the sociological perspectives and concepts from Introductory Sociology paper 113. It focuses on the New Zealand Health Care system, its workers, providers and users.

The Caring relationship 215 (3) The purpose of this paper is for the student to make meaning out of the lived experience of self and others through reflection on practice in the health care system. An emphasis on the processes in the nurse/patient relationship is made with particular emphasis upon caring as a core value in nursing. 
COMPETENCIES - YEAR 1

Appendix 8

\section{PROFILE OF STUDENT AT THE END OF YEAR 1}

\section{GOAL}

Advanced student beginner, confident to begin student nurse engagement with people in the health care system and able to identify personal constraints to critical learning.

The student by the end of Year 1 will:

1 Understand fundamentals of nursing.

2 Systematically perform identified skills.

3 Express elements of a healthy lifestyle and increase own repertoire of healthy behaviours.

4 Access information with support.

5 Evaluate arguments.

6 Express logical arguments.

7 Respond to feedback (beginning of dialectic process).

8 Show willingness to engage in reflection so that insight is gained into own:

- Attitudes

- Learning style

- Culture formations (national, historical, personal, political)

- Patterns of communication

- Emotional responses

- Physical health

- Relations with the health care system (ie can access for self)

- Self and peer assessments

- Willingness to reflect on self

9 Identify own barriers to learning and act to change.

10 Have a conscious awareness of self.

11 Begin to identify conflicts/differences to own and multiple ways of knowing.

12 Acknowledge student role in nurse development. 
After consultation with tutors, students are invited to select the two nursing practice papers they intend to undertake, one for each semester of study, at this level of the Programme.

During this year of the Programme, students are expected to be able to consolidate the learning from Year 1 of the Programme and build on that learning by applying the knowledge of nursing practice in a range of clinical contexts.

Associated papers undertaken in Year 2 foster a broader spirit of inquiry for the student which they use to enhance the nurse/client interaction.

\section{YEAR 2 LEARNING COMPETENCIES}

Students are expected to plan and monitor their own learning and are able to provide informed feedback to peers.

Students will be introduced to Benner's domains of nursing and Pere's model of health.

Competence in self governorship is reflected in negotiated learning in a variety of practice environments with tutor assistance. Increasingly learners are expected to become more autonomous and self directed.

A major emphasis in Year 2 is in empowerment of patients through understanding their perceptions, relating to health and illness, and effectively assisting or responding to clients.

Domains of knowledge emphasised in Year 2 are technical, and especially interpretive, with an increasingly critical stance.

\section{PROFILE OF STUDENT AT THE END OF YEAR 2}

\section{GOAL}

Confidence as a student nurse, able to relate to clients and ready to engage with the wider profession.

The student by the end of Year 2 will:

1 Know selected nursing theory and related disciplines in relation to practice.

2 Systematically perform a range of identified skills in a variety of contexts.

3 Practise as a student nurse within the New Zealand health care system and relevant New Zealand legislation.

4 Care for 1-2 clients with stable or predictable needs with supervision.

5 Organise and prioritise workload with help.

6 Administer and monitor therapeutic interventions with help.

7 Assess others' safety and intervene to maintain safety of self and others in non-complex environments.

8 Independently access information.

9 Critically evaluate others' arguments, and nursing research.

10 Give feedback to others, including rationales.

11 Communicate accurately within the health care system.

12 Show willingness to enter dialogue with others to develop insight into others':

- Experiences and realities

- World views

- Culture (Kaupapa Maori)

- Personal history in relation to health

- Emotional responses

- Access to the health care system

13 Show attending practices which reflect autonomy of others. 
14 Show mutuality in relationships.

15 Teach and coach well clients or stable groups with non-complex health issues.

16 Reflect on own and others' acts in the nursing dyad.

17 Understand consequences of student nurse experience in relation to own health.

18 Facilitate health for tangata whenua with support.

19 Show conscious awareness of health of tangata whenua.

20 Identify political issues in relation to health.

21 Enquire as to rationales for habitual practice.

22 Act as client advocate with support. 